\title{
La lucha
}

por el

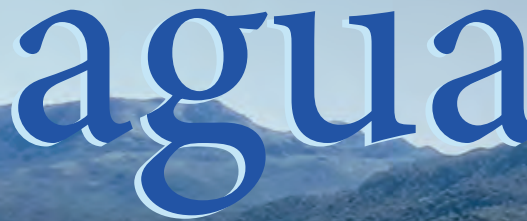

Gestión Comunitaria del Proyecto de Agua Potable Pesillo-Imbabura

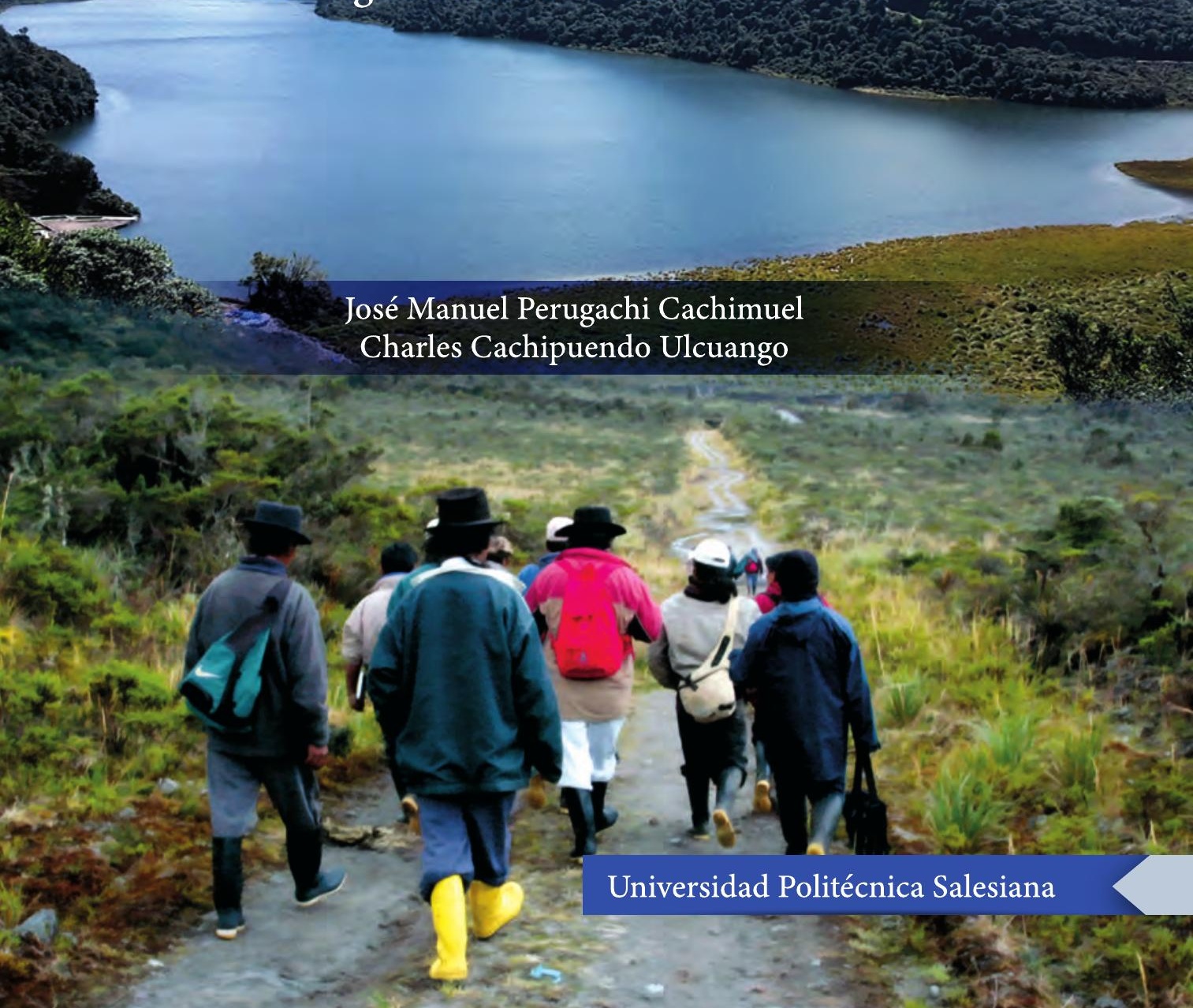




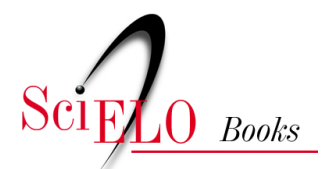

\title{
La lucha por el agua \\ Gestión Comunitaria del Proyecto de Agua Potable Pesillo-Imbabura
}

\author{
José Manuel Perugachi Cachimuel \\ Charles Cachipuendo Ulcuango
}

\section{SciELO Books / SciELO Livros / SciELO Libros}

PERUGACHI CACHIMUEL, J. M., and CACHIPUENDO ULCUANGO, C. La lucha por el agua: Gestión Comunitaria del Proyecto de Agua Potable Pesillo-Imbabura [online]. Quito: Editorial Abya-Yala, 2020, 172 p. ISBN: 978-9978-10-473-6. http://doi.org/10.7476/9789978105764.

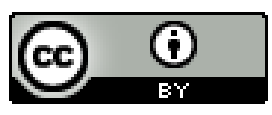

All the contents of this work, except where otherwise noted, is licensed under a Creative Commons Attribution 4.0 International license.

Todo o conteúdo deste trabalho, exceto quando houver ressalva, é publicado sob a licença Creative Commons Atribição 4.0.

Todo el contenido de esta obra, excepto donde se indique lo contrario, está bajo licencia de la licencia Creative Commons Reconocimento 4.0. 


\section{La lucha por el agua}

Gestión Comunitaria del Proyecto de Agua Potable Pesillo-Imbabura 

José Manuel Perugachi Cachimuel

Charles Cachipuendo Ulcuango

\section{La lucha por el agua}

Gestión Comunitaria del Proyecto de Agua Potable Pesillo-Imbabura

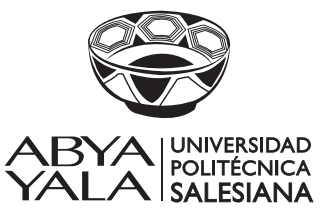

2020 


\section{La lucha por el agua}

Gestión Comunitaria del Proyecto de Agua Potable Pesillo-Imbabura (OJosé Manuel Perugachi Cachimuel - Charles Cachipuendo Ulcuango

1ra edición: @ Universidad Politécnica Salesiana

Av. Turuhuayco 3-69 y Calle Vieja

Cuenca-Ecuador

Casilla: 2074

P.B.X. $(+593$ 7) 2050000

Fax: (+593 7) 4088958

e-mail: rpublicas@ups.edu.ec

www.ups.edu.ec

CARRERA DE GESTIÓN PARA EL DESARROLLO

LOCAL SUSTENTABLE

Grupo de Investigación en Ciencias Ambientales

(GRICAM)

Línea de investigación en gestión sustentable

del agua y suelo.

Diagramación: Editorial Universitaria Abya-Yala

Quito-Ecuador

Depósito legal: $\quad 006594$

Derechos de autor: 058396

ISBN UPS: $\quad$ 978-9978-10-405-7

ISBN digital: $\quad$ 978-9978-10-473-6

Impresión: $\quad$ Editorial Universitaria Abya-Yala

Quito-Ecuador

Tiraje: $\quad 300$ ejemplares

Impreso en Quito-Ecuador, marzo 2020

Publicación arbitrada de la Universidad Politécnica Salesiana

Agradecemos a todas las instituciones y personas que facilitaron la recopilación de información en especial al compañero Juan Serrano expresidente del Consejo de Coordinación de Juntas Administradoras de Agua Potable del Proyecto Regional Pesillo -Imbabura y a la Constructora Hidalgo e Hidalgo. 


\section{Índice}

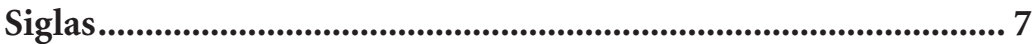

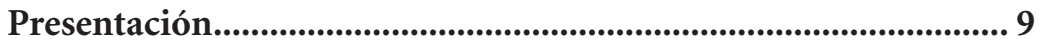

CApítulo I

Comunidades indígenas del norte de Pichincha y sur de Imbabura enfrentando la escasez de agua ........................................................ 13

Las comunidades nor-andinas y acceso al agua ............................. 15

El abastecimiento de agua

en territorios rurales en el siglo XX................................................20

Cambio climático y su efecto en lo local..........................................25

La calidad del agua: causas y consecuencias ...................................2 28

Capítulo II

Comunidades organizadas impulsando el acceso al agua ............................................................ 33

Construyendo la organización y el proyecto Pesillo-Imbabura ............................................................ 35

Disponibilidad, acceso y uso del agua ............................................... 50

La organización en el diseño

y elaboración del proyecto 66

El financiamiento del proyecto

y el modelo de ejecución 88 
La ejecución de la infraestructura

del proyecto Pesillo-Imbabura ............................................................ 99

La administración del proyecto Pesillo-Imbabuara........................ 114

Capítulo III

La gestión comunitaria del agua, garantía para su acceso, control, distribución y uso eficiente en las comunidades indígenas 119

El derecho al agua y la organización comunitaria ......................... 122

Territorio y tejido social en la gestión y manejo del agua............. 140 La gestión comunitaria del agua un proceso en construcción 153

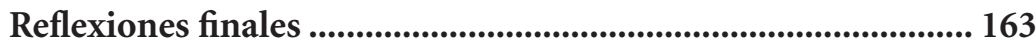

Bibliografía .............................................................................................. 169 


\section{Siglas}

AFD

BEDE

BDE

$\mathrm{CNRH}$

CMCC

$\mathrm{CNC}$

CODEMIA

CODENPE

COOTAD

EPAP

Pesillo-Imbabura

FONASA

FICI

GAD

INEN

IEOS

INEC

JAAP

JAAPC

MAE

MAGAP
Agencia Francesa de Desarrollo

Banco Ecuatoriano de Desarrollo

Banco del Estado

Consejo Nacional de Recursos Hídricos

Convención Marco sobre el Cambio Climático

Consejo Nacional de Competencias

Consorcio de Desarrollo de Manejo Integral de Agua y Ambiente para Cayambe y Pedro Moncayo

Consejo de Desarrollo de Nacionalidades y Pueblos del Ecuador

Código Orgánico de Organización Territorial Autonomía y descentralización

Empresa Pública de Agua Potable Pesillo-Imbabura

Fondo Nacional de Saneamiento Ambiental

Federación Indígena y Campesina de Imbabura

Gobierno Autónomo Descentralizado

Servicio Ecuatoriano de Normalización

Instituto Ecuatoriano de Obras Sanitarias

Instituto Nacional de Estadísticas y Censo

Juntas Administradoras de Agua Potable

Juntas Administradoras de Agua Potable Comunitarias

Misión Andina del Ecuador

Ministerio de Agricultura, Ganadería, Acuicultura y Pesca 


$\begin{array}{ll}\text { MIDUVI } & \text { Ministerio de Desarrollo Urbano y Vivienda } \\ \text { PNUD } & \text { Programa de la Naciones Unidas para el Desarrollo } \\ \text { PPI } & \text { Proyecto de agua potable Pesillo-Imbabura } \\ \text { SENAGUA } & \text { Secretaría Nacional del Agua } \\ \text { UPS } & \text { Universidad Politécnica Salesiana } \\ \text { UNOPAC } & \text { Unión de Organizaciones Populares de Ayora y Cayambe } \\ \text { UGP-PI } & \text { Unidad de Gerenciamiento del Proyecto }\end{array}$




\section{Presentación}

Personas de las comunidades lamentan que el cerro o Tayta ${ }^{1}$ Imbabura no tenga fuentes hídricas, que doten de agua al territorio para sus diferentes usos, mientras que sus vecinos: la Mama ${ }^{2}$ Cotacachi, el cerro Mojanda y el nevado Cayambe, tienen importantes fuentes de agua. En la tradición oral aún viva se explica sus causas:

En los primeros tiempos, Atzil Tayta (deidad principal de los pueblos indígenas de Imbabura) llamó a todos los cerros a una asamblea para repartir agua. Tayta Imbabura tenía su esposa, la Mama Cotacachi. Él era perezoso y mujeriego, además de su esposa tenía una amante, la Mama Cayambe. La noche anterior a la reunión pasó con su amante, quedándose dormido y llegando atrasado a la reunión, por lo tanto, se quedó sin agua.

Otra versión manifiesta que:

Atzil Tayta fue dispuesto a dar todo lo que necesiten, cuando a Tayta Imbabura preguntó qué necesidades tenía, él respondió: si tengo un poco de agua para cocinar y beber, lo que me hace falta son piedras para la tullpa — piedras que sostienen las ollas para cocinar- así que Atzil Tayta cubrió de piedras negras todo el alrededor del Tayta Imbabura.

El relato cambia según las comunidades, evidenciando la capacidad de las personas para buscar respuestas a los hechos del tiempo pasado y desde su cosmovisión explicar fenómenos naturales

1 Padre.

2 Madre. 
10

como la escasez del agua, pues como bien se conoce, el cerro Imbabura se caracteriza por no tener vertientes de agua y muchas de sus zonas están cubiertas de piedras de origen volcánico.

Este tipo de relatos y mitos a la vez tiene mensajes que orientan la vida comunitaria en donde las diferentes acciones tienen sus consecuencias, así, los anti-valores como la pereza o el ocio, contrario del valor del trabajo hacen perder oportunidades; nos dice también que no debemos ser ingenuos, que es importante tomar decisiones que prioricen la vida y tener una visión integral y a largo plazo.

En la vida comunitaria estos relatos sirven para reflexionar los acontecimientos naturales y su interrelación con el ser humano en el territorio, donde, se construyen relaciones sociopolíticas de poder que en muchas ocasiones vulneran derechos de los sectores comunitarios, como es el caso de las comunidades indígenas del territorio nor-andino que no tenían o tienen agua de manera permanente en el año, afectando su calidad de vida.

En un modelo de gestión y manejo del agua implementadas por el Estado, que privilegia a las grandes ciudades, los comuneros de los territorios indígenas para enfrentar una vida con déficit de agua se han unido para diseñar, implementar y manejar sistemas de agua potable comunitarios.

En ese contexto, la población indígena de las comunidades de los cantones del sur de Imbabura y norte de Pichincha, gestan —en sus inicios - la organización denominada Consejo de Coordinación de Juntas Administradoras de Agua Potable Proyecto Regional Imbabura; posteriormente, en el año de 2001 pasa a denominarse Consejo de Coordinación de Juntas Administradoras de Agua Potable del Proyecto Regional Pesillo-Imbabura. 
La organización mediante diversas formas de participación: reuniones de dirigentes, asambleas de usuarios, protestas, mingas, ${ }^{3}$ aportes económicos y el diálogo con diversos actores públicos, privados y de la cooperación internacional, logran acuerdos interinstitucionales para llevar el agua a sus territorios; es decir, el diseño y ejecución del Proyecto Pesillo-Imbabura (en adelante PPI).

El documento se divide en cuatro partes: primero, se explora las formas de acceso del agua en las diferentes épocas: prehispánica, colonia y republicana. Se aborda la realidad del acceso al agua con especial énfasis desde la década de 1970, tiempo en el cual existía una injusticia hídrica, con la limitada dotación del servicio de agua potable. Estas realidades y los procesos de reivindicación de los derechos de las comunidades indígenas al acceso a la tierra, permite entender el cómo y por qué las comunidades se organizaron e impulsaron alternativas de acceso al agua y enfrentar las nuevas realidades políticas, económicas y ambientales que afectan al Buen Vivir de los comuneros. ${ }^{4}$

En la segunda parte se realiza un recuento de cómo los líderes indígenas van generando un tejido social que permite la concreción de la organización que agrupa a las Juntas Administradoras de Agua Potable Comunitarias (JAAPC), que traspasan las divisiones geográficas, hídricas y territorios de los diversos pueblos indígenas: Kayambi, Otavalo, Karanqui y Natabuela, que realizaban gestión y manejo el agua en estos territorios.

Así surgió el Consejo de Coordinación de Juntas Administradoras de Agua Potable del Proyecto Regional Pesillo-Imbabura. Esta organización es de hecho; es decir, legitimada por los diferentes usuarios del agua y sus organizaciones de base. También se realiza un recuento de cómo la organización gestiona el proyecto de agua potable Pesillo-Imbabura

3 En la cultura andina es el trabajo comunitario de los miembros de una comunidad que buscan el beneficio común. También es toda acción colectiva o ideas que contribuyan a un futuro mejor como el caso del PPI.

4 Grupo de personas que viven en un territorio comunitario. 
y su involucramiento en las diferentes etapas: búsqueda de fuentes de agua, diseño, financiamiento, ejecución y administración (manejo) del proyecto, (el proyecto sigue en etapa de ejecución).

En la tercera parte se analiza cómo la gestión comunitaria del agua, es un enfoque que en las prácticas y acciones implementadas por las organizaciones comunitarias integran los principios del Buen Vivir y la sustentabilidad. Se analizan la integración de los conceptos del derecho al agua y la organización comunitaria: territorio y tejido social para la construcción de proyectos multipropósitos, el PPI comparte fuentes de agua e infraestructura de conducción con el proyecto canal de riego Cayambe-Pedro Moncayo; para la ejecución del PPI fue necesario contar con un proceso de coordinación con diversos actores sean estos de la sociedad civil, comunitarios e instituciones del Estado, por lo que se abordan los conceptos de gobernanza y gobernabilidad del agua en los territorios comunitarios. Según las dinámicas de acceso, control, distribución y uso del agua que han implementado las comunidades, se hace una aproximación de las diferencias entre acciones de gestión y manejo del agua. Por último, se puntualizan algunas reflexiones finales a modo de conclusión, acerca de cómo la visión de gestión del agua mantenida por las comunidades indígenas impulsa alternativas para acceder al agua. 


\section{Capítulo I \\ Comunidades indígenas del norte de Pichincha y sur de Imbabura enfrentando la escasez de agua}

La vida comunitaria es una forma que tienen los comuneros de enfrentar las adversidades ambientales, políticas, económicas. Es así que, las comunidades que viven una desatención del Estado frente a la escasez de agua para consumo buscan alternativas que los vuelve resilientes; es decir, adquieren habilidades y destrezas que les permite proponer proyectos que solucionen sus problemas y mejoren sus condiciones de vida, manteniendo su identidad sociocultural, económica y ambiental.

Un claro ejemplo de este tipo de acciones, son las comunidades que impulsaron un proyecto de agua potable conocido como Pesillo-Imbabura. Esta idea fue acogida por instituciones del Estado a nivel local, nacional y por la cooperación internacional. En esta experiencia se ve una relación de abajo hacia arriba, fundamentada en las capacidades de participación, sus medios de negociación y en muchas ocasiones de presión; así, las y los comuneros ejercen su derecho y obligaciones de acceso, control, distribución, uso y disposición final del agua. 


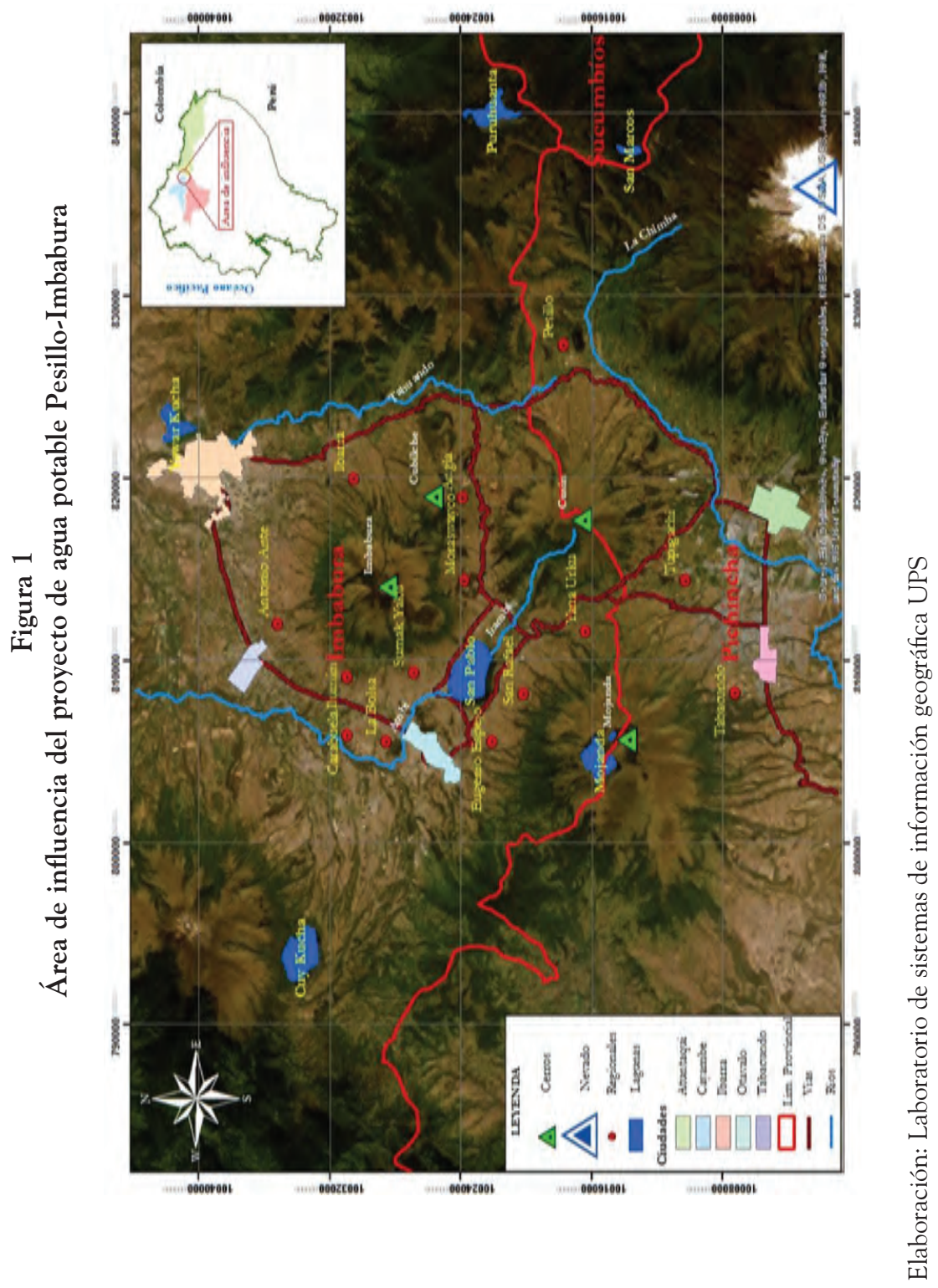


Las comunidades que buscan soluciones a sus condiciones adversas se localizan en el norte de la provincia de Pichincha, en los cantones de Pedro Moncayo y Cayambe, con las comunidades de las parroquias de Tupigachi, Tabacundo, Olmedo, Ayora y Cayambe respectivamente. En la provincia de Imbabura: en el cantón Otavalo, con las parroquias y comunidades de la cuenca de la laguna de San Pablo: Gonzáles Suárez, San Pablo del Lago, San Rafael de la Laguna, Eugenio Espejo, comunidades de la parroquia urbana El Jordán, más las parroquias Miguel Egas Cabezas (Peguche) e Ilumán; Antonio Ante, con las parroquias y comunidades ubicadas a las faldas del cerro Imbabura; Ibarra, con las parroquias y comunidades ubicadas al sur, y sur oriente de este cantón (Figura 1); y las poblaciones de las cabeceras cantonales y parroquiales.

En términos de identidad étnica — por ser las comunidades indígenas las gestoras del proyecto- - abarca un extenso territorio de los pueblos kichwas: Kayambi, Otavalo, Karanki y una parte del pueblo que se identifica como Natabuela en Antonio Ante. Estos pueblos conciben el agua como génesis de la vida; por lo que, en su acceso, control, distribución y uso, mantienen relaciones respetuosas y sagradas.

\section{Las comunidades nor-andinas y acceso al agua}

Las comunidades indígenas tienen sus propias formas de acceder al agua; sin embargo, han sufrido su falta por las injusticias de las relaciones de poder e inequidades en su distribución, mas no, porque no existan fuentes de agua en sus territorios. Así, se analiza el problema de acceso al agua desde una perspectiva histórica, con énfasis en la evolución del servicio de dotación del agua por parte del Estado desde las últimas décadas del siglo XX hasta la actualidad.

En la época prehispánica, en el medio nor-andino se desarrollaron conocimientos y soluciones prácticas para resolver los problemas de falta o exceso de agua (Ramón, 2008), siendo aspectos muy importantes para las poblaciones que se desarrollaron en este territorio. 
Muchos asentamientos se ubicaron cerca de las fuentes hídricas: lagunas, ríos, riachuelos, afloramientos de agua (ojos de agua) e incluso fuentes subterráneas (Foro de Recursos Hídricos, 2013). Por ejemplo, Otavalo antiguo se encontraba en la orilla sur de la laguna San Pablo que en el inicio de la colonización española fue trasladada al lugar actual.

En zonas de menor humedad, las acequias ${ }^{5}$ tuvieron mucha importancia para la agricultura mediante la irrigación. Knapp (1992) plantea que varias acequias que se utilizaron en la Colonia y que se siguen utilizando en nuestros días fueron construidos en épocas anteriores a los Incas; una de ellas es la acequia San Antonio que nace en la cascada de Peguche, atraviesa importantes restos prehispánicos en su trayecto hasta la parroquia de San Antonio de Ibarra.

Otras tecnologías conocidas y practicadas estuvieron enfocadas en el almacenamiento de agua lluvia para recargar acuíferos y crear humedales, o en elevar los campos para evitar la inundación, derivar acequias, humedecer terrazas o guardar agua de riego (Ramón, 2008), que en general servían para tres usos importantes: consumo humano, abrevaderos de animales y el riego.

Los incas introdujeron innovaciones que por el corto tiempo en el área fueron poco difundidos. Por investigaciones realizadas en la localidad de Karanki — cerca de la ciudad de Ibarra— se conoce la existencia de acueductos con revestimientos de piedra que conducían el agua desde otros sitios.

Los canales para el ingreso del agua están ubicados en el lado este de la estructura, y aún funcionan. En el centro se encuentra una fosa de agua que, según los registros históricos, fue utilizada para ceremonias rituales entre el Inca y sus doncellas. (Diario El Telégrafo, 2015)

5 Es un canal construido por el ser humano que sirve para conducir agua para regadío, en algunos casos también sirve para consumo doméstico, abrevadero de animales, entre otros usos. 
El agua era asociada como un elemento inseminador de la tierra, propiciador de la fertilidad y fuente de poder, cuyos favores reclamaban relaciones especializadas y ritualizadas con la madre tierra. Los pogyos, ${ }^{6}$ glaciares y lagunas, fueron verdaderos "espacios rituales" o “espacios de poder" (Ramón, 2008).

En la época colonial, con la conquista y posterior colonización por parte de los españoles cambia los contextos locales. Medios tan importantes para la reproducción social, cultural y espiritual como la tierra y el agua fueron objeto de conquista y despojo. Al mismo tiempo inicia un cambio radical en el uso de suelo y la cobertura vegetal nativa con técnicas introducidas con fines únicamente de incrementar el capital económico, muchas veces inapropiadas para los territorios, causando en la naturaleza la disminución de la capacidad de retención del agua, las zonas de recarga hídrica y generando cambios en las relaciones de las sociedades de la época.

En la Colonia, el agua y la tierra no estaban separados, no existía legislación que, de un tratamiento independiente, así que los "derechos" que se adquirían sobre la tierra incluían automáticamente al agua, por ello florecieron disputas por acceso y control del agua, como por ejemplo el caso de la acequia Ambuquí, como indica Ramón (2008) "a mediados del siglo XVII, había una aguda disputa por el agua entre los indígenas y los españoles”.

Los indígenas fueron excluidos del acceso a los elementos naturales y particularmente el agua, pasó de ser una condición básica para la supervivencia a presentarse como dádiva del encomendero o hacendado; una pequeña fracción de aguas sobrantes para la manutención de la familia, o también una carencia total de propiedad que se suple por el "robo" del agua, asumido como una parte de la relación de servidumbre (Foro de los Recursos Hídricos, 2013).

6 Nacientes o fuentes de agua. 
Pese a estas adversidades, fueron las comunidades indígenas los principales gestores de los sistemas de riego y también de los primeros sistemas de agua de consumo humano, aunque estos frecuentemente fueron apropiados por los hacendados o por las autoridades coloniales (Foro de los Recursos Hídricos, 2013).

En síntesis, este periodo se caracteriza porque, el control y gobernanza del agua pasó a manos de los conquistadores y colonizadores, de esta manera se controla a las personas y colectivos humanos, precarizando enormemente la vida de las poblaciones de los diversos territorios indígenas.

En la época republicana, no se afectaron las estructuras de poder construidas durante la Colonia; dicho de otra manera, la independencia y la fundación del Estado no trajo cambios y mejoras a las poblaciones de los territorios indígenas, quienes siguieron siendo negadas al acceso de los elementos pilares de la vida material, cultural y espiritual: la tierra y el agua.

La mayoría de las comunidades tomaban el agua de fuentes existentes dentro o cerca de sus territorios de manera casi clandestina: pequeñas vertientes, ojos de agua en quebradas, eran sus principales fuentes y utilizando recipientes cargados en la espalda (Figura 2) llevaban el agua a sus domicilios o a las casonas de las haciendas. En muchos hogares se construían pozos o $\operatorname{coch}^{7}{ }^{7}$ que captaban el agua en época de lluvias que servían de reserva para las épocas secas y para crear pequeños humedales. Solo las comunidades de las orillas de la laguna de San Pablo no tenían tantos problemas para acceder al agua.

La exclusión de las comunidades en el acceso al agua ambientaba levantamientos y reclamos contra las autoridades, que fueron arbitrados por el Estado. Según las regulaciones de aquellas décadas, "el agua es un bien nacional de uso público", pero los hacendados, los

7 Depósito artificial de agua que muchas familias construían cerca de sus viviendas. También designa lagos, lagunas, charcos. 
funcionarios públicos o los funcionarios del Estado Central eran instancias que manejaban la Ley según las conveniencias de los grupos de poder, así: mezquinaban, prohibían, cobraban o arrendaban el agua a las comunidades, pese a que las fuentes estaban en sus territorios.

Figura 2

Formas de provisión de agua a mediados del siglo XX
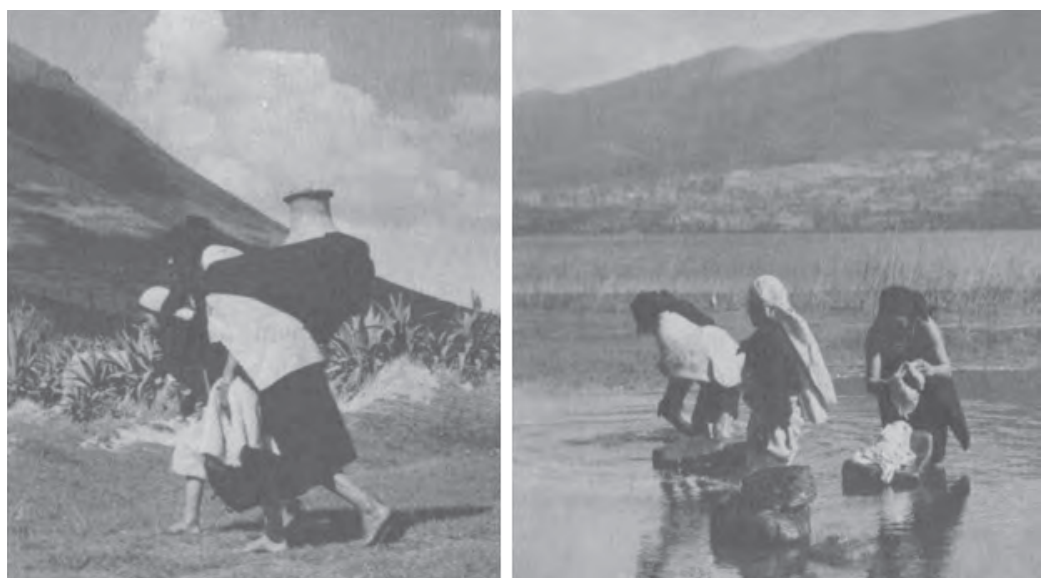

Fuente: Collier y Buitrón (1971). The awakening valley.

La primera intervención del Estado en planificar la gestión del agua de consumo humano y saneamiento en el sector rural fue con la Misión Andina del Ecuador (MAE) (décadas de 1950 y 1960), auspiciada por las Naciones Unidades. El objetivo fue llevar el desarrollo a las comunidades indígenas y rurales con obras de apertura de caminos, producción agropecuaria, canales de riego y construcción de casas comunales, dentro de este marco se inscribieron los proyectos de dotación y abastos de agua y letrinización (Borja, 2002).

Luego se origina un modelo para la gestión del agua de consumo humano con la creación del Instituto Ecuatoriano de Obras Sanitarias (IEOS), en 1965, como parte del Ministerio de Salud Pública. Se creó el Fondo Nacional de Saneamiento Ambiental (FONASA), 
para el sector rural, cuya responsabilidad era dotar de servicios básicos a las poblaciones identificadas como prioritarias (Borja, 2002).

El Estado tomó las riendas en la gestión del agua y priorizó la construcción de obras para el abastecimiento de agua, pero hubo un limitado seguimiento, participación y capacitación a los beneficiaros para que los sistemas construidos sean gestionados y manejados adecuadamente por las comunidades indígenas (Foro de Recursos Hídricos, 2013), por lo que se asentó la brecha de acceso al agua entre las comunidades rurales y las ciudades.

\section{El abastecimiento de agua en territorios rurales en el siglo XX}

En 1972 se aprueba la Ley de Aguas y en 1979 se reconoce a las organizaciones comunitarias que gestionan el agua, a través de la normativa que rige la creación de las Juntas Administradoras de Agua Potable (JAAP) (Foro de Recursos Hídricos, 2013). El objetivo de la última era dotar de un marco jurídico que permita a las comunidades beneficiarias de las obras de agua y saneamiento organizarse para la construcción, administración, operación y mantenimiento de los sistemas que se construían por parte del Estado (Borja, 2002). Este sistema de gestión y manejo del agua en territorios comunitarios es perverso pues el Estado se deslinda de la responsabilidad de brindar el derecho que tiene todo ciudadano de acceder al agua. Las comunidades rurales a través de sus capacidades organizativas y aliados estratégicos construyen sistemas de agua de consumo humano.

Este proceso de atención en obras y coberturas se extiende y profundiza en las décadas de los años 70 y 80 (Foro de Recursos Hídricos, 2013). Los indicadores de acceso al agua que muestran los datos del Censo de Vivienda de 1974 evidencian el limitado alcance de la dotación de agua en el sector rural (Tabla 1). 
El análisis se realiza de los cinco cantones: Pedro Moncayo, Cayambe, Otavalo, Antonio Ante e Ibarra, porque se encuentran dentro del área del PPI.

Tabla 1

Abastecimiento de agua por vivienda en sector rural censo 1974

\begin{tabular}{|l|r|r|r|r|r|}
\hline \multirow{2}{*}{$\begin{array}{c}\text { ABASTECIMIENTO } \\
\text { DE AGUA }\end{array}$} & \multicolumn{5}{|c|}{ CANTONES } \\
\cline { 2 - 6 } & P. Moncayo & Cayambe & Otavalo & A. Ante & Ibarra \\
\hline De red pública: & & & & & \\
\hline Dentro de la vivienda & 45 & & 353 & 73 & 496 \\
\hline $\begin{array}{l}\text { Fuera de la vivienda pero } \\
\text { en el edificio }\end{array}$ & 224 & & 273 & 177 & 1.384 \\
\hline Fuera del edificio & 993 & & 1.865 & 1.281 & 2.936 \\
\hline De otras fuentes: & 411 & & 2.413 & 286 & 2.919 \\
\hline Pozo o vertiente & 42 & & 75 & 36 & 121 \\
\hline Aljibe (cisterna, tanque) & 535 & & 3.486 & 767 & 5.335 \\
\hline Río o acequia & 115 & & 553 & 47 & 499 \\
\hline Otros & 2.365 & & 9.018 & 2.667 & 13.690 \\
\hline Total viviendas & & & & & \\
\hline
\end{tabular}

Fuente: Censo de Vivienda de 1974. Instituto Nacional de Estadísticas y Censo, INEC.

En el caso de cantón Cayambe no se encontró datos.

En dos cantones: Pedro Moncayo y Antonio Ante, el número de viviendas que acceden a agua de red pública es más alto que el número de viviendas que se abastecen de agua de otras fuentes. Si bien acceden a agua de red pública, la mayoría queda fuera del edificio (vivienda); aunque los que acceden a red pública son viviendas de las cabeceras parroquiales rurales y no de las comunidades indígenas.

En los cantones de Otavalo e Ibarra, la situación es inversa, porque más del $75 \%$ de las viviendas se abastecen de diversas fuentes: (1) de río y acequia, (2) pozo y vertiente, y (3) otros. El restante $25 \%$ de las viviendas tiene cobertura de agua de red pública, pero en la mayoría de los casos quedan "fuera de la vivienda". 
En las zonas urbanas o cabeceras cantonales, hay más viviendas cubiertas con red pública, aunque también se abastecen de río o acequia en Cayambe y Antonio Ante; pozo o vertiente en Otavalo; (otros) sin especificar cuáles y cómo en Pedro Moncayo e Ibarra.

En síntesis, las zonas rurales (cabeceras parroquiales y comunidades) carecen de red pública, abasteciéndose de diversas fuentes como: pozos, vertientes, ríos, acequias y otros; al igual que un importante porcentaje de viviendas de las cabeceras cantonales.

El censo de 1982, evidencia que no existen mejoras significativas en el abastecimiento de agua en las zonas rurales (comunidades indígenas) (Tabla 2).

\section{Tabla 2}

Abastecimiento de agua por viviendas en sector rural y urbano

\begin{tabular}{|l|r|r|r|r|r|}
\hline \multirow{2}{*}{$\begin{array}{c}\text { ABASTECIMIENTO } \\
\text { DE AGUA }\end{array}$} & \multicolumn{5}{|c|}{ CANTONES } \\
\cline { 2 - 6 } & P. Moncayo & Cayambe & Otavalo & A.Ante & \multicolumn{1}{c|}{ Ibarra } \\
\hline De red pública: & & & & & \\
\hline Dentro de la vivienda & 525 & 2.081 & 3.195 & 2.840 & 9.675 \\
\hline $\begin{array}{l}\text { Fuera de la vivienda pero } \\
\text { en el edificio }\end{array}$ & 945 & 936 & 1.351 & 954 & 4.033 \\
\hline Fuera del edificio & 567 & 494 & 2.360 & 729 & 3.805 \\
\hline De otras fuentes: & 438 & 948 & 2.790 & 359 & 1.304 \\
\hline Pozo o vertiente & 520 & 3.722 & 3.181 & 397 & 3.094 \\
\hline Río o acequia & 6 & 12 & 35 & 5 & 458 \\
\hline Carro repartidor & 162 & 275 & 429 & 219 & 562 \\
\hline Otros & 3.163 & 8.468 & 13.341 & 5.503 & 22.931 \\
\hline Total viviendas & & & & & \\
\hline
\end{tabular}

Fuente: Censo de Vivienda de 1982. Instituto Nacional de Estadísticas y Censo, INEC. 
A nivel de cantones, Cayambe es el único cuyo porcentaje alcanzó indicadores negativos, ya que el 59\% de las viviendas no tienen acceso a agua por red pública, por lo que el abastecimiento de agua de otras fuentes tiene un peso importante como de río o acequia con 3722 viviendas, de un total de 8468 .

En Pedro Moncayo, Antonio Ante e Ibarra se incrementó el porcentaje de viviendas con abastecimiento de agua por red pública; con el $65 \%$ de $100 \%$, el $82 \%$ y con un poco más del $76 \%$ respectivamente, aunque en Ibarra más de 3000 viviendas accedían a agua de río o acequia.

En Otavalo, del 100\%, el 51\% de las viviendas tienen cobertura de agua por red pública; no obstante, el abastecimiento de pozo, vertiente, río y acequia suman cerca de 6000 viviendas. Los indicadores a nivel cantonal mejoran porque las cabeceras cantonales reciben atención y mejoramientos, no así las parroquias rurales y sus comunidades como veremos a continuación:

La mayoría de las comunidades indígenas siguen sin ser atendidas y siguen por fuera del acceso a agua de forma permanente y segura. Sorprende que Peguche, cabecera parroquial de Miguel Egas tenga porcentaje bajo de viviendas con acceso a agua por red pública (Tabla 3), pese a estar apenas de $2 \mathrm{~km}$ de la ciudad de Otavalo.

Entre 1981 y 1990 fue la Década Internacional del Agua, un espacio para revisar críticamente las causas y limitaciones que impidieron lograr mayores éxitos en la dotación del servicio y el mejoramiento de la calidad de vida de la población (Borja, 2002).

Los resultados del censo de 1990 (que recoge datos del periodo 1982-1990) evidencia cierta mejora en cada cantón; es decir, el abastecimiento de agua por red pública es el principal medio (Tabla 4). Aunque en la ruralidad (comunidades) el abastecimiento de agua de río y acequia sigue siendo alto. Son evidencias que las políticas públicas no benefician por igual a los sectores urbano y rural. 
José Manuel Perugachi Cachimuel - Charles Cachipuendo Ulcuango

24
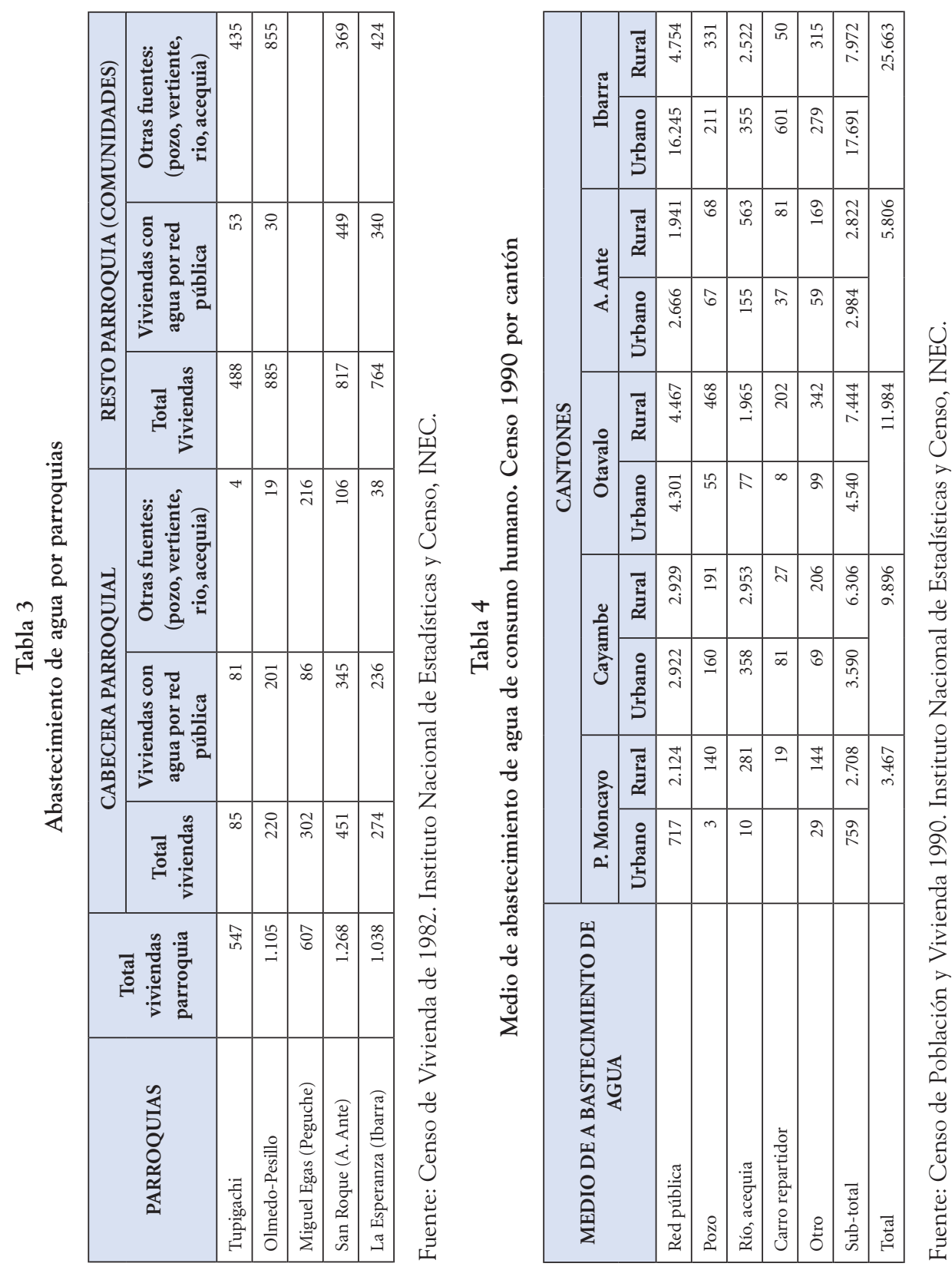
Los problemas señalados, más los altos costos de los sistemas de agua a bombeo, los sistemas de agua comunitarios con grifos focalizados, los cortes o racionamientos de agua por sequias en verano, incidieron en muchos dirigentes a pensar en proyectos de agua que solucionen estos problemas, mediante alianzas intercomunales. Por eso, a mediados de la década de 1990, hay muchas ideas de solución en la mayoría de las comunidades y parroquias, como es el caso del PPI.

\section{Cambio climático y su efecto en lo local}

Para la Convención Marco sobre el Cambio Climático (CMCC), el cambio climático es "el cambio de clima atribuido directa o indirectamente a la actividad humana que altera la composición de la atmósfera mundial y que se suma a la variabilidad natural del clima observado durante períodos de tiempo comparables". Mientras que el Programa de la Naciones Unidas para el Desarrollo (PNUD), en su informe de Desarrollo Humano (2007-2008) manifiesta que "el cambio climático es el problema que determina el desarrollo humano en nuestra generación, este minará los esfuerzos que se emprenden en el ámbito internacional con el fin de combatir la pobreza”.

A nivel global una de las formas de manifestación del cambio climático es el incremento de la temperatura, las modificaciones en los ciclos de la precipitación en su intensidad y trayectorias (Miller, 2007). Particularmente en la región andina se manifiesta en las modificaciones de los fenómenos del Niño y de la Niña que regulan los ciclos de precipitación.

En el hemisferio norte, la temperatura media anual en la última década del siglo XX alcanzó los más altos niveles de incremento y se contrapone a la tendencia general de enfriamiento del último milenio (Mann et al., 1998). Estos cambios afectan a los territorios locales, manifestándose principalmente con la disminución de caudales de agua de las diversas fuentes, tal es el caso del nevado Cayambe que en el periodo de 1979 al 2009 reduce su glaciar en el torno al 25.58\% (Castro et al., 2018), siendo los glaciares indicadores que evidencian cambios en el clima, presentándose principalmente por el incremento de la temperatura y los ciclos de las lluvias. 


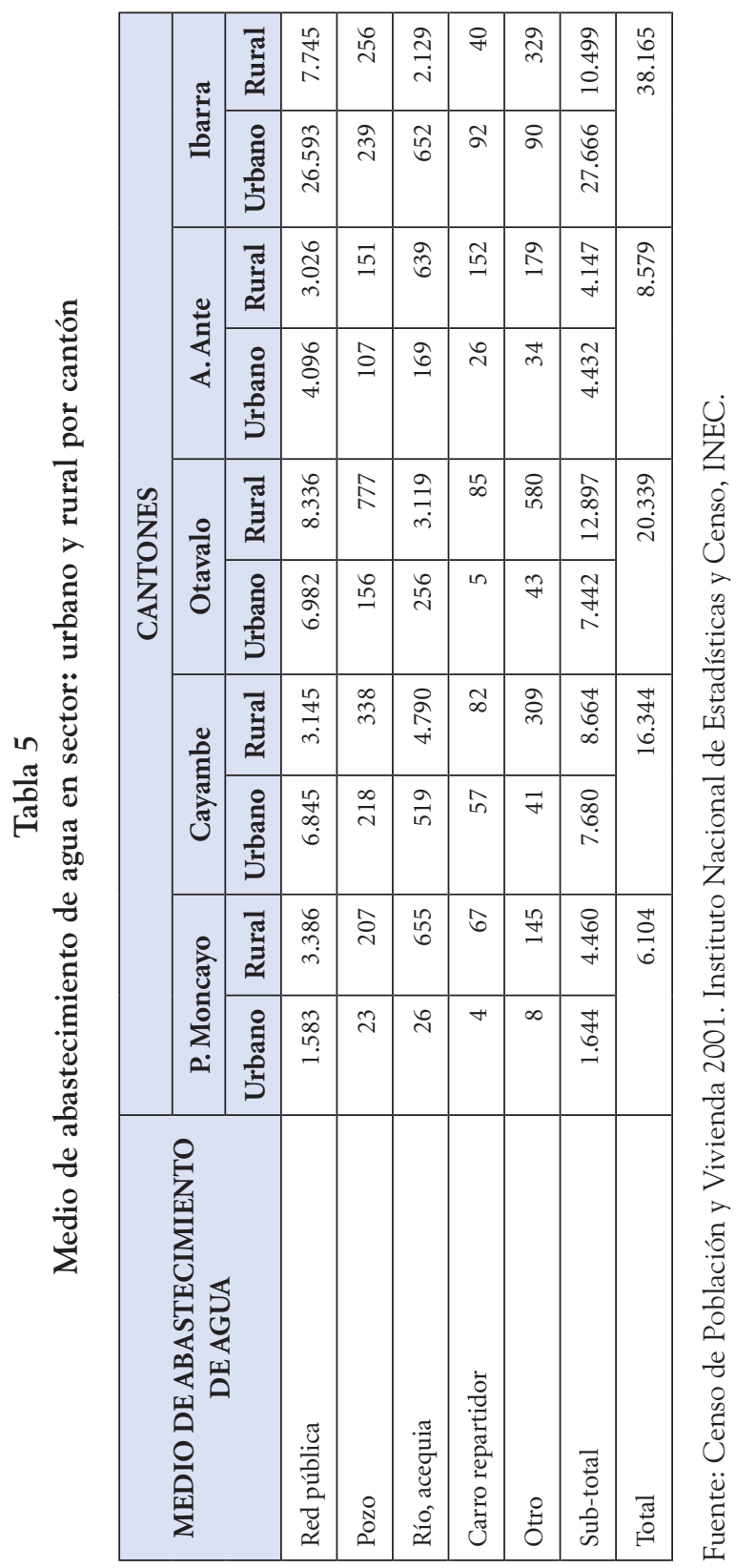


En estos contextos globales y locales del cambio climático a finales del siglo XX e inicios del nuevo siglo, es evidente que el acceso al agua en las comunidades rurales sigue con dificultades; así, según el censo de 2001 no muestra mejoras significativas de dotación de agua, la red pública no llega al 100\% de los hogares tanto en las zonas urbanas y peor aún en las zonas rurales (Tabla 5).

Si se compara con los datos de 1990, hay un notable incremento de viviendas en todos los cantones, mucho más en el sector rural, quizás esa sea la causa para que el medio de abastecimiento de agua de pozo, río y acequia siga siendo alto, incluso superando los casos de 1990 como en Cayambe y Otavalo.

Los problemas ambientales se hacen sentir con fuerza, cuyas consecuencias deben afrontar las JAPP. En el área del PPI es evidente la disminución de caudales de agua en vertientes y humedades, así como el agua superficial de quebradas, ríos, lagunas.

Hay varias causas que han llevado a esta situación:

1. Desde mediados del siglo XX, muchas comunidades y haciendas atraídas por los beneficios económicos, plantaron miles de eucaliptos (Eucalyptus globulus) cerca de páramos, fuentes de agua y humedales, desconociendo las afectaciones ambientales y en las reservas hídricas. Hay investigaciones que sostienen que las raíces de los eucaliptos pueden incursionar en las capas freáticas hasta los 50 metros bajo tierra, en un solo día absorber hasta 500 litros de agua, pudiendo secar los suelos (Saransig, 2017).

2. El escaso tratamiento a las aguas utilizadas en las viviendas, los modos y hábitos de producción. La cuenca de la laguna de San Pablo llegó a sufrir deterioro ambiental, provocando problemas de salud a la población por la calidad del agua que consumían y utilizaban en las actividades agrícolas, razones por las que, en marzo de 1999, se declaró de interés público prioritario la preservación y conservación de la cuenca del Lago San Pablo y encaminar procesos de 
remediación ambiental, principalmente en el tratamiento de aguas residuales domésticas.

3. Los efectos del calentamiento global y las actividades antrópicas bajo un modelo neoliberal servil al sistema capitalista impuesto por los países económicamente desarrollados, provocan cambios en los ciclos naturales del clima a nivel global, que afectan en las diferentes localidades manifestándose con la ausencia de lluvias, incremento de la temperatura y vientos con mayores velocidades.

4. Los incendios con fines de incrementar la frontera agrícola también han afectado muchas zonas de ecosistemas de páramo. Estos cambios han incidido para la disminución de caudales de humedales pequeños y medianos, tanto en zonas bajas, medias y altas. En la cuenca de la laguna San Pablo - y en otras zonas- a medida que se aleja de la cota de la laguna hacia arriba, muchas fuentes se han secado y en otras los caudales se han disminuido drásticamente.

\section{La calidad del agua: causas y consecuencias}

Primero analicemos los datos del censo de población y vivienda del año 2010 (Tabla 6). El abastecimiento de agua en las viviendas rurales por red pública se incrementó.

En los cinco cantones se incrementa el número de viviendas en lo rural como urbano. El porcentaje de viviendas del sector urbano y rural que acceden a agua por red pública es: Pedro Moncayo urbano $80 \%$, rural 71\%; Cayambe: urbano 73\%, rural 56\%; Otavalo: urbano 72\%, rural 60\%; Antonio Ante: urbano 85\%, rural 76\%; e Ibarra: urbano $90 \%$, y rural $75 \%$.

En Pedro Moncayo, Cayambe y Otavalo, el promedio rural supera la urbana, aunque continúan vigentes decadentes formas de procedencia de agua para las viviendas: de pozo; de río, vertiente, acequia o canal; sigue habiendo casos en los que se abastecen de agua de lluvia. Para una época de avances sociales, técnicos y tecnológicos es incompresible. 


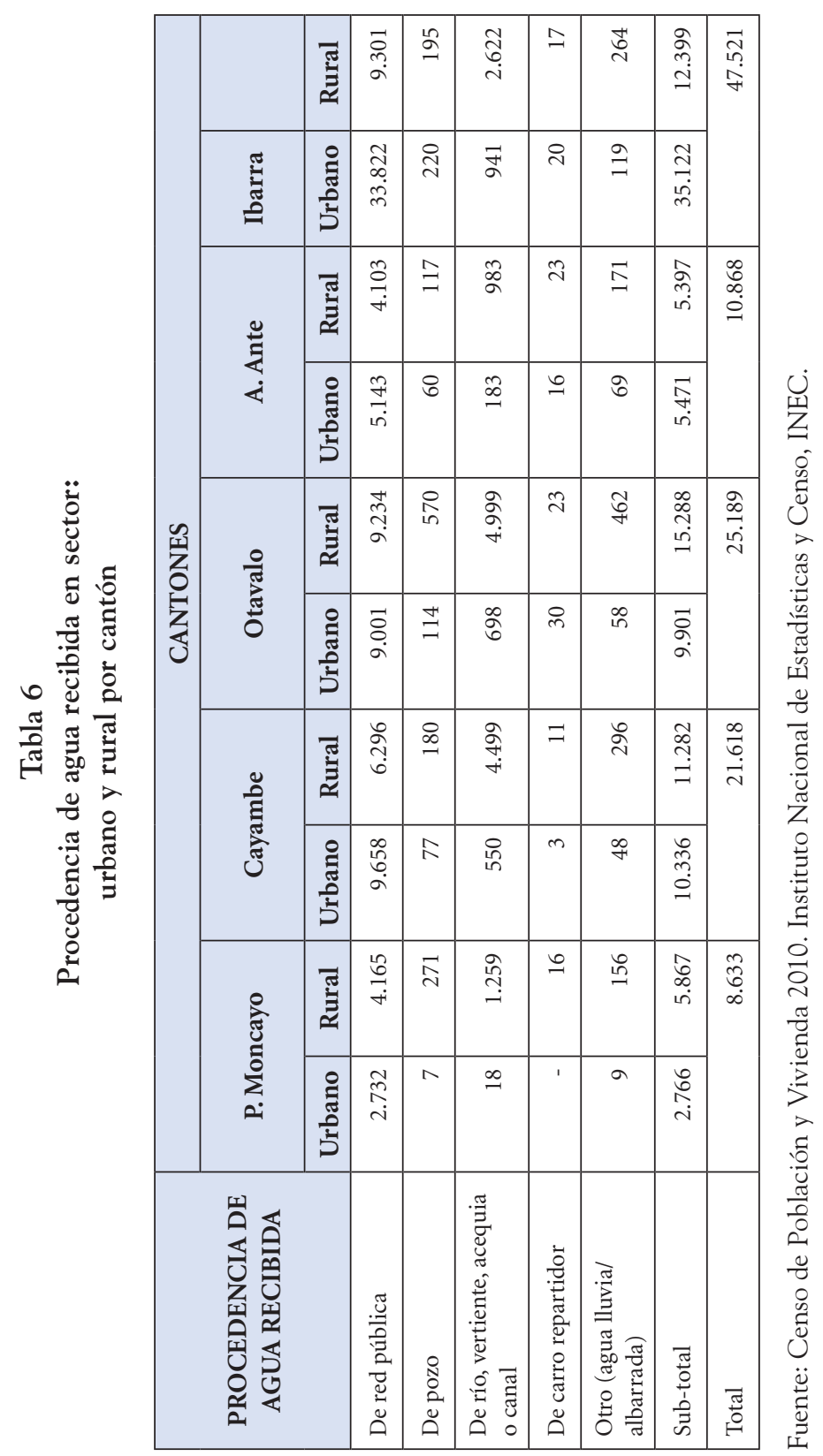


El porcentaje de viviendas en el sector rural que acceden a gua por red pública es la siguiente: Pedro Moncayo 71\%, Cayambe 55\%, Otavalo 60\%, Antonio Ante 76\%, Ibarra 75\%. Si en la ruralidad la obertura no alcanza el $100 \%$ de las viviendas, un problema latente en las que acceden a red pública o comunitaria es la calidad del agua.

Las JAAP pequeñas y medianas no logran generar ingresos económicos suficientes para reemplazar los sistemas comunitarios de agua y/o dar tratamiento adecuado al agua que consumen sus usuarios. La consultoría para adecuar los sistemas del PPI detectó varios problemas:

En los sistemas de 20 a 25 años adolecen de falta de agua, con déficit en cuanto al caudal; la calidad del agua no cumple con las normativas establecidas por el INEN (Servicio Ecuatoriano de Normalización) presentándose contaminación microbiológica principalmente. Los sistemas comunitarios tienen deficiencias en los procesos de cloración del agua y de desinfección de la infraestructura. (Acta PPI, 13 de marzo de 2008)

Tabla 7

Tratamiento de agua para consumo humano por cantón: urbano y rural

\begin{tabular}{|l|r|r|r|r|r|}
\hline \multirow{2}{*}{$\begin{array}{c}\text { CATEGORIA DE } \\
\text { CONSUMO DE AGUA }\end{array}$} & \multicolumn{5}{|c|}{ CANTONES } \\
\cline { 2 - 7 } & P. Moncayo & Cayambe & Otavalo & A. Ante & Ibarra \\
\hline Beben tal como llega & $63 \%$ & $47,10 \%$ & $66,60 \%$ & $76 \%$ & $77,9 \%$ \\
\hline Hierven & $33,60 \%$ & $45,60 \%$ & $29,30 \%$ & $17,80 \%$ & $17 \%$ \\
\hline Ponen cloro & $1,50 \%$ & $2 \%$ & $1 \%$ & $0,80 \%$ & $1,20 \%$ \\
\hline Filtran & $0,30 \%$ & $0,50 \%$ & $0,60 \%$ & $0,60 \%$ & $0,50 \%$ \\
\hline Compran agua purificada & $1,60 \%$ & $4,80 \%$ & $2,80 \%$ & $4,80 \%$ & $3,40 \%$ \\
\hline
\end{tabular}

Fuente: Censo de Población y Vivienda 2010. Instituto Nacional de Estadísticas y Censo, INEC.

Los esfuerzos que han realizado las JAAP con el poco apoyo del Ministerio de Desarrollo Urbano y Vivienda (MIDUVI) y los municipios para potabilizar el agua no fueron suficientes, por lo que 
la mayoría de las JAAP entregan agua no apta para el consumo humano. Tampoco existe la cultura de tratar el agua cruda que llega a los hogares (Tabla 7), por lo que hay el riesgo de contraer enfermedades gastrointestinales.

Entre los años 2013 y 2014, la Universidad Politécnica Salesiana (UPS), realizó estudios de calidad de agua en varias JAAP regionales, encontrando E.coli (una bacteria presente en las heces fecales de animales y humanos) en Carabuela y Chilca-Cochimbuela, en ambos casos en las captaciones, que puede ser por la presencia de animales domésticos cerca de las fuentes de agua.

En otras JAAP, hay presencia de elementos físicos y químicos que en altos porcentajes no es recomendable para el consumo humano. Y un último problema es que se realizan cloraciones por encima o por debajo de lo recomendado, por el desconocimiento y poca capacitación que tienen los operadores de los sistemas comunitarios de agua.

Por otro lado, hay una distribución inequitativa de los caudales de agua. En el foro Gestión del Agua realizado en la ciudad de Otavalo en el 2015, se mostró que, de las aproximadamente 400 concesiones o autorizaciones de agua existentes en el cantón, la mitad es para uso doméstico, lo que es destacable si por ello se tratara; pero cuando se analiza el volumen del caudal solo 776 1/s de un total de 7892 1/s, es decir, el 10\% del caudal concesionado o autorizado es para consumo humano o doméstico.

En la parroquia de Tupigachi, donde están afincadas muchas plantaciones florícolas, la mayoría de las autorizaciones de agua corresponden a personas naturales y empresas para uso industrial y riego, pese al alto déficit de agua para consumo humano. Frank Gualsaquí alcalde de Pedro Moncayo aseguró que:

Es uno de los cantones más pobres de Pichincha porque la cobertura de agua potable y alcantarillado es muy baja. Por eso el PPI beneficiará con el $90 \%$ al sector rural del cantón y concluyo que es un tema clave para Ibarra, pero para Pedro Moncayo es fundamental. (Diario El Norte, 2018) 
En este contexto, y dado que el acceso a agua de consumo humano y saneamiento en la ruralidad es deficiente, en el año 2013, el Estado elaboró el Plan Nacional del Buen Vivir (2013-2017, p. 58) en donde una de las políticas es:

Garantizar el acceso universal, permanente, sostenible y con calidad a agua segura y a servicios básicos de saneamiento, con pertinencia territorial, ambiental, social y cultural, y las metas hasta el año 2107 son: Alcanzar el 95\% de viviendas en el área rural con sistema adecuado de eliminación de excretas y Alcanzar el 95\% de viviendas con acceso a red pública de agua.

Sin duda, los indicadores mostrados cambiarán cuando el sistema de agua potable más grande de la Sierra norte se construya. Hasta ahora las JAAP y el mismo proyecto PPI han venido caminando (gestionando) en medio de muchos problemas, a veces los dirigentes han tratado de dar atención y solución, pero son tantos que pocas manos no alcanzan, centrándose en lo fundamental la concreción y ejecución de la infraestructura física del PPI.

En síntesis, se pueden diferenciar varios momentos que reflejan el acceso al agua, así tenemos: (1) la gestión propia en la época precolombina, (2) el despojo y la colonización del agua desde la invasión española hasta la época republicana, (3) el arbitraje del Estado desde mediados del siglo XX, (4) reivindicación de sus derechos con la inclusión en la Constitución de la gestión comunitaria del agua en coexistencia con la gestión pública.

Luego del análisis histórico y contemporáneo sobre la situación del agua de consumo humano en el área del PPI, pasamos de lleno a abordar los procesos organizativos que llevaron a la creación del Consejo de Juntas Administradoras de Agua Potable Regional Pesillo-Imbabura y por ende del proyecto de agua, que es el tema central de esta investigación. 


\section{CApítulo II \\ Comunidades organizadas impulsando el acceso al agua}

En la década de 1990, la cultura organizativa había tomado una dimensión política y supra comunal, el levantamiento indígena por los 500 años de resistencia es una muestra de ello. Sin embargo, el método de solución de problemas que había en cada localidad no iba más allá de la comunidad, cada una de ellas en la medida de sus posibilidades informaban a las entidades del Estado y gestionaban sus diversos problemas.

Las experiencias en el ámbito de agua y organización intercomunitaria se aprecian en varias JAAP regionales (reunión de varias comunidades que tienen un sistema de agua). Pero los problemas señalados en el capítulo anterior derivaron en presión por el agua, y conflictividad entre comunidades por las pocas fuentes de agua existentes. Si el método de llevar cada quien o según puedan el agua para su molino, había el riesgo de que la conflictividad por el agua se incremente.

Conscientes de las adversas realidades, muchos dirigentes tuvieron una visión futurista. Era necesario unir a las comunidades para formular proyectos más grandes, que solucionen el problema del agua a mediano y largo plazo. Así inician las comunidades a organizarse, cuyo resultado es el Consejo de Juntas Administradoras de Agua Potable del Proyecto Regional Imbabura, instancia desde donde se impulsó un proyecto de agua. En lo sustancial, este proyecto nace como res- 
puesta a la exclusión histórica que sufren las comunidades indígenas, al acceso al agua para consumo en cantidad y calidad.

Es así, que, por la tenacidad y visión de los dirigentes de las comunidades, inician a buscar fuentes de agua que abastezca sus necesidades. En este proceso, la organización Consejo de Coordinación de Juntas amplía sus horizontes hacia otras comunidades, con el apoyo de las diferentes instituciones del Estado logran impulsar y diseñar el proyecto, y actualmente la ejecución de la construcción de la infraestructura del sistema (aunque las obras están paralizadas temporalmente). ${ }^{8}$

\section{Figura 3}

Momentos importantes donde la organización consigue el diseño y ejecución del proyecto

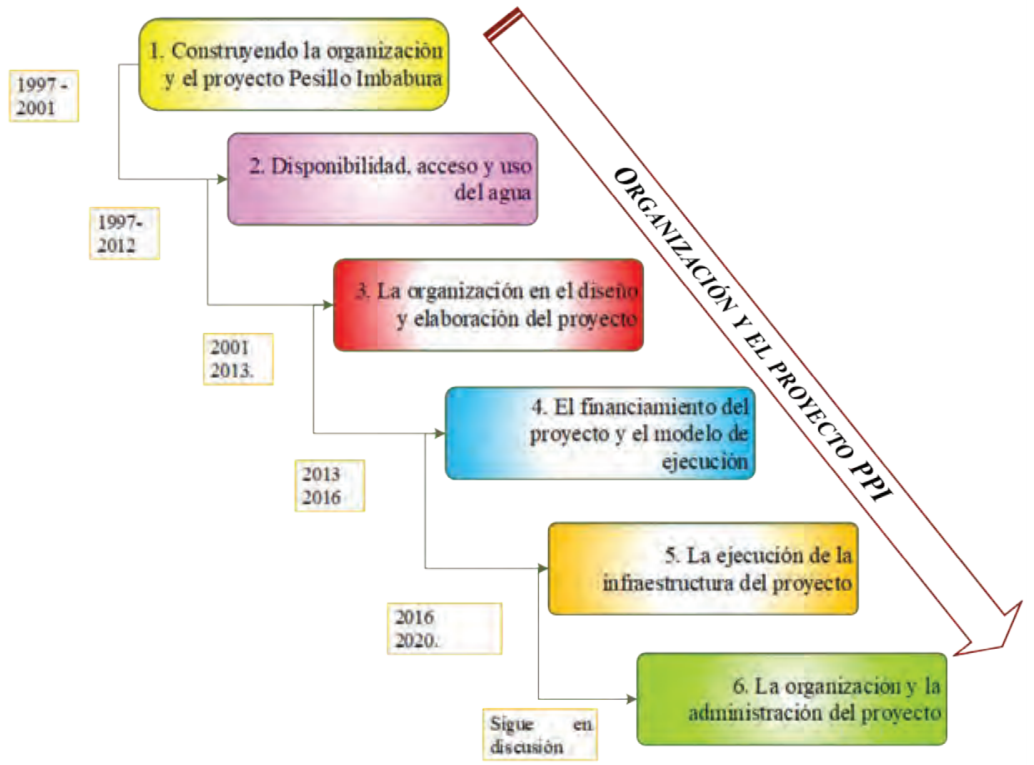

8 Las obras de infraestructura del proyecto debían terminarse en el segundo semestre del año 2019; sin embargo, la constructora ha encontrado varios problemas que ha retrasado su culminación. A enero del año 2020 los avances no superan el $40 \%$ de las obras civiles, por lo que las comunidades siguen esperando que este importante proyecto sea culminado. 
Las comunidades y la organización al impulsar el proyecto con el apoyo de diferentes instituciones pasan por diferentes momentos que marcan relaciones con la institucionalidad del Estado que se resumen en seis momentos o hitos relevantes (Figura 3): 1) acceso al agua e inicios de la organización, 2) disponibilidad y acceso al agua, 3) uso del agua diseño del proyecto (estudios técnicos), 4) financiamiento del proyecto, 5) ejecución de la inversión del proyecto y 6) administración del proyecto.

\section{Construyendo la organización y el proyecto Pesillo-Imbabura}

En las condiciones actuales, el agua es un elemento que socialmente puede dividir a las comunidades y en otros casos las une, permitiendo proponer ideas innovadoras desde el punto de vista social y tecnológico, con el fin de acceder a este elemento al menor costo posible. Así, se hace un recuento que, desde la escasez y los altos costos para el acceso del agua, las comunidades que enfrentan estas realidades se organizan y confrontan las adversidades.

\section{La escasez y los altos costos del agua}

En la década de 1990, la dotación de agua que reciben las comunidades del cantón Otavalo es por medio de red pública y otras formas como de pozo, acequia (Tabla 4 y 5). En algunas JAAP, varios problemas se sienten con intensidad: la escasez de agua, crecimiento de la población y el alto costo del servicio, como en la regional Ilumán y La Compañía (ahora Sumak Yaku') que contaban/cuentan con sistemas de agua mediante bombeo utilizando la energía eléctrica, lo que ponía en mayor vulnerabilidad a los usuarios de este sistema.

9 Es una Junta Administradora de Agua Potable que agrupa a siete comunidades ubicadas al margen norte de la laguna de San Pablo. Sumak es un adjetivo que equivale a: bueno, agradable, delicioso, bello, precioso, y yaku es agua. Que hayan adoptado dicho nombre para la JAAP supone la importancia del agua como elemento vital para el buen vivir. 
En ese contexto, las comunidades buscan soluciones innovadoras a sus problemas; así fueron propuestas dos ideas: en el primer caso, los dirigentes querían reemplazar los sistemas de bombeo, utilizando la energía de la gravedad para abaratar costos económicos al usuario por lo que se analiza la necesidad de buscar fuentes de agua en otros territorios; otros apostaron por proyectos a base de bombeo, como el caso de las comunidades de la parroquia de San Pablo del Lago, o la comunidad de Pijal en la parroquia de Gonzáles Suárez. Ambos proyectos se proponían bombear el agua desde unas vertientes localizadas casi al mismo nivel de la laguna de San Pablo, en cota de $2600 \mathrm{~m} \mathrm{s.} \mathrm{n.} \mathrm{m.,} \mathrm{y} \mathrm{elevar} \mathrm{hasta} \mathrm{las} \mathrm{zonas} \mathrm{habitadas} \mathrm{ubicadas}$ a más $3000 \mathrm{~m} \mathrm{s.n.m.}$

Entre 1996 y 1997, los dirigentes de la JAAP regional Ilumán, de la difícil situación que atravesaban, pensaron en proyectos alternativos; en fuentes que puedan cubrir las demandas de sus comunidades y otras cercanas. El problema era que no había fuentes de agua cerca con el suficiente caudal para satisfacer las demandas de las comunidades con alta densidad poblacional. Jaime Cáceres (2018), ${ }^{10}$ uno de los fundadores del proyecto recuerda el contexto y cómo inició:

El agua para Ilumán viene de la comunidad Araque de San Pablo, se inauguró en 1997. Es a bombeo. La JAAP regional La Compañía bombeaba hasta nuestra regional, para no pagar nosotros el costo del bombeo hicimos un convenio con la Prefectura de Imbabura, para que paguen a la regional La Compañía. Pero después de un año no renovamos el convenio porque era muy costoso y los de La Compañía empezaron a cortar el agua.

Por eso me reuní con los dirigentes de la JAAP Ilumán y dijimos que no podemos vivir así todo el tiempo. Entonces fui a conversar con Carmen Yamberla presidenta de la FICI $^{11}$ que era de Ilumán.

10 Información facilitada por Jaime Cáceres, iniciador del proyecto en entrevista realizada en Ilumán-Otavalo, 2018.

11 Federación Indígena y Campesina de Imbabura (FICI), es la organización provincial filial de la Confederación de Nacionalidades Indígenas de Ecuador (CONAIE). 
Planificamos y nos reunimos con otros dirigentes para ver cómo hacemos para solucionar el problema de agua de una vez.

Iniciamos las conversaciones con Juan Guatemal de la zona de Ibarra, Manuel Imbaquingo de Pijal de Gonzáles Suárez. Salieron algunas ideas. Con la ayuda de los dirigentes de la FICI socializamos en muchas comunidades. La gente nos recibió bien, los dirigentes de las comunidades y JAAP pidieron que dejen ingresar y participar; no podíamos decir no, lo que nos interesaba era que más comunidades se unan para hacer fuerza.

Comenzamos a buscar agua, primero fuimos a Mojanda, los técnicos de la Agencia de Aguas aforaron la laguna, pero no había suficiente cantidad, fuimos a la laguna de Puruhuanta en Pimampiro, y a la laguna de Ciucocha, las alturas (cota) no daban para servir las comunidades de las partes altas, también fui a las lagunas de Piñán cerca del cerro Cotacachi, si daba la altura, pero tocaba construir túneles muy grandes.

Luego fui donde un amigo en la Agencia de Aguas de Quito. Como tenía amistad empezamos a buscar en las cartas topográficas, ahí vimos Chahuancorral y Pucapaccha en la zona de Pesillo. (Jaime Cáceres, entrevista 17 de julio de 2018)

De esta situación de la JAAP Ilumán, nace la necesidad de crear una organización comunitaria que confronte la problemática en el territorio y explica el comienzo del PPI. Después de las reuniones iniciales, se ampliaron las invitaciones a otras comunidades de otras parroquias de Otavalo, Antonio Ante e Ibarra. La mayoría de las comunidades sufrían diferentes problemas relacionadas con la falta y/o la mala calidad del agua, por eso desde los primeros años pasó a constituirse en la esperanza para dar solución definitiva a un problema que aquejaba principalmente a las poblaciones de las comunidades (Figura 4). 
José Manuel Perugachi Cachimuel - Charles Cachipuendo Ulcuango

38

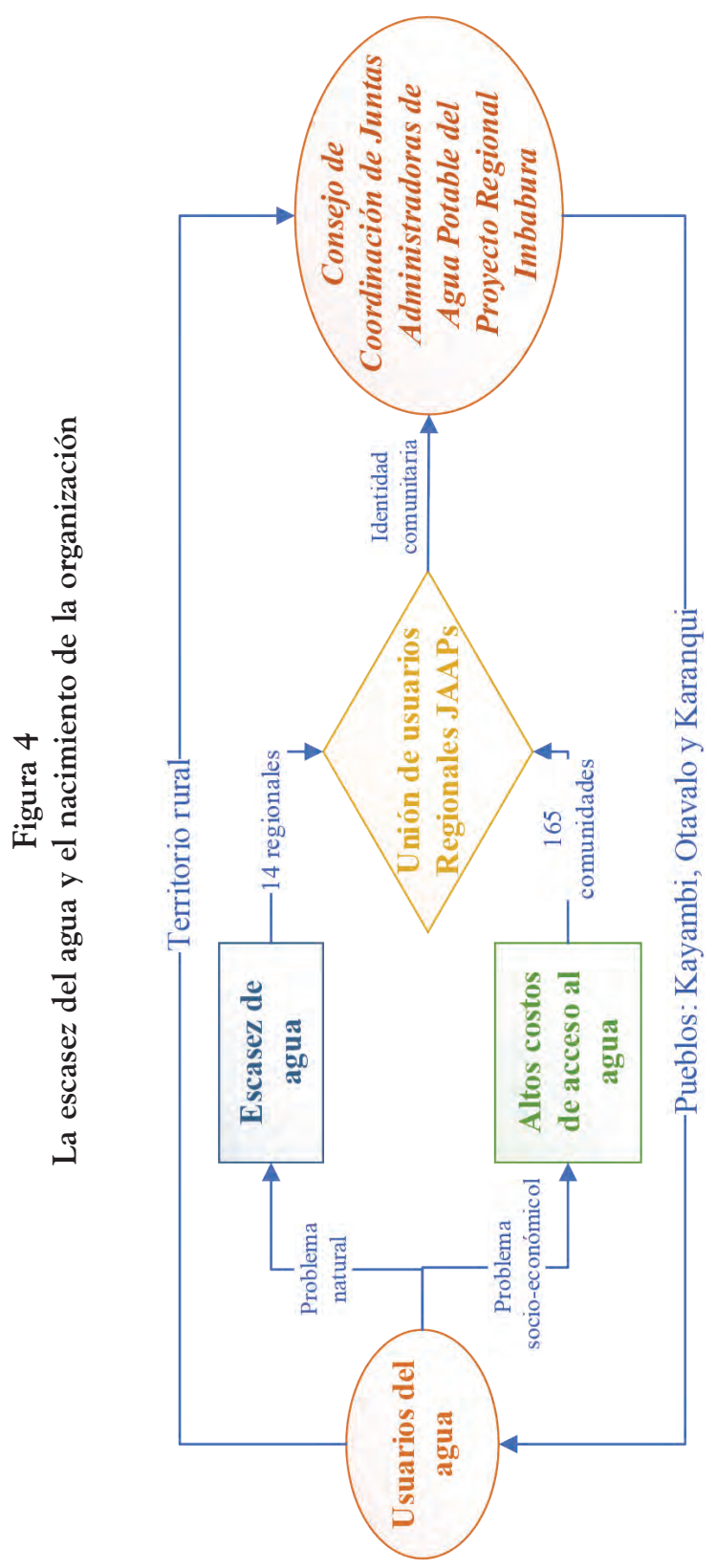




\section{La organización reclamando los derechos al acceso del agua}

Para exigir el derecho al agua, debieron constituir una organización que represente a las comunidades indígenas y campesinas. Así, en 1997, se constituyó el Consejo de Coordinación de Juntas Administradoras de Agua Potable del Proyecto Regional Imbabura. En el mes de abril de ese mismo año, en una reunión mantenida en la sede de la FICI en Otavalo, Jaime Cáceres de la regional Ilumán es nombrado coordinador de la organización que impulsa el PPI, acompañado por otros dirigentes: Segundo Santillán de la Regional La Compañía, Juan Guatemal representando a las comunidades del cantón Ibarra (parroquias Angochawa, la Esperanza, Karanki) y Manuel Imbaquingo de la comunidad de Pijal. Después se sumaron las comunidades de cantón Pedro Moncayo.

En enero del año 2001, con el propósito de unificar esfuerzos para viabilizar y permitir que se ejecute el Proyecto, formalizan un acuerdo entre el Consejo de Coordinación de Juntas Administradoras de Agua Potable del Proyecto Regional Imbabura y la Junta de agua de Pesillo para denominarlo Consejo de Coordinación de Juntas Administradoras de Agua Potable del Proyecto Regional Pesillo-Imbabura (Figura 5) (en adelante Consejo de Juntas). Se integró también la Unión de Organizaciones Populares de Ayora y Cayambe (UNOPAC), y se recomendó la inclusión de las cabeceras cantonales de Otavalo, Antonio Ante e Ibarra, quedando configurada la organización —según la cobertura - del PPI tal como se la conoce en la actualidad.

Por haber iniciado en Ilumán, la sede reposaba en la casa del Gobierno Autónomo Descentralizado Parroquial de San Juan de Ilumán. En el año 2012, la sede pasó a la ciudad de Otavalo, luego pasó a la comunidad de La Bolsa, y por último pasó a funcionar en la ciudad de Ibarra, en el Ministerio de Agricultura, Ganadería, Acuicultura y Pesca (MAGAP). 
Figura 5

Estructura de la organización después del año 2001

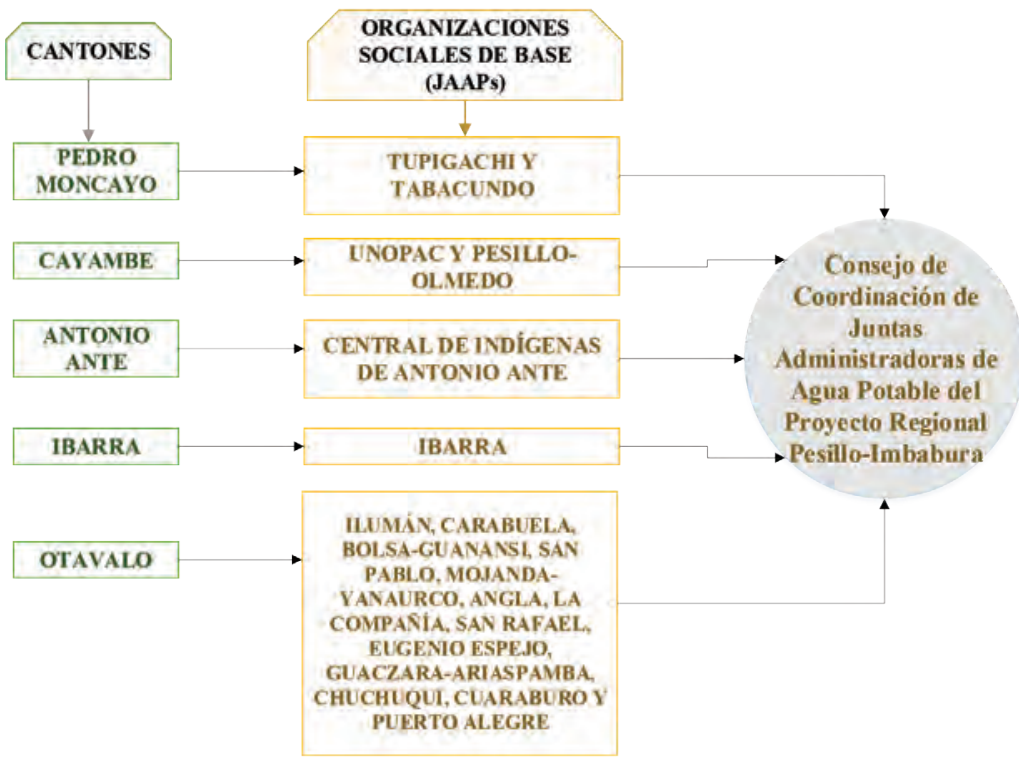

Una vez que el proyecto recibe el financiamiento para la fase de ejecución del sistema de agua, ya no será necesario que se llame Consejo de Coordinación de Juntas de Agua Potable del Proyecto ${ }^{12}$ Regional Pesillo-Imbabura, por lo que, en el año 2018, inicia el proceso formal para cambiar a (Organización de Juntas Administradoras de Agua Potable Pesillo-Imbabura) con la discusión y elaboración del estatuto de acuerdo con la Ley Orgánica de Recursos Hídricos Usos y Aprovechamiento del Agua.

12 Generalmente las fases de un proyecto son: idea, estudio de prefactibilidad, estudio final de factibilidad, gestión y ejecución del proyecto. En el caso del Proyecto Pesillo-Imbabura, después de la ejecución ya no necesita ser proyecto, razones por las que han decidido denominar Organización de Juntas Administradoras de Agua Potable y Saneamiento Pesillo-Imbabura, que representará a las comunidades y usuarios en la fase operativa hasta el 2042, año luz del sistema de agua que se construye. 
En marzo del 2018, en la ciudad de Ibarra, se reúnen representantes de las JAAP: Angla, Santa Rosa de Ayora, Moras Huayco, Sumak Yaku, Carabuela, Ilumán, Pesillo, Ibarra, más la Secretaría Nacional del Agua (SENAGUA), para elegir a los miembros de la directiva, siendo Juan Serrano su presidente.

En junio, en la parroquia de San Roque del cantón Antonio Ante, los representantes de las regionales aprueban el Estatuto de "Organizaciones de Juntas Administradoras de Agua Potable Pesillo-Imbabura", misma que entró a trámite en la SENAGUA para su aprobación y otorgación de la personería jurídica.

El artículo 1 dice:

Constitúyase la Organización de Juntas Administradoras de Agua Potable y Saneamiento Pesillo-Imbabura, las Regionales, R, Ibarra, R, Antonio Ante, R, Ilumán, R, Carabuela, R, R, Sumak Yaku, R, Moras Huayco, R, Angla, R, Espejo, R, San Rafel, Junta de Pesillo y Junta de Ayora, como una organización de segundo grado, sin fines de lucro, con patrimonio propio, administración autónoma y personería jurídica; con capacidad legal para ejercer derechos y contraer obligaciones; la misma que se regirá por el presente Estatuto y más Reglamentos Internos que se aprobaren para la buena marcha de la entidad, por las disposiciones de la Constitución de la República, Ley Orgánica de Recursos Hídricos, Usos y Aprovechamiento del Agua, e inspirados en los procesos de participación comunitaria y dotación de servicios de agua y saneamiento.

El acuerdo ministerial de creación de la organizaciones debía ser entregada por la SENAGUA a finales del 2018 o inicios del 2019; sin embargo, la institución ha presentado excusas, sosteniendo que el estatuto no está bien elaborado, por lo que deben hacer de nuevo el proceso para buscar la legalización.

Hasta abril del 2018, una comisión realiza las gestiones para legalizar la organización, se espera que a finales del 2019 se emita la resolución respectiva; sin embargo, el principal problema por lo que la SENAGUA no otorga la personería jurídica se debe a que la ma- 
yoría de JAAP regionales como organizaciones comunitarias de base del proyecto, son entidades de hecho y no de derecho, por lo que a la fecha los trámites continúan.

\section{Cultura organizacional y sistema de elección de los dirigentes de la organización}

El sistema organizativo del Consejo de Coordinación de Juntas de Agua Potable del Proyecto Regional Pesillo-Imbabura, parte de las organizaciones sociales de base que son las comunidades agrupadas en JAAP regionales. En el cantón Otavalo se encuentran más comunidades y JAAP, pero en cuanto a la composición de los dirigentes, siempre se ha cuidado que sean de los cinco cantones, bajo los principios de igualdad, solidaridad e inclusión.

Para elegir a los miembros de la directiva, la asamblea extraordinaria del Consejo de Juntas nombraba una comisión de elección integrada por dirigentes de comunidades, JAAP y usuarios con probidad, mismos que realizaban reglamentos con los requisitos básicos para los candidatos y cronogramas para el proceso electoral. Cada JAAP podía presentar candidatos para diferentes dignidades, con aval de la comunidad y respaldo de la JAAP regional (Figura 6).

Las elecciones se realizan democráticamente en las asambleas generales ordinarias que también se llamaban congresos ordinarios. Por ser una organización intercomunitaria, el porcentaje de sufragantes se determina por el número de usuarios miembros de cada comunidad y JAAP. Las votaciones se hacen a mano alzada o mediante voto secreto en urnas $\mathrm{u}$ otros sistemas bajo el principio de participación y trasparencia. Las formas no importan siempre y cuando no se vulneren los intereses de los candidatos ni los objetivos de la organización. 


\section{Figura 6}

Directiva de la organización en el periodo 2005-2007

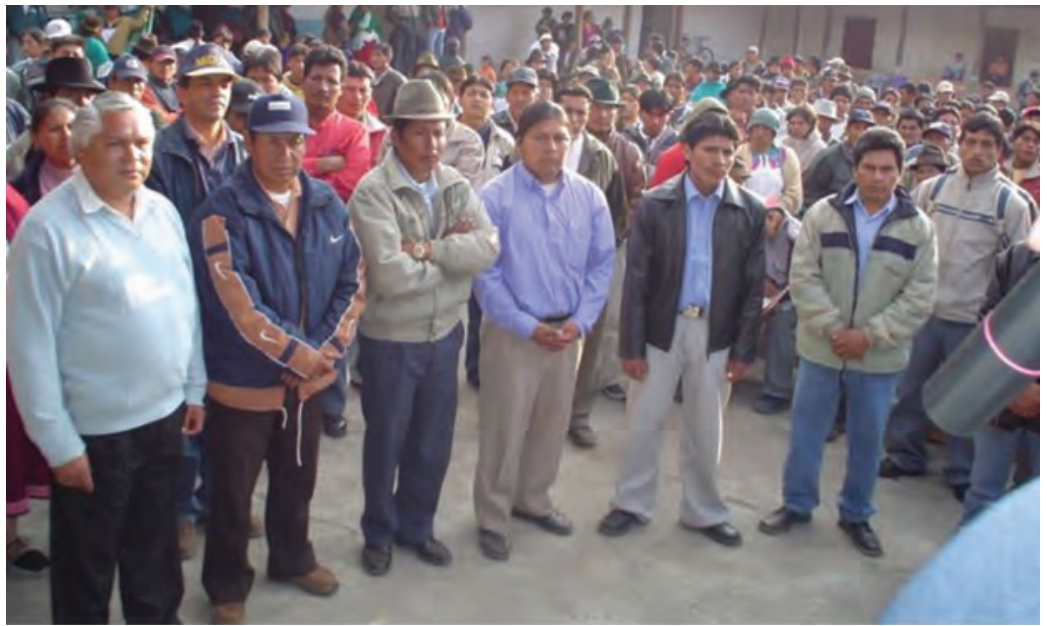

Fuente: Archivo PPI.

Los dignatarios son electos cada dos años según el reglamento. Los principales cargos de dirección del Consejo de Juntas son: presidente, vicepresidente, secretario/a, tesorero/a, actas y comunicación, comisión de gestión y medio ambiente, vocalías y veedurías (Figura 7).

Jaime Cáceres fue el primer (coordinador/presidente) del Consejo de Juntas del proyecto, reelegido en cinco ocasiones, cada uno de dos años de duración. En total estuvo cerca de diez años al frente de la organización impulsando la consecución del PPI. Después, desde el año 2007 hasta inicios de 2012, le sucedió el abogado Gonzalo Cabascango de la JAAP regional Tupigachi. Finalmente, desde el 2012, hasta inicios del 2019, Juan Serrano de JAAP regional Ibarra estuvo al frente, con sucesivas reelecciones. Actualmente (año 2019 y 2020), una comisión transitoria lleva los destinos de la organización y consecución de la fase de ejecución del PPI.

Algunos cargos como el de actas y comunicación, comisión de gestión y medio ambiente, fueron creados por necesidades coyuntu- 
rales dado la amplitud geográfica del PPI, así como por la importancia del medio ambiente. En la Ley de Aguas no hay estas dignidades, es por eso que en algunos años se elegían y en otros se los suprimía como puede apreciarse en la Tabla 8.

Con fines de mejorar los procesos de gestión de consecución del proyecto, la organización tenía libertad de crear dignidades que los actores creyeron conveniente y abordar el proyecto desde los ámbitos: ambiental, social, económico, político, legal y cultural. Generalmente, las personas de estas dignidades cumplían funciones de soporte del presidente en su localidad. El vicepresidente y los vocales debían suplir al presidente, al secretario/a, tesorero/a en caso de ausencia. Los veedores eran responsables de vigilar la actuación de los directivos, siendo ellos los únicos que dependían o respondían a la asamblea general y no a los directivos.

\section{Figura 7}

\section{Cultura organizacional del Consejo de Juntas PPI}

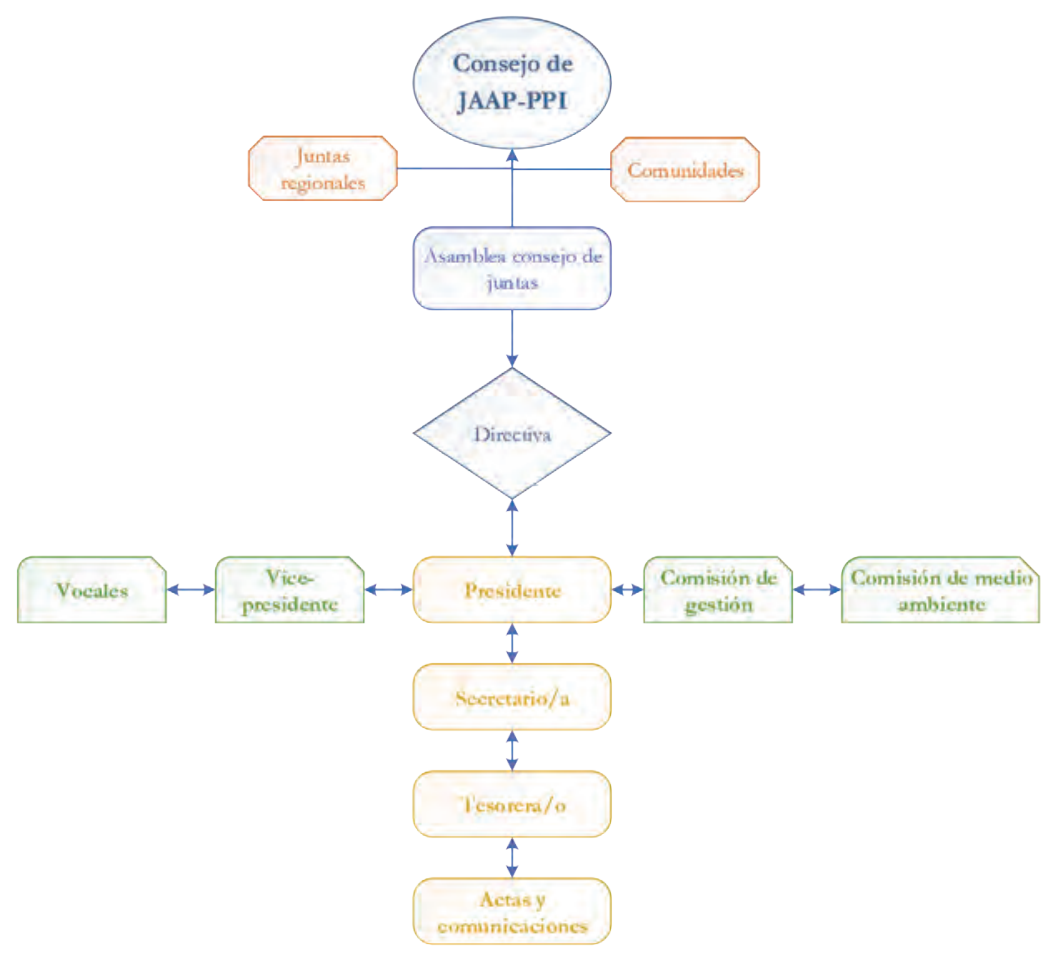


Los directivos del Consejo de Juntas dependían de los recursos provenientes de las comunidades y JAAP, pero estas organizaciones se retrasaban en los aportes, o algunas en rebeldía por los escasos o lentos avances en la obtención de resultados del proyecto se negaban a recolectar el dinero para traspasar a la tesorería del Consejo de juntas. Varias veces los dirigentes han tenido que ver otras formas de autofinanciamiento para no dejar las gestiones correspondientes. Por ello, el principal problema con la mayoría de las directivas, excepto el presidente, fueron los casos de acefalia; es decir, ausencia de sus cargos. La mayoría incumplió las funciones para el que fueron electos o su participación fue parcial u ocasional, debiendo cubrir las exigentes actividades el presidente y otros pocos dirigentes, con los limitados recursos provenientes de los contribuyentes, o en otros casos con recursos propios.

Asumir cargos ad-honorem, es una muestra que los dirigentes estaban comprometidos con los objetivos supremos del proyecto y dispuestos a entregar el valioso tiempo al servicio de todos. En general, en el tiempo de existencia del Consejo de Juntas se han realizado diez elecciones de sus representantes (Tabla 8).

\section{Organización comunitaria y actores del proyecto PPI}

Las comunidades con fines de acceder a agua segura en cantidad y calidad al menor costo proponen el PPI. Desde que emerge como idea, ha venido incorporando diversos actores que han aportado a su consecución (Figura 8). También se han generado disyuntivas en los procesos organizativos comunitarios y con las empresas públicas de agua potable. Así, en este caminar, en el diseño y ejecución (construcción de la infraestructura del sistema) del proyecto intervienen instituciones del Estado, de la sociedad civil y la academia, siendo los principales protagonistas las comunidades indígenas, agrupadas en el Consejo de Coordinación de Juntas de Agua Potable del Proyecto Regional Pesillo-Imbabura. 
José Manuel Perugachi Cachimuel - Charles Cachipuendo Ulcuango

46

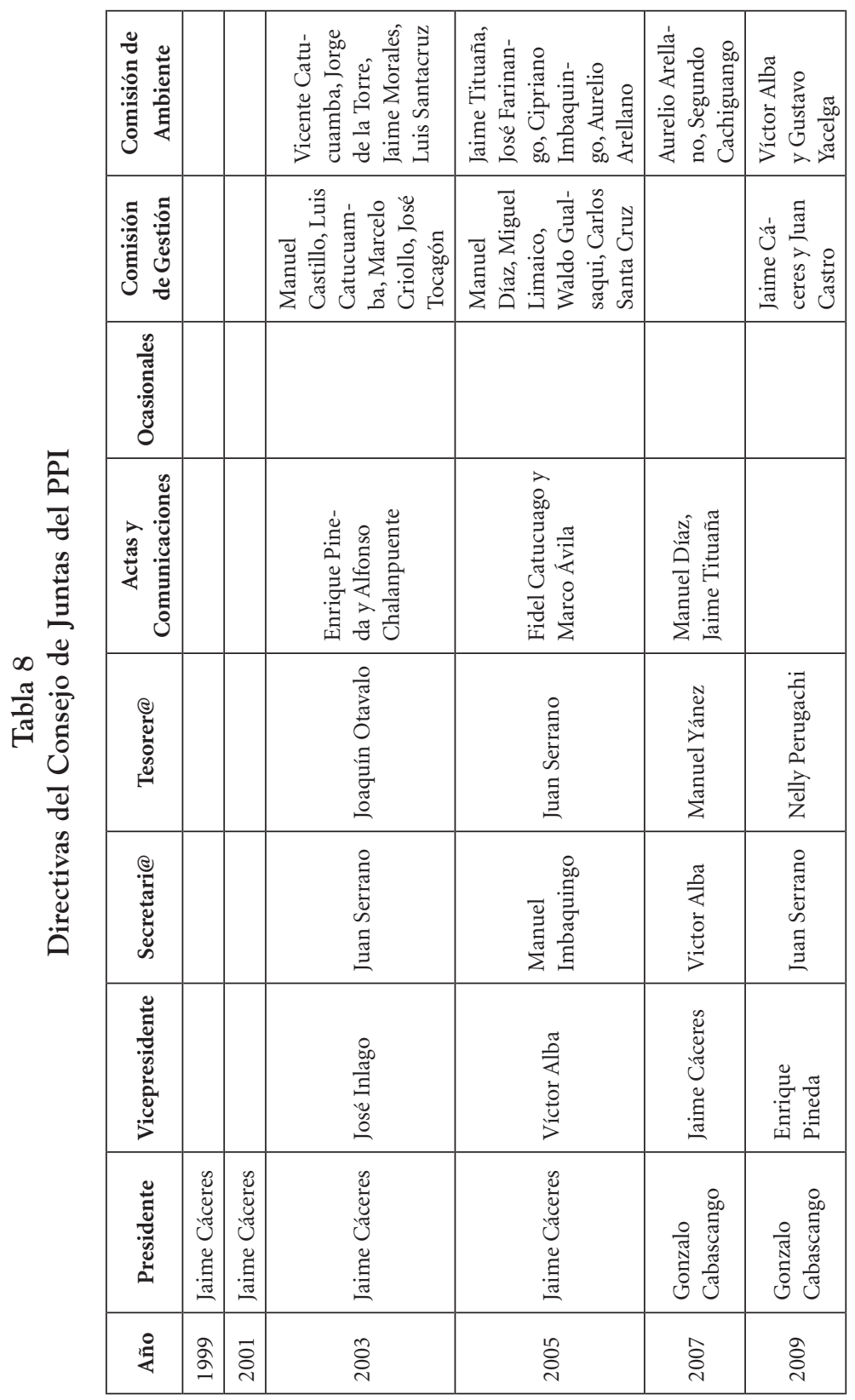




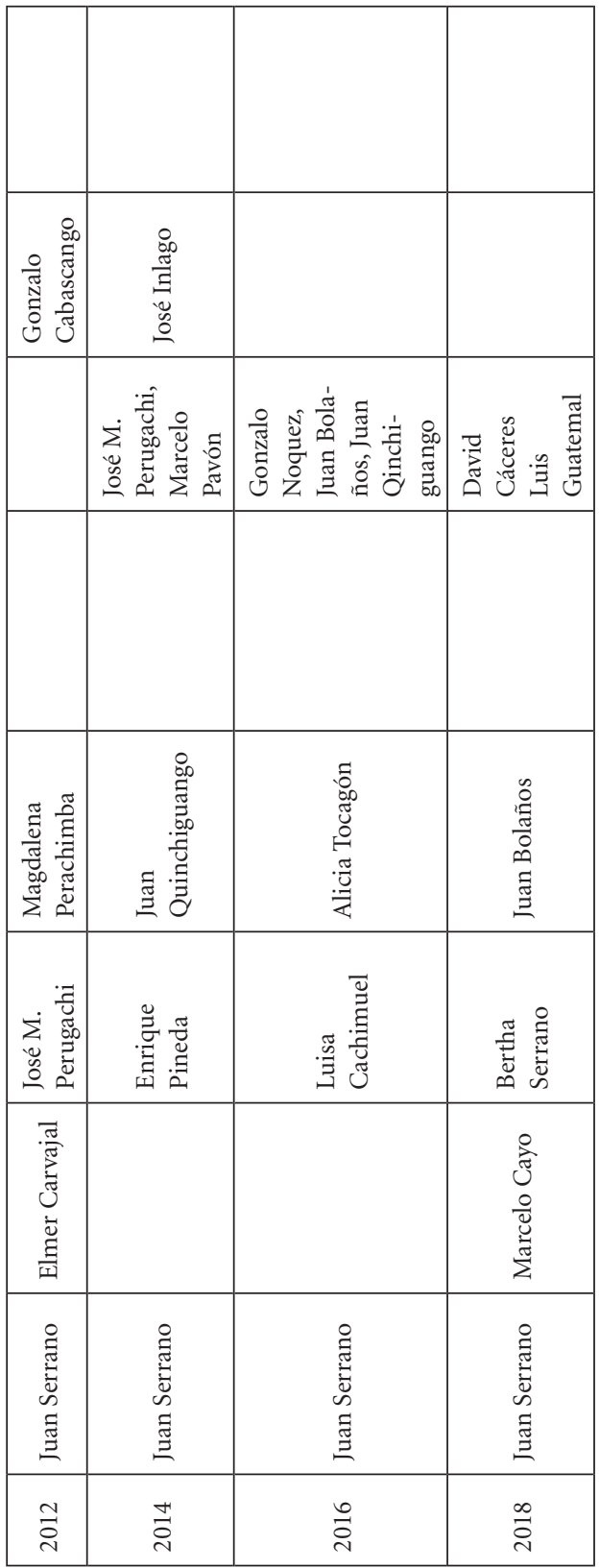




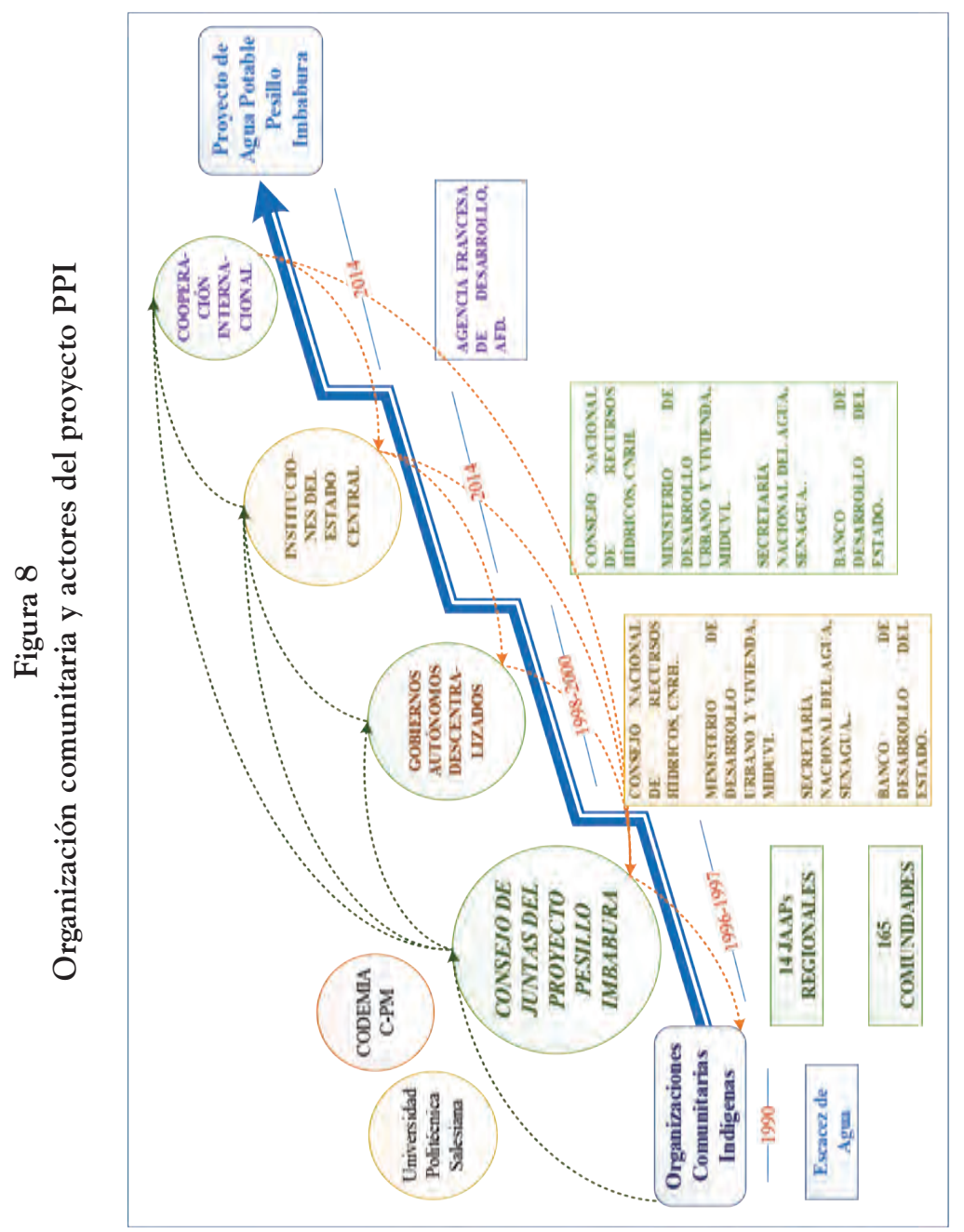


Entre los diversos actores, una organización fraterna-amiga-hermana es el Consorcio de Desarrollo de Manejo Integral de Agua y Ambiente para Cayambe y Pedro Moncayo (CODEMIA C-PM), que gestiona el proyecto canal de Riego Cayambe-Pedro Moncayo. ${ }^{13}$ Con el Consejo de Juntas han coordinado varias veces acciones de presión a las instituciones del Estado para que respondan a las demandas de ambos proyectos. Para las medidas de presión, los dirigentes del CODEMIA han participado en las asambleas y reuniones del Consejo de Juntas y viceversa.

Las acciones conjuntas realizadas en el año 2014 (ver más adelante), permitieron conseguir los estudios definitivos y compromisos del gobierno central para financiar la ejecución del PPI. Ambas organizaciones quedaron con importantes lecciones, que al ser proyectos que van abastecerse de la misma cuenca hidrográfica y el mismo sistema hidráulico deben unirse, aunque el agua sea para distintos usos: consumo humano y riego. Aquí se han descubierto discordias y problemas leves durante los primeros años; el CODEMIA se sentía amenazado por el PPI, porque pensaban que entran a disputar el preciado caudal que requiere el proyecto de riego, pero con el paso de los años, las disyuntivas han sido superadas. De esta manera estos proyectos se convierten en un proyecto de dotación de agua multi-

13 El proyecto de riego Cayambe-Pedro Moncayo nace por la necesidad de contar con agua de riego para la seguridad y soberanía alimentaria en los cantones Cayambe y Pedro Moncayo. Este sueño nace por los años 1903, se construye el sistema de conducción de riego, pero esto no es suficiente por lo que se busca nuevas fuentes de agua. Luego de realizar varias medidas de presión se realizan los estudios y se adjudicó en el año 1998 a la constructora Andrade Gutiérrez, la empresa inicia la construcción dejando con un avance del $48 \%$ y se termina el presupuesto quedando desfinanciado. Se inicia de nuevo la búsqueda de recursos y estudios complementarios; para conseguir este objetivo nos unimos con el PPI, y en una medida de presión junto a CODEMIA, se declaró el proyecto multipropósito de prioridad nacional. Luego de un paro realizado entre el Proyecto Pesillo-Imbabura, y el PreDirectorio, luego CODEMIA-C.PM, el 17 de septiembre del 2007 se consigue declarar "proyectos prioritarios y emergentes" (Información facilitada por Fabián Morocho, exdirigente de CODEMIA, junio 2018). 
propósito, para consumo humano y para riego, siendo parte de su población beneficiaria en los dos tipos de uso.

La organización ve una oportunidad en la Universidad Politécnica Salesiana (UPS) de tener un espacio para generar procesos de diálogo y reflexión sobre la gestión y manejo del agua por parte de las organizaciones comunitarias. La UPS no aporta directamente en la construcción del proyecto, pero apoya en procesos de capacitación y monitoreo de la calidad del agua en los sistemas regionales de agua potable.

Cada uno de los actores cumplieron diferentes roles. La organización planteó e impulsó el proyecto, comprometidos siempre a alcanzar el objetivo mayor, disponer de agua. Otros actores, las autoridades en representación de las instituciones del Estado central y los GAD, apoyaron la iniciativa de las comunidades, otras veces se mostraban en contra debilitando los objetivos iniciales, por consiguiente, la organización también se debilitaba. Por eso, la organización toma diferentes estrategias y acciones que le permite manejar estas circunstancias y llevar a cabo el proyecto.

\section{Disponibilidad, acceso y uso del agua}

Las comunidades y posteriormente la organización Consejo de Juntas, para acceder al agua requieren estudios de la disponibilidad del agua, ver cuáles son las posibilidades de conducirla hasta los territorios rurales e identificar los potenciales beneficiarios, en este caminar se presentan conflictos entre los usuarios del agua, pero según la dinámica de las comunidades se logran acuerdos, permitiendo el avance y posterior construcción del proyecto.

\section{Búsqueda de fuentes y concesiones de agua}

Una vez constituido el Consejo de Juntas, los dirigentes inician a buscar fuentes de agua. Al inicio obtuvieron la concesión de dos fuentes ubicadas en la micro cuenca del río La Chimba, cerca de 
la comunidad de Pesillo, cantón Cayambe, misma que encontró la oposición de las organizaciones de la parroquia de Olmedo.

En el mes de junio de (1997), Jaime Cáceres, en representación del Consejo de Juntas solicita al Consejo Nacional de Recursos Hídricos $(\mathrm{CNRH})^{14}$ el derecho de concesión de las fuentes de aguas localizadas cerca del nevado Cayambe:

En la estribación nororiental de la jurisdicción parroquial de Olmedo, cantón Cayambe, provincia de Pichincha, cordillera que circula la laguna de San Marcos, cota 3440 m s. n. m., aflora la vertiente sin nombre que alimenta la quebrada Chahuancorral que origina del río Chalpar y posteriormente río La Chimba; que bajo el amparo de las normas de los arts. 83, 84 y 85 de la Ley de Aguas, solicita el derecho de concesión.

En el mes de septiembre, Jaime Cáceres, nuevamente presenta en el CNRH, agencia de Quito, ${ }^{15}$ la solicitud de derecho de aprovechamiento de las aguas de la quebrada Chahuancorral y Pucapaccha, un caudal no menor a 400 1/s, a fin de destinarlos a la implementación del sistema de agua potable del proyecto Regional Imbabura, esta vez contando con el compromiso y auspicio del Consejo Provincial de Imbabura.

A finales de septiembre, el CNRH, nombra como Perito ${ }^{16}$ al Ing. Rafael Valladares. Luego de realizar la inspección, presenta el informe técnico a la solicitud de concesión hecha por Jaime Cáceres:

14 Con la Ley de Aguas anterior, el CNRH era la Autoridad Nacional encargada de administrar los recursos hídricos del país que otorgaba las concesiones de agua para los diferentes usos.

15 Las Agencias de Agua de cada cabecera provincial, es donde se resolvían los juicios de concesión de agua si es que habían. La solicitud de concesión se hace en Quito porque las fuentes están ubicadas en la provincia de Pichincha.

16 Es un profesional en un área o materia que sirve para medio de prueba en un proceso judicial, en este caso el Perito es un profesional en materia de agua. 
Existe un alto déficit hídrico en la región sur oriente de la provincia de Imbabura para cubrir las más elementales necesidades de consumo doméstico de 65 comunidades considerando una población de más de 70000 habitantes, un crecimiento del 2,5 anual durante treinta años y una población proyectada de más de 140000 habitantes, debería cubrirse con lo menos de 204 l/s.

Que se conceda el derecho de aprovechamiento de las aguas que provienen de las quebradas Chahuancorral en un caudal de $154 \mathrm{l} / \mathrm{s}$, y de la quebrada Pucapaccha en un caudal de 50 l/s, que están ubicados en la parroquia Olmedo del cantón Cayambe de la provincia de Pichincha; las que se tomaran mediante obras de capacitación en la cota 3400 y $3350 \mathrm{~m}$ s. n. m. Los beneficiarios deberán presentar en esta Agencia los estudios de pre factibilidad en un plazo no mayor de 180 días, los estudios de factibilidad en un plazo de 120 días y las obras de toma y captación deberán estar culminados en un plazo no mayor de 24 meses, contados a partir de la resolución de aprobación de los planos y diseños de las obras hidráulicas que deberán presentarse en esta Agencia.

Así, se logra la primera concesión de agua para las comunidades del Consejo de Juntas (Figura 9).

El 30 de enero del 1998, el Jefe de la Agencia de Aguas de Quito, luego de tramitar la solicitud de derecho de concesión, "concede el derecho de aprovechamiento de las aguas que provienen de las quebradas Chahuancorral y Pucapaccha". Sin embargo, la Junta de Riego de la comunidad de Pesillo se opuso a esta concesión, (se detalla más adelante).

En mayo de 1998, otro Perito presenta un estudio manteniendo gran parte del informe del Perito hecho en 1997. Además, señala que:

Por tratarse de aguas para consumo humano se exonera de pago; $y$, estas fuentes de la microcuenca Pucapaccha y Chahuancorral tienen suficiente recarga, por la presencia de vegetación natural no se altera durante la mayor parte del año. 
LA LUCHA POR EL AGUA

53

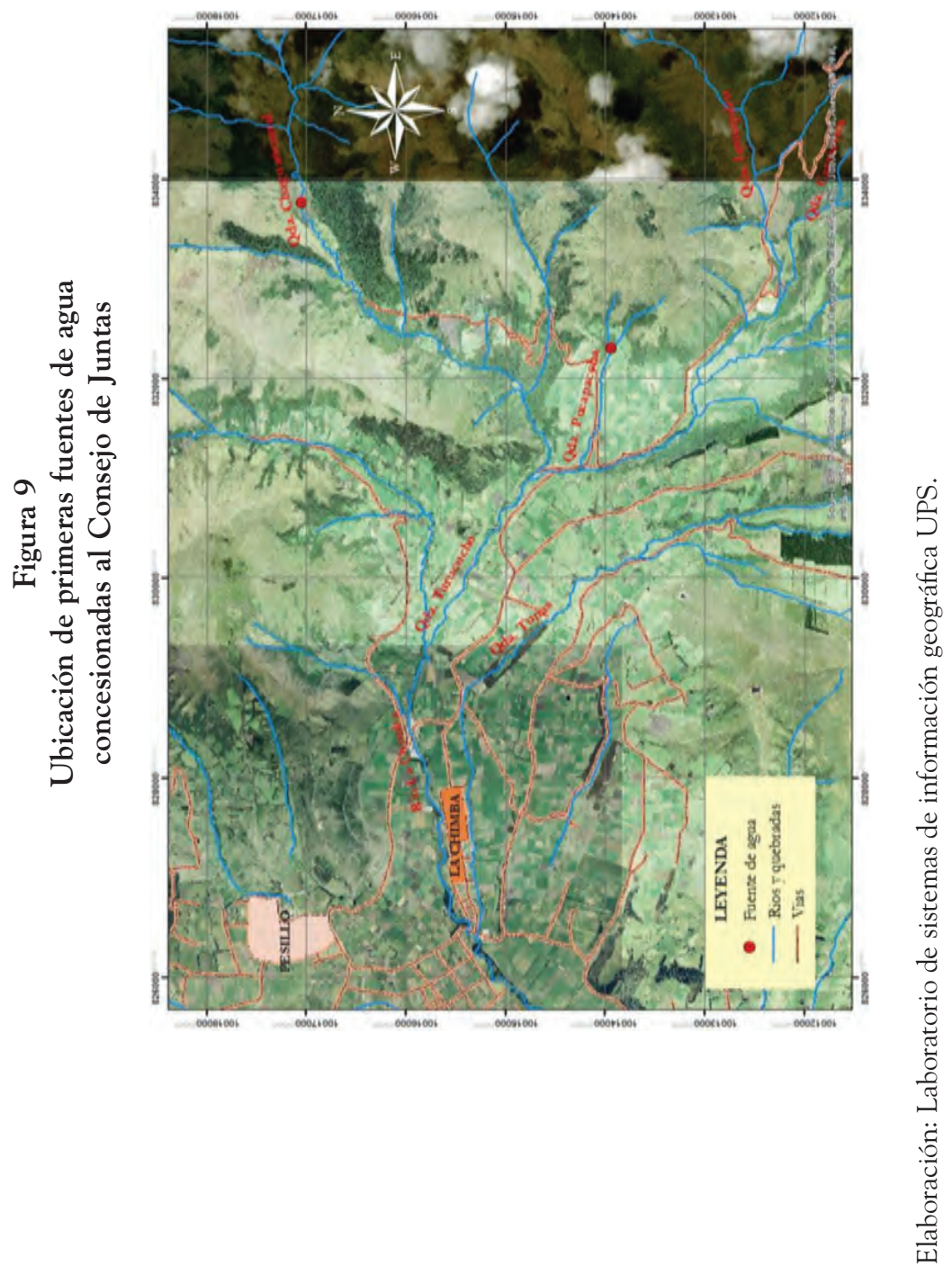


Un informe elaborado entre agosto y septiembre concluye y recomienda que el caudal requerido podrá ser dispuesto:

Única y exclusivamente en los meses de superávit, esto es durante los meses de febrero y marzo en los sitios denominados: quebradas Chahuancorral y Pucapaccha, en un caudal de 140 1/s., en tal virtud, el Consejo de Juntas Administradoras de Agua Potable Regional Imbabura, se halla limitada totalmente para cubrir su demanda. ${ }^{17}$

En febrero de 1999, presentan una solicitud al Consejo Consultivo de Aguas para realizar un nuevo estudio técnico en las fuentes mencionadas. En el mes de marzo, el Ing. Renzo Yerovi deja las siguientes conclusiones y recomendaciones:

1. No existen caudales disponibles de la quebrada Chahuancorral que permitan satisfacer los requerimientos hídricos del proyecto regional de agua potable de Imbabura, ya que cualquier asignación de dichas aguas, afectaría las concesiones existentes en el río La Chimba, al que desembocan las aguas de la quebrada Chahuancorral, afectación que se produciría exclusivamente en los meses de estiaje (agosto, septiembre, octubre, noviembre, diciembre y enero).

2. Con la construcción - en plena ejecución- del proyecto de riego "Tabacundo" se cambiará la hidrología del río, en razón de que el caudal de $6,86 \mathrm{~m} 3 / \mathrm{s}$ que se captara en los ríos de la cuenca oriental de la laguna de San Marcos se trasvasaran por túnel hasta descargarlos en el curso alto de río La Chimba es decir en el cauce del río Ismuquiru, para posteriormente captarlos a la altura del Olmedo, lo que implicará de acuerdo al estudio de factibilidad del proyecto Tabacundo, que las aguas de la acequia Tabacundo (400 a 450 l/s) quedarían completamente liberadas.

3. De lo anterior concluye que, una asignación de las aguas de la quebrada Chahuancorral influiría en las concesiones dadas en el río La Chimba, en los meses de estiaje; una vez declaradas liberadas las

17 Este informe va en contra de los informes anteriores y pretensiones del Proyecto Regional Pesillo-Imbabura para beneficiarse de la concesión de las dos fuentes de agua, y da razón a las personas de Pesillo que habían puesto oposición. 
aguas captadas del río en el actual canal Tabacundo, se compensaría el caudal que se derivaría para satisfacer los requerimientos del proyecto regional de agua potable Imbabura.

4. Que mientras no se declaren legalmente liberadas las aguas que se captan del río La Chimba, no existe caudales disponibles de la quebrada Chahuancorral, que permitan satisfacer los requerimientos hídricos del proyecto regional de agua potable Imbabura (...).

Al existir dos informes cuyas conclusiones se contraponen, el 13 de julio, el Tribunal del Consejo Consultivo de Aguas, ${ }^{18}$ se declara competente para reconocer y resolver, para ello acoge el perito presentado en marzo. Se reforma la sentencia a favor del PPI y dispone que: "La Concesión tendrá lugar una vez que las aguas se encuentren liberadas, luego de que el Consejo Provincial de Pichincha haya construido las obras del proyecto de riego Tabacundo".

En enero de 2001, Ramiro Gonzáles, prefecto de la provincia de Pichincha, comparece ante el Jefe de la Agencia de Aguas de Quito, solicitando la Concesión del Derecho de Aprovechamiento de las aguas del río San Jerónimo:

Ampliamos la solicitud de Concesión del Derecho de Aprovechamiento de las Aguas del Río San Jerónimo requiriendo también los caudales de los ríos Montoneras, Cuscungo y La Chimba $^{19}$ (...), para destinarlos a irrigación de 12923 ha, de suelos altamente productivos que hoy no se benefician de riego (...). Los caudales requeridos suman alrededor de 4500 l/s, que complementarán los volúmenes de agua requeridos para la operación y funcionamiento del Canal de Riego Tabacundo, los sitios de captación serían sobre la cota $3500 \mathrm{~m}$ s. n. m.

18 Era un organismo que analizaba las políticas públicas en torno al agua. Cuando la Agencia de Agua se declaraba que no es competente para resolver los juicios de concesión, esta pasaba al Consejo Consultivo como última instancia de resolución.

19 Representantes del comité de desarrollo de la comunidad de La Chimba se opusieron a esta solicitud, especialmente las aguas del río La Chimba. 
En febrero de 2002, el Gobierno Provincial de Imbabura y el presidente del Consejo de Juntas comparecen por escrito ante el Jefe de la Agencia de Aguas de Quito y solicitan:

La reforma de la sentencia de concesión de aguas de las fuentes Chaguancorral y Pucapacha, a fin de que dentro de su microcuenca, aguas arriba se determine la cota óptima de captación que permita la operatividad del proyecto regional de abastecimiento de agua PesilloImbabura con la fuente Ismuquiru con todo su caudal liberado.

Además, el Gobierno Provincial de Imbabura y el presidente del Consejo de Juntas solicitan la adhesión para la concesión del derecho de aprovechamiento de aguas presentada por el Gobierno Provincial de Pichincha. ${ }^{20}$ En marzo, la Agencia de Aguas de Quito analizó y aceptó la petición del Gobierno Provincial de Imbabura y el Consejo de Juntas. Ese mismo mes, Ramiro Gonzáles se dirige al Jefe de la Agencia de Aguas de la ciudad de Quito para dejar la siguiente posición:

En cuanto a la adhesión — presentada por el Gobierno Provincial de Imbabura - lo rechazamos, toda vez que se trata de una solicitud de concesión de aprovechamiento de aguas y servidumbres (...) y, además que no contamos con el suficiente caudal para el Canal de Riego Tabacundo.

En agosto, el Ing. Rafael Valladares funcionario del CNRH presenta el informe técnico al Jefe de la Agencia de Aguas de Quito, que contiene lo siguiente — versión resumida—.

Petición:

Mediante sentencia de abril 15, 1999, el H. Consejo Provincial de Pichincha, cuenta con la concesión de las aguas de las siguientes fuentes: Nacimiento del río Azuela, río San Pedro, río Boquerón, río Arturo, destinadas para el proyecto de riego Tabacundo (...).

20 A la solicitud de ampliación de Concesión del derecho de Aprovechamiento de las aguas del río San Jerónimo, requiriendo también los caudales de los ríos Montoneras, Cuscungo y La Chimba, para el proyecto de Riego Tabacundo, presentado en enero del año 2001. 
Posteriormente el señor Econ. Ramiro Gonzáles prefecto Provincial de Pichincha, amplia la solicitud de concesión, requiriendo también los caudales de los ríos Montoneras, San Jerónimo, Cuscungo y La Chimba, los caudales requeridos suman alrededor de 4500 l/s.

Situación actual:

4. Los señores: Lic. Gustavo Pareja Cisneros prefecto de Imbabura; y, Jaime Cáceres en su calidad de presidente del Consejo de Juntas, manifiestan entre otras consideraciones legales que por existir el orden de preferencia prioritario en el uso del agua para necesidades domésticas, se adhieren ${ }^{21}$ a la presente solicitud de concesión, a fin de atender a las 130 localidades rurales y 7 centros urbanos que integran el proyecto regional Pesillo-Imbabura, con una población de 879.000 habitantes, con horizonte de diseño de 50 años.

\section{Conclusiones:}

5. No existe inconveniente de orden técnico para que se atienda las peticiones del Gobierno Provincial de Pichincha, por ser un proyecto de interés nacional; así como la adhesión del Gobierno Provincial de Imbabura por existir orden de preferencia prioritario en el uso de agua para el abastecimiento de poblaciones para necesidades domésticas. Además de lo anterior, existe caudal suficiente en las diferentes fuentes y no se causa interferencia alguna a las concesiones emitidas por esta Agencia en lo que respecta a la microcuenca del río La Chimba. 6. Se deberá desechar la oposición presentada por los señores: Ernesto Necpas y Hernán Catucuamba en sus calidades de presidente, vicepresidente del Comité de Desarrollo La Chimba (...).

\section{Recomendaciones:}

1. Que se conceda el derecho de aprovechamiento de las aguas a favor del Gobierno Provincial de Pichincha (...) aguas que provienen de los ríos Montoneras, San Jerónimo, Cuscungo y La Chimba, respetando las concesiones existentes en el río La Chimba; para ser destinadas a optimizar la operación del Canal de Riego Tabacundo, en un caudal de $4,5 \mathrm{~m} 3 / \mathrm{s}$. 2. Que se conceda el derecho de aprove-

21 A la solicitud de ampliación de concesión presentado por el señor Ramiro Gonzáles, prefecto de Pichincha. 
chamiento de las aguas a favor del Gobierno Provincial de Imbabura un caudal de 2000 l/s, para ser destinada en uso doméstico del proyecto regional Pesillo-Imbabura. Las servidumbres que permitan el legal y debido aprovechamiento de las aguas concesionadas tanto a los actores como a los adherentes, se deberán tramitar por cuerda separadas. 7. El Gobierno Provincial de Pichincha, y el Gobierno Provincial de Imbabura, deberán presentar los diseños de todas las obras de infraestructura hidráulica del proyecto "Canal de Tabacundo", y "Sistema Regional de Agua Potable Pesillo-Imbabura, para su estudio, aprobación y orden de construcción por parte de esta agencia en un plazo de 180 días.

\section{Tabla 9}

Caudales medios anuales $(\mathrm{m} 3 / \mathrm{s})$

\begin{tabular}{|l|r|r|r|r|}
\hline FUENTES & $\begin{array}{c}\text { GOB. PROV. } \\
\text { PICHINCHA }\end{array}$ & $\begin{array}{l}\text { GOB. PROV. IMBABURA } \\
\text { Y PESILLO-IMBABURA }\end{array}$ & $\begin{array}{c}\text { CAUDAL } \\
\text { ECOLÓGICO }\end{array}$ & $\begin{array}{c}\text { CAUDAL TOTAL } \\
\text { DE LA FUENTE }\end{array}$ \\
\hline $\begin{array}{l}\text { Río } \\
\text { Montoneras }\end{array}$ & 0.5000 & 0.500 & 0.674 & 1.674 \\
\hline $\begin{array}{l}\text { Río San } \\
\text { Jerónimo }\end{array}$ & 1.000 & 1.000 & 2.500 & 4.500 \\
\hline $\begin{array}{l}\text { Río } \\
\text { Cuscungo }\end{array}$ & 1.000 & 0.500 & 2.355 & 3.855 \\
\hline $\begin{array}{l}\text { Río La } \\
\text { Chimba }\end{array}$ & 2.000 & 0 & 0.021 & 2.021 \\
\hline Total & 4.500 & 2.000 & 5.550 & 12.050 \\
\hline
\end{tabular}

Fuente: Informe técnico, Ing. Rafael Valladares funcionario del CNRH.

En octubre de 2002, el prefecto de Imbabura y el presidente del Consejo de Juntas se dirigen al Jefe del CNRH, Agencia Quito para decir:

El Gobierno Provincial de Pichincha, como el adherente Gobierno Provincial de Imbabura, expresamente manifestamos que el referido informe técnico pericial no afecta a nuestros derechos hídricos e intereses institucionales, por lo que libre y voluntariamente, decidimos aprobarlo en su integridad, a la vez que solicitamos que el mismo sea acogido en sentencia por parte del señor Jefe de la Agencia de Aguas de Quito, del Consejo Nacional de Recursos Hídricos, porque está elaborado en función del desarrollo regional y social de las dos provincias. 


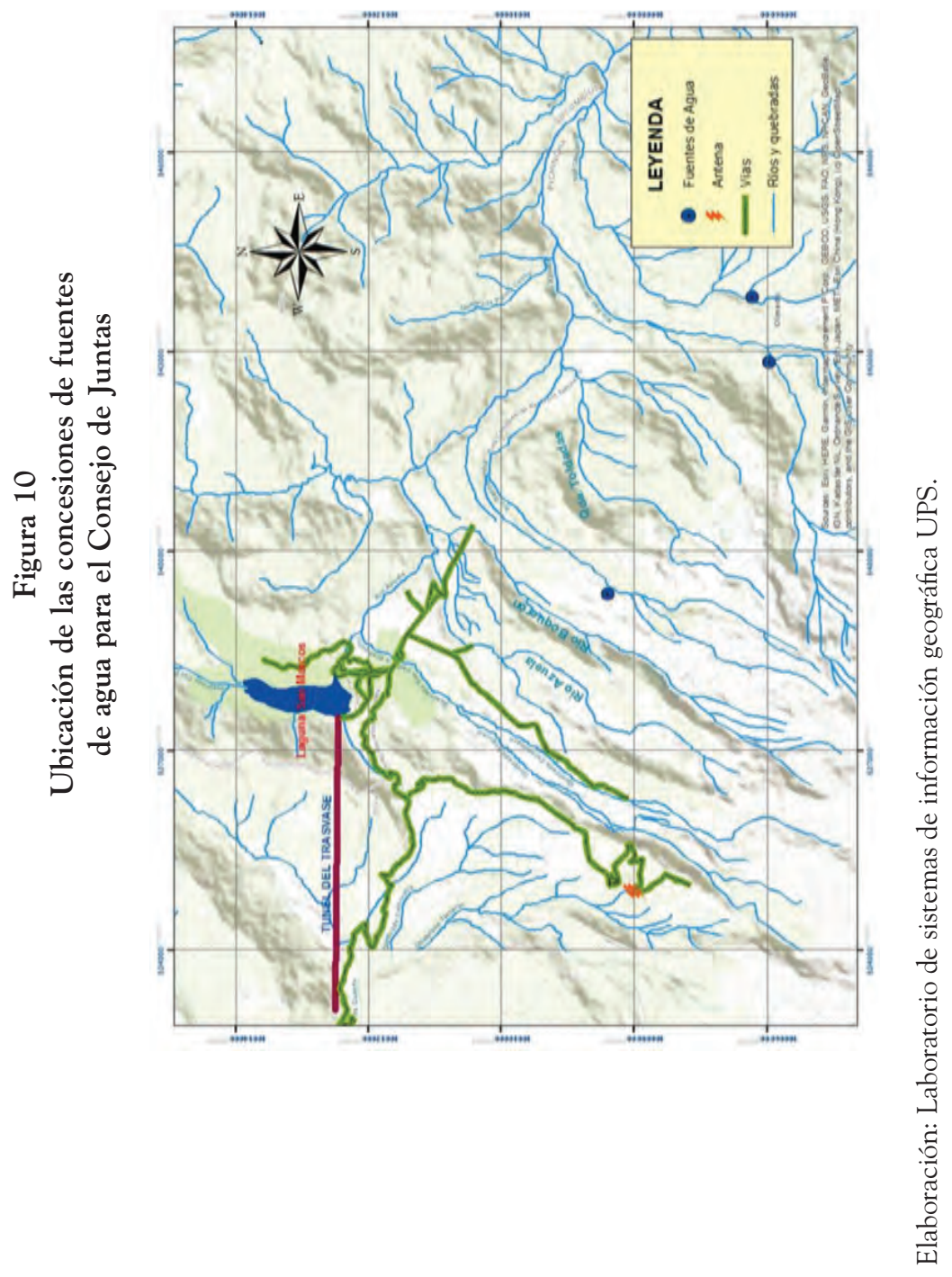


El Consejo Provincial de Pichincha, por intermedios de sus representantes, desisten de la oposición presentada el 26 de marzo del 2002, a la adhesión solicitada por el Gobierno Provincial de Imbabura (...).

En mayo de 2003, el CNRH, Agencia Quito, a la solicitud de concesión de aprovechamientos de las aguas presentada por el Consejo Provincial de Pichincha, a la que se adhirió el Gobierno Provincial de Imbabura y el Consejo de Juntas del PPI, dispone la siguiente sentencia:

Se concede a favor del Gobierno Provincial de Imbabura, debidamente representada por el Lic. Gustavo Pareja y Jaime Cáceres presidente del Consejo de Juntas Administradoras de Agua Potable Regional Pesillo-Imbabura, aguas que provienen de los ríos: MONTONERAS, el caudal de 0,25 m3/s., SAN JERÓNIMO el caudal de $1,10 \mathrm{~m} 3 / \mathrm{s}$., CUSCUNGO el caudal de $0,25 \mathrm{~m} 3 / \mathrm{s}$.; es decir un caudal total de 1,60 m3/s., para ser destinadas en uso doméstico de 130 localidades rurales y 7 centros urbanos, con una población de 879000 habitantes, cuyo horizonte está proyectado para 50 años. 8.- El Gobierno Provincial de Pichincha, y el Gobierno Provincial de Imbabura deberán presentar los diseños de todas las obras de infraestructura de toma y captación de los caudales concedidos del proyecto "Canal de Tabacundo" y "Sistema Regional de Agua Potable Pesillo-Imbabura" respectivamente, para su aprobación y orden de construcción por parte de esta Agencia, en un plazo de 180 días, a partir de la ejecutoria de la presente sentencia, de no cumplir con esta disposición, se procederá a declarar la caducidad y cancelación de la concesión, quedando las aguas libres de concesión, sin trámite previo, a favor del Consejo Nacional de Recursos Hídricos. 13.- Las fuentes hídricas anotadas están a cota media $3000 \mathrm{~m} \mathrm{s.} \mathrm{n.} \mathrm{m.} \mathrm{(...).}$

En enero de 2008, el Tribunal del Consejo Consultivo de Agua reforma la sentencia y dicta lo siguiente:

2.- A favor del Consejo Provincial de Imbabura y en forma conjunta al Consejo de Juntas Administradoras de Agua Potable del Proyecto Regional Pesillo-Imbabura, las aguas provenientes de los ríos: Montoneras en un caudal medio de 0,1044 m3/s y San Jerónimo en un caudal de $0,3052 \mathrm{~m} 3 / \mathrm{s}$, dando un caudal total medio de 0,4096 $\mathrm{m} 3 / \mathrm{s}$ equivalente al $56,06 \%$ del caudal total de los ríos menciona- 
dos, para destinarse a la dotación de agua potable de los habitantes de 153 comunidades rurales y cinco centros urbanos de las provincias de Pichincha e Imbabura, aguas a captarse sobre la cota de 3500 m s. n. m.; concesión que se la otorga por tiempo indefinido porque así disponer la Ley.

El caudal asignado al PPI por el Consejo Consultivo de Aguas de CNRH es de 409 l/s.

\section{Los conflictos por el acceso y uso del agua}

Las oposiciones a las concesiones de agua a favor del Consejo de Juntas son entre otras cosas por el uso del agua (conflictos por prelación). Durante los primeros años, los que buscan la concesión argumentan que el consumo humano es lo principal que es lo que falta en las comunidades rurales de Imbabura y en el cantón Pedro Moncayo de Pichincha, mientras que los opositores sostienen que la concesión afectaría los caudales que disponen para la producción ganadera de leche, que en la zona de Pesillo-Olmedo y sus comunidades depende del riego.

En 1997, después de que Jaime Cáceres solicitara al CNRH, el derecho de concesión de las fuentes de aguas localizadas en la microcuenca del río La Chimba: Chahuancorral y Chalpar, organizaciones comunitarias de la parroquia de Olmedo, se opusieron porque serían afectadas los caudales que disponían para las actividades agropecuarias. Durante el mes de julio, el CNRH, conforme dicta la Ley de Aguas, publica en el Diario La Hora, a los usuarios conocidos o no para que presenten impugnaciones a la solicitud de concesión hecha por Jaime Cáceres en representación del Consejo de Juntas. Ante el llamado comparecen Vicente Catucuamba Lechón y Juan Manuel Pujota en calidad de presidente y tesorero de la Junta de Agua de Riego de la comunidad de Pesillo y dicen lo siguiente:

Que la solicitud de concesión es totalmente improcedente en tanto y en cuanto pretende arrebatar las aguas que tantas otras comunida- 
des como la de ellos, se encuentran utilizando para las diarias faenas agrícolas que se llevan a cabo todos los días.

En enero de 1998, el Jefe de la Agencia de Aguas de Quito, desecha las oposiciones presentadas por Vicente Catucuamba Lechón y Juan Manuel Pujota por: "Carecer de fundamentación y concede el derecho de aprovechamiento de las aguas que provienen de las quebradas Chahuancorral y Pucapaccha" al Consejo de Juntas. En el mes de julio, luego que la Agencia de Aguas de Quito ratificó de la concesión a favor del PPI:

Salieron gente de Pesillo y otras comunidades cercanas y me retuvieron en Olmedo por un día. Dijeron: ¡No!, como van a llevarse agua a Imbabura si nosotros no tenemos. Correrá sangre, pero agua no dejamos, dijeron. Por la tarde y noche me liberaron, y después de varias reuniones con autoridades de Imbabura hubo acuerdo para que Pesillo y otras comunidades se integren al proyecto. (Jaime Cáceres, entrevista 17 de julio de 2018)

En enero de 2001, en la Notaría Primera del cantón Ibarra, con el propósito de unificar esfuerzos a fin de viabilizar y permitir que se ejecute el PPI, firman un acuerdo de conciliación entre el Consejo de Juntas y la Junta de Riego de Pesillo:

UNO. Mantener coordinación permanente para desarrollar todas las actividades económicas, sociales, políticas, a fin de permitir se culmine el proyecto.

DOS. Integrar al Consejo de Juntas Administrativas de Agua Potable del Proyecto Regional Imbabura, con todos los derechos y beneficios a las Comunidades Hermanas de la Regional Pesillo y la Organización UNOPAC ambas del cantón Cayambe.

TRES. Desistir conforme derecho, con el respectivo reconocimiento de firmas y rúbricas por parte de los representantes legales de la Junta de Aguas de Pesillo a la demanda interpuesta en contra del Consejo de Coordinación de Juntas.

CUATRO. Reprogramar el nombre del proyecto y denominarlo Regional Pesillo-Imbabura. 
Después de que Ramiro Gonzáles prefecto de Pichincha, solicitara la concesión de aguas del río San Jerónimo, Montoneras, Cuscungo y La Chimba, a la que se adhirió el Gobierno Provincial de Imbabura y al Consejo de Juntas del PPI —en el mes de febrero- el Jefe de la Agencia de Aguas de Quito, a través de varios medios de prensa escrito, publica una citación a los usuarios conocidos o no, que se opongan a la solicitud de concesión de las aguas provenientes del Río San Jerónimo, Montoneras, Cuscungo y La Chimba: "Fíjense carteles durante treinta días, en tres de los lugares más frecuentados de la parroquia Olmedo para que presenten impugnaciones".

En mayo, Ernesto Necpas y Hernán Catucuamba, presidente y vicepresidente del Comité de Desarrollo "La Chimba", dentro de la solicitud de ampliación de concesión de aguas solicitada por el Consejo Provincial de Pichincha, se dirigen al Jefe de la Agencia de Aguas de Quito y señalan:

En caso de darse dicha concesión afectará a toda nuestra comunidad, por cuanto dicho caudal abastece el riego para la comunidad de La Chimba, razón por la cual expresamente nos oponemos a la concesión de aprovechamiento de aguas para riego, específicamente del río La Chimba, pues, a título de beneficiar a un sector de la provincia de Pichincha, se va a conculcar los derechos de otro sector de la misma provincia.

En febrero de 2003, el Jefe del CNRH, Agencia Quito, convoca a Audiencia de conciliación a todos los actores (a los que solicitan la concesión y a los opositores). Ante el llamado comparecen: la doctora Rocío Flores, en representación del prefecto Provincial de Pichincha; doctor Luis Jiménez, en representación del prefecto Provincial de Imbabura; el doctor Héctor Nepas, ofreciendo poder al Comité de Desarrollo de La Chimba; y el señor Jaime Cáceres, presidente del Consejo de Juntas. El doctor Nepas expone:

No existe posibilidad alguna de llegar a alguna Conciliación, nos ratificamos en oposición frontal planteada por el Honorable 
64

Consejo Provincial de Pichincha ya que la misma afecta legítimos derechos a los comuneros

El doctor Luis Jiménez interviene y dice:

En lo principal apruebo en todas sus partes el informe emitido por el Ing. Rafael Valladares, técnico de la Agencia de Aguas de Quito, mismo que está apegado a la realidad de los hechos, y por sobre todo en las recomendaciones determina que existe el caudal suficiente de las fuentes de los ríos Montoneras, San Jerónimo y Cuscungo (...) que es parte de la presente causa, se le conceda dos mil litros por segundo con la finalidad de promover y ejecutar el proyecto regional Pesillo-Imbabura.

Seguidamente interviene la doctora Rocío Flores y señala:

Que no es posible seguir dando más adjudicaciones toda vez que perjudicarían a las que se conceden para el Canal de Riego Tabacundo, que tienen un estudio técnico debidamente fundamentado. La oposición debería tomar en cuenta que el verdadero sentido del Canal de Riego es beneficiar a todo el sector.

Por último, interviene el señor Jaime Cáceres y dice:

En representación del Consejo de Juntas nos encontramos conforme con el informe técnico realizado por el Ing. Rafael Valladares, en su totalidad, en cuanto a la oposición presentada no tienen objeto, ya son integrantes de proyecto de agua potable, en toda la zona de Olmedo incluido La Chimba, por lo que solicitamos se dé trámite lo más rápido la concesión.

En el mes de abril de 2003, Ernesto Necpas y Hernán Catucuamba solicitan a la Agencia de Aguas una Inspección Judicial en los sitios. El perito designado es el Ing. Ángel Gualsaquí, quien presenta el siguiente informe:

El $98 \%$ de las comunidades consideradas en el proyecto regional Pesillo-Imbabura carecen de agua potable. Por tal razón han previsto la captación y aprovechamiento de las aguas provenientes de las quebradas: Ismuquiru, Terreros y Carnicería, que son afluentes del río 
La Chimba; como también, de los ríos: San Jerónimo, Montoneras, y Cuscungo, para completar el caudal de demanda calculado; que es motivo del presente trámite de concesión de aguas planteado.

En la última parte señala:

En virtud de la revisión de los estudios hidrológicos presentados, como del informe técnico adjunto al proceso, me permito exponer las siguientes sugerencias, para considerarse de creer conveniente en el dictamen de la respectiva sentencia.

No existe ningún estudio hidrológico con relación a los ríos: San Jerónimo, Montoneras y Cuscungo, para determinar la disponibilidad del recurso.

Debe considerarse los caudales anteriormente concedidos de 154 y 50 1/s., provenientes de las quebradas Chanchuacorral y Pucapaccha, a favor de la Regional Pesillo-Imbabura, según la sentencia otorgada el 30 de enero de 1998; como también debe considerarse el caudal total que al momento disponen los diferentes sistemas de agua potable. ${ }^{22}$

El prefecto de Imbabura, y el presidente del Consejo de Juntas, en relación con el informe técnico anterior se dirigen a la Agencia de Aguas de Quito para señalar que dicho informe no guarda conformidad alguna:

2. Que el proyecto Pesillo-Imbabura no utilizará para su operación y funcionamiento aguas de la quebrada La Chimba, ni de sus fuentes alimentadoras conocidas como Chanchuacorral y Pucapaccha. 3. Que de conformidad con el informe pericial técnico suscrito y elaborado por el Ing. Valladares se tiene un idóneo referente hidrológico de los ríos San Jerónimo, Montoneras y Cuscungo. 3. Que los ríos San Jerónimo, Montoneras y Cuscungo tienen caudales suficientes para atender las peticiones existentes. 6. Se garantiza la reserva del caudal ecológico de los ríos San Jerónimo, Montoneras y Cuscungo. 7. Que los estudios de factibilidad deben y pueden ser replanteados a las fuentes y caudales de los ríos San Jerónimo,

22 Este informe se opone a los Peritos anteriores, y está alejado de la realidad pues señala otros sitios de concesión, dilatando las pretensiones del PPI de tener concesiones en los tiempos planificados. 
Montoneras y Cuscungo. 8. Que la comunidad La Chimba es parte integrante del proyecto.

Ernesto Necpas y Hernán Catucuamba, en relación con el informe presentado por el Ing. Ángel Gualsaquí, manifiestan disconformidad:

Por cuanto a simple vista en la zona se puede observar que los caudales de los ríos que se pretende concesionar se encuentran secos. Por estas razones impugnamos dicho informe y solicitamos al señor Perito nos amplíe dicho informe y nos explique en qué estudio de carácter técnico se sustentó para concluir en los términos que los ha hecho, además la sequía y el estiaje que soporta la zona es imposible técnicamente informar que exista dichos recursos hídricos o caudales de manera suficiente.

En el mes de mayo, el CNRH, Agencia Quito, desecha las oposiciones presentadas por Ernesto Necpas y Hernán Catucuamba y concede a favor del Gobierno Provincial de Imbabura, el Consejo de Juntas Administradoras de Agua Potable Regional Pesillo-Imbabura, aguas que provienen de los ríos: Montoneras, San Jerónimo y Cuscungo (señalado más arriba). Mientras que el abogado patrocinador de Ernesto Necpas y Hernán Catucuamba, se dirige al Jefe de la Agencia de Aguas de Quito, para señalar que no están de acuerdo con la sentencia dictada.

\section{La organización en el diseño y elaboración del proyecto}

Los dirigentes de la organización en representación de los beneficiarios del proyecto, participan en el diseño del proyecto, principalmente acompañando al equipo técnico en los recorridos de identificación de los puntos de ubicación de los principales componentes del sistema, también participan en reuniones para la aprobación del proyecto, la organización es clave en la socialización del proyecto con los usuarios y la negociación de los pasos de servidumbre por donde se construirá la infraestructura, como también en la conciliación en la obtención de las concesiones del agua. 
Existen aportes económicos de parte de los futuros beneficiarios para cubrir algunos costos que incurre en la gestión de la organización como también el pago de abogados que aceleren el proceso de servidumbres y concesiones. Según informe de gastos y aportes parciales que reposan en los archivos, el aporte comunitario en dinero y mano de obra sumaban: 92959300 de sucres hasta abril de 2001; y otros 37620 dólares en aportes y 60071 dólares en mano de obra.

\section{Los estudios técnicos}

Los estudios se modificaron a medida que los sitios de concesión cambiaron, por lo que se hicieron varios estudios que demoraron muchos años. El primero lo hizo el Consejo Provincial de Imbabura - trabajos de topografía, estudios de pre-diseño desde la vertiente de Ismuquiru hasta el cantón Ibarra- y el MIDUVI a través de empresas consultoras externas.

En abril de 1998, la Agencia de Aguas de Quito concesionó a favor del PPI, las fuentes de agua en las quebradas Chahuancorral y Pucapaccha. En septiembre, el Consejo Provincial de Imbabura inició trabajos de topografía en toda la zona: siguiendo el cerro Imbabura, las comunidades de Cayambe hasta la parte alta de Tabacundo (Pedro Moncayo), aproximadamente 200 kilómetros. Ese trabajo duro más de un año.

La captación prevista estaba a $3600 \mathrm{~m} \mathrm{~s}$. n. m., las alturas en Imbabura eran 3330-3440 m s. n. m. Según los trabajos de topografía todos los territorios interesados iban a tener agua a gravedad, incluso las comunidades más altas (Jaime Cáceres, expresidente del PPI, entrevista 17 de julio de 2018). Pero por falta de recursos los avances fueron muy limitados.

En noviembre de 2000, en Ilumán suscriben un acta de compromiso para la ejecución del proyecto: el Secretario Nacional Ejecutivo del Consejo de Desarrollo de Pueblos y Nacionalidades, CODENPE; presidente del Directorio del Banco de Desarrollo, BEDE; 
Gustavo Pareja, prefecto de Imbabura; Diego Bonifaz, alcalde de Cayambe; Cecilia Mantilla, alcaldesa de Pedro Moncayo; Mario Conejo, alcalde de Otavalo; Gonzalo Yépez, alcalde de Antonio Ante; Mauricio Larrea, alcalde de Ibarra; Ramiro Gonzáles, prefecto de Pichincha; Juan Flores, consejero provincial de Imbabura:

El Consejo de Coordinación de Juntas de Administradoras de Agua Potable Regional Imbabura, junto al Consejo Provincial de Imbabura vienen desarrollando los trabajos relacionados con el levantamiento topográfico y los estudios de pre diseño desde la vertiente de Ismuquiru hasta el cantón Ibarra, que serán entregados en el mes de diciembre. Por lo tanto, "se requiere de la elaboración de los estudios de prefactibilidad, factibilidad y ejecución de obras por lo cual las instituciones presentes se comprometen a asumir partidas presupuestarias específicas para el proyecto, Banco del Estado USD 30000 y CODENPE USD 20 000, valores que serán entregados al Consejo Provincial de Imbabura.

En mayo de 2001, los municipios de Cayambe, Pedro Moncayo, Otavalo, Antonio Ante, Ibarra, y el Gobierno Provincial de Imbabura firman un Convenio de Transferencia de Fondos y Cooperación Interinstitucional para los estudios del PPI. Aportan UDS 5112,00 cada uno de los municipios.

En junio, el Consejo Provincial de Imbabura elabora las bases y Términos de Referencia ${ }^{23}$ (TdR) para contratar la ejecución del estudio de agua potable regional Pesillo-Imbabura, nombrando un comité de concurso privado de consultoría. El ganador fue la consultora CONSULPIEDRA.

En julio, en Ilumán, el Gobierno Provincial de Imbabura contando con la presencia los dirigentes de las JAAP y comunidades beneficiarias suscriben el contrato con CONSULPIEDRA para realizar estudios en un plazo máximo de 150 días:

23 Es un documento base para la ejecución de un estudio y cuáles son los resultados esperados. 
El objeto y alcance del contrato consiste en efectuar el estudio y diseño del sistema de agua potable denominado "Regional PesilloImbabura" que pretende diseñar y/o mejorar la captación y línea de conducción para incrementar el caudal de los sistemas existentes de las poblaciones ubicadas en los cantones Cayambe y Pedro Moncayo pertenecientes a la provincia de Pichincha y los cantones Otavalo, Antonio Ante e Ibarra, perteneciente a la provincia de Imbabura y dotar de un nuevo caudal a las poblaciones que sea factible hacerlo, utilizando tecnologías apropiadas de bajo costo, factible de ser auto sostenido por la comunidad mediante el pago de tarifas adecuadas a su nivel socioeconómico, estudios preliminares, evaluación de los sistemas existentes, alternativas, diseño definitivo y elaboración de planos y memoria técnica.

\section{Estudios (primera etapa)}

En septiembre de 2001, CONSULPIEDRA presenta el primer informe técnico sobre caudales:

1. En la quebrada Ismuquiru medimos un caudal de $537 \mathrm{l} / \mathrm{s}$, el mismo que con un trasvase de un riachuelo de la misma zona, que dispone de un caudal de $88 \mathrm{l} / \mathrm{s}$; la suma de estos dos caudales nos da un resultado de 625 l/s. Si tomamos un porcentaje de $64 \%$ de las dos cuencas tenemos el caudal asignado para el proyecto que es de 400 l/s. 2. En la quebrada Carnicería, tenemos un caudal de 282 l/s a una cota de $3578 \mathrm{~m} \mathrm{s.} \mathrm{n.} \mathrm{m.} \mathrm{3.} \mathrm{En} \mathrm{la} \mathrm{quebrada} \mathrm{Terreras,} \mathrm{tenemos} \mathrm{una}$ caudal de $475 \mathrm{l} / \mathrm{s}$ a una cota de $3622 \mathrm{~m} \mathrm{~s}$. n. m. Si sumamos el caudal de los numerales 2 y 3 tenemos un caudal de 757 l/s. Logrando captar el $64 \%$ de este caudal que sería $484.5 \mathrm{l} / \mathrm{s}$, semejante a $490 \mathrm{l} / \mathrm{s}$. tenemos algunas alternativas.

Opción 1. Quebrada de Ismuquiru, asignado $=400$ 1/s.

Opción 2. Captar el caudal total de Ismuquiru, es decir, 625 l/s o captar el 90\% del caudal de Ismuquiru, es decir, 563 l/s.

Si sumamos el 90\% del caudal de Ismuquiru, más el 65\% de la suma de los caudales de las quebradas de Terreras y Carnicerías ( $757 \mathrm{l} / \mathrm{s}$ ), es decir, 492 l/s. tenemos un caudal total de 1055 l/s. De acuerdo con las normas internacionales de diseño para agua potable, el factor adecuado es una dotación de 200 litros por habitante por día. Con esta dotación y la población que tenemos actualmente cubrimos el diseño con 
el caudal de $400 \mathrm{l} / \mathrm{s}$ que disponemos, con un margen de seguridad del $10 \%$. Si contamos con la posibilidad de incorporación de más población al sistema, semejante a los 210000 habitantes que esperábamos, nos encontramos con la necesidad de un caudal de $490 \mathrm{l} / \mathrm{s}$.

Para satisfacer el caudal antes mencionado, podríamos optar con la opción de ocupar todo el caudal de Ismuquiru, que es de $625 \mathrm{l} / \mathrm{s}$, teniendo así un margen de seguridad del $27.6 \%$. Si ocupamos los 490 l/s, tenemos un saldo de los 1055 l/s.; que, traducido a población a servir, son 244080 habitantes que contarían con la opción de tener agua potable para diversas zonas aledañas al proyecto, mismas que ahora no se incluyen en su cobertura.

En diciembre presenta las alternativas.

Se puede advertir la importancia del proyecto, considerando que el sistema regional "Pesillo-Imbabura" está integrado por $130 \mathrm{comu}-$ nidades de las provincias de Imbabura y Pichincha, y su población actual de 101833 habitantes, la misma que proyectada alcanza los 145 396. Se espera sin embargo llegar a un techo de una población proyectada de 210000 habitantes (...) para un periodo de diseño de 30 años. Esto implica que se cubrirán las necesidades de agua potable hasta un horizonte de diseño al año 2031 en forma eficiente. A esta opción se le ha denominado Alternativa 1, para lo que se requerirá un caudal de $490 \mathrm{l} / \mathrm{s}$.

La Alternativa 2, considera utilizar un caudal adicional de la quebrada Terreros y Carnicería, para en conjunto con el caudal de la quebrada Ismuquiru, ajustar 1055 l/s, lo que implica servir a una población adicional de 244000 habitantes. Entonces, el Proyecto servirá en total a 454000 habitantes, entre el sector rural y urbano (...), con la inclusión de siete centros urbanos: Cayambe, Tabacundo, San Pablo, Otavalo, Cotacachi, Atuntaqui e Ibarra.

Análisis económico:

Alternativa 1, costo \$45 379771,00 ;

Alternativa 2, costo $\$ 59740684,70$. 
En febrero de 2002, CONSULPIEDRA presenta otra memoria ejecutiva donde recomienda: la Alternativa 2 en razón que es la más factible para ser ejecutada. Se eliminaría el riesgo de falta de agua en las ciudades consideradas en los próximos 30 años. Consideran fundamental el asunto jurídico de la adjudicación de las aguas del proyecto.

Muchos dirigentes de las JAAP, comunidades y el Consejo de Juntas están de acuerdo con las recomendaciones técnicas, no tanto con la propuesta de incluir a los centros urbanos: Cayambe, Tabacundo, San Pablo, Otavalo, Cotacachi, Atuntaqui e Ibarra como potenciales beneficiarios.

En marzo, CONSULPIEDRA presenta los estudios que consta de: "estudio tarifario", "especificaciones técnicas" e "impacto ambiental":

Propuesta de tarifaria:

1. Sin aportes, se tiene una tarifa diferenciada para el componente rural de $\$ 3.00 /$ mes, y la urbana de $\$ 8.20 /$ mes.

2. La tarifa con un subsidio del $35 \%$ se transforma en una tarifa rural de \$1.50 USD y la urbana de $\$ 5.40$.

Especificaciones Técnicas:

La descripción general de las obras a ejecutarse, son: Captación, desarenador, conducción, planta de tratamiento, tanques de reserva, cada uno con los trabajos a realizarse y costos aproximados.

El informe de Impacto Ambiental identifica los impactos negativos como consecuencia de las obras:

1. Alteración permanente en la capa vegetal y uso natural del suelo al interior de la reserva ecológica Cayambe-Coca.

2. Alteración paisajística permanente por el corte de vías de comunicación, construcción de tanques de almacenamiento y plantas de potabilización. 
Planes de almacenamiento de caudales:

Plantea implementar un plan de manejo con medidas preventivas, correctivas y compensatorias, y programas de vigilancia ambiental.

En julio, CONSULPIEDRA, funcionarios del Gobierno Provincial de Imbabura y CNRH se reúnen en la Agencia de Aguas de Quito, concluyen que:

Existen caudales más que suficientes que se podrían aprovechar en un gran sistema regional de agua potable que abarcaría unas 130 localidades del sector rural con un caudal de conducción de 760 l/s y a un componente urbano integrado por Cayambe, Tabacundo, San Pablo, Otavalo, Cotacachi, Atuntaqui e Ibarra, quienes requerirían un caudal de conducción de 870 l/s, que en total se requerirían unos 1630 l/s, esto si consideramos un horizonte de diseño de 30 años. Debido a la enorme magnitud del proyecto se podría pensar en un periodo superior que incluso podría llegar a los 50 años, a fin de que un gran sistema regional no solo cubra el déficit de los centros urbanos, sino que pueda considerarse como una solución futura de esas ciudades. Esto implicaría un análisis de poblaciones y consumo de agua potable que podría estar en torno a los $2000 \mathrm{l} / \mathrm{s}$.

Días después el prefecto de Imbabura y CONSULPIEDRA suscriben un acta de compromiso:

El consultor en forma libre y voluntaria se compromete a presentar a favor del Gobierno Provincial de Imbabura, la memoria ejecutiva técnica que deberá contener lo siguiente: 1. Elaboración de un horizonte de un diseño de 50 años. 2. Definir que la obtención de los caudales se los efectuará de las cuencas de los ríos Montoneras, San Jerónimo y Cuscungo. ${ }^{24}$ 3. Que para la ejecución del proyecto se requiere $2000 \mathrm{l} / \mathrm{s}$.

24 En mayo de (2003) el CNRH, Agencia Quito, concedió a favor del Gobierno Provincial de Imbabura y el Consejo de Juntas, las aguas de los ríos: Montoneras, San Jerónimo y Cuscungo. 
En agosto, CONSULPIEDRA y el Gobierno Provincial de Imbabura suscriben un contrato para elaborar estudios complementarios. Se abandona definitivamente la propuesta para conducir las aguas desde las quebradas que alimentan o forman la microcuenca del río La Chimba: Ismuquiru, Terreras y Carnicería. Los estudios complementarios fijan como potenciales fuentes las concesionadas en mayo de 2003 a favor del Consejo de Juntas: Montoneras, San Jerónimo y Cuscungo, tributarios del río Azuela que va a la cuenca amazónica, ubicadas al noreste de las faldas del nevado Cayambe.

A inicios de 2004, la memoria técnica de los estudios complementarios recomienda dos alternativas para la implementación del PPI:

\section{Alternativa 1.}

Implica que el caudal de 1055 l/s que se entrega en el río Arturo pueda ser conducido a través de obras hidráulicas del proyecto de Riego Tabacundo y hasta la quebrada Ismuquiru en donde se distribuirá el caudal conducido tanto al PPI como riego Tabacundo, tomar a la salida de túnel en la cota $3401 \mathrm{~m} \mathrm{s.} \mathrm{n.} \mathrm{m.} \mathrm{para} \mathrm{integrarlo}$ al PPI mediante una conducción por tubería de lámina de acero y que se conecta a la tubería del proyecto original Pesillo-Imbabura.

\section{Alternativa 2.}

Conducir el mismo caudal del río Arturo para a través de un canal llevar hasta el punto de entrada al túnel del Proyecto Regional Pesillo de una longitud de $2457 \mathrm{~m}$ y que finaliza en la cota equivalente a 3472 m s. n. m. para llegar a la cuenca del Ismuquiru e integrarse al sistema original por medio de un canal abierto que finaliza en la cota $3470 \mathrm{~m}$ s. n. m. Esta alternativa propone un desarrollo del proyecto en forma totalmente independiente del proyecto Riego Tabacundo.

El consultor recomienda que se tome la Alternativa 1, debido a que implica un menor costo para llevar el agua desde el río Arturo a Ismuquiru; y el proyecto de riego Cayambe-Pedro Moncayo construirá obras que estarán en capacidad de servir a los dos proyectos, es decir, el túnel de trasvase desde la laguna de San Marcos hasta el sector de 
Guayllabambilla; la idea es atravesar el túnel con tubería que llevará el agua de consumo humano. Pero los dirigentes y beneficiarios no estaban de acuerdo, querían un proyecto independiente al del riego.

El mismo mes, CONSULPIEDRA entrega otros informes complementarios: informe técnico, informe de estudios de mecánica de suelos, informe geológico, memoria de cálculo, planos hidráulicos y estructurales, anexos y presupuesto.

En inicio del año 2005, a pocos días de iniciar la construcción de la obra, el Gobierno Provincial y otras autoridades reconocieron la falta de estudios complementarios y la necesidad de construir un túnel de 2400 m (Castañeda, 2009, p. 97), por lo que el proyecto quedó pospuesto hasta nueva fecha.

\section{Servidumbres forzosas}

Con los avances de los estudios, había esperanzas que el proyecto se ejecute, para ello era necesario pedir autorización a los dueños de los predios por donde pasaría la línea de conducción del agua, generándose así un proceso de servidumbres forzosas. ${ }^{25}$

En abril de 2004, Jaime Cáceres y Juan Serrano (secretario) solicitan al prefecto de Imbabura que siga el trámite de Servidumbre Forzosa en la Agencia de Aguas de la ciudad de Quito — pedida por las autoridades de la parroquia de Olmedo-Pesillo- por la línea de conducción que comprende desde la quebrada de Ismuquiru hasta la finalización de la red de conducción.

La asamblea de la organización analizó tres ofertas de servicios profesionales para definir la servidumbre forzosa del acueducto del PPI. La mayoría acordó aceptar la más económica, del Doctor Arturo

25 Este trámite era necesario porque según los estudios, la red de conducción principal y ramales para llevar agua a las diferentes comunidades pasaba por terrenos privados y comunitarios, para que cuando inicie la obra no haya oposición de los propietarios. 
Godoy. Para iniciar el proceso solicitan ayuda a Gobierno Provincial de Imbabura del 50\% y el otro 50\% aportará el Consejo de Juntas.

En julio, el prefecto de Imbabura y Jaime Cáceres se dirigen mediante oficio al Jefe de la Agencia de Aguas de Imbabura y Carchi para solicitar lo siguiente:

Demanda. - (...) acudo ante su autoridad en mejor forma de derecho y demando, que previo al trámite legal-administrativo y técnico pertinente, se establezcan forzosamente las servidumbres de acueducto a lo largo de todo el tendido de red del sistema hídrico, que nos permita optimizar la captación, conducción y distribución de las aguas. En su Auto de calificación se permitirá señalar días, horas hábiles y designar perito para que intervenga como tal en la presente causa, emitiendo el informe correspondiente.

Beneficiarios. - Cantón Ibarra, Central de Indígenas de Antonio Ante, Ilumán, Carabuela, Bolsa Guananci, San Pablo, Mojanda Yanaurco, Angla, Compañía, San Rafael, Eugenio Espejo, Guaczara Ariaspamba, Chuchuquí Cuaraburo y Puerto Alegre; y en lo que corresponde a la Provincia de Pichincha, identificadas así: Tupigachi, Tabacundo, UNOPAC, Pesillo-Olmedo.

En septiembre, el Jefe de la Agencia de Aguas de Ibarra, para dar trámite a la solicitud ordena:

Por desconocer el domicilio de los legítimos contradictores de la causa, cítese a los señores: Pedro Ichau, Jaime Morales, Enrique Pineda, Alberto Guaján, Aurelio Arellano, Juan Ávila, Luis Quilimbaquí, Cipriano Imbaquingo, Segundo Cañamar, Juan Anguaya, Fausto Benalcázar, José Burga, Alberto Villagrán; y, por la jurisdicción de la provincia de Pichincha a los señores: Fidel Catucuago, Manuel Fernández, Soledad Inlago y Víctor Alba, mediante tres publicaciones en el Diario del Norte y La Hora que tienen circulación regional para las provincias de Pichincha, Imbabura y Carchi, mediando entre cada una el plazo de ocho días a fin de que se informen, contesten y señalen domicilio legal para sus notificaciones. Hecho que sea previo al pago de la tasa de ley, se designará Perito y se señalará día y hora para que se lleve a cabo la diligencia de inspección técnica. 
Entre septiembre y octubre, el jefe de la Agencia de Aguas de la ciudad de Ibarra ordena que se cite mediante publicaciones en tres medios de prensa a las personas mencionadas (citación 8 de septiembre 2004) para que informen, contesten y señalen domicilio legal para sus notificaciones y actúen en caso de ser necesario presentando oposición a las solicitudes de Servidumbres Forzosas.

En enero de 2005, luego de las publicaciones editadas por el Diario El Norte y La Hora, el Jefe de la Agencia de Aguas de la ciudad de Ibarra, nombra como Perito al Ing. Oswaldo Haro - funcionario de la misma- para que realice el estudio técnico de "Servidumbre Forzosa”. El mismo mes de enero el Ing. Oswaldo Haro, presenta el informe del peritaje de Servidumbre Forzosa:

2.- Análisis Técnico. - (...) este proyecto que es de gran magnitud se deben establecer las servidumbres forzosas de acueducto en la forma como se plantea en el plano, en las redes principales como de las secundarias. Toda conducción se realizará por medio de tubería en sus diferentes diámetros de acuerdo al sitio, misma que va enterrada a una profundidad que garantice seguridad para el proyecto de acuerdo al perfil topográfico correspondiente al estudio, por lo que los predios sirvientes apenas sufrirán las molestias del caso solo cuando se ejecuten los trabajos de movimientos de tierra para este fin, luego de los cual el área ocupada en este trabajo seguirá sirviendo en los fines anteriores, por lo general la agricultura. Para el caso de las obras especiales como son las de división de caudales, tanques de tratamiento, tanques de distribución y otras, estas si ocuparán espacios físicos permanentes, pero de acuerdo a la indicación de los representantes del Consejo de Juntas, todo está debidamente coordinado y arreglado con los propietarios de los predios donde estas obras se ubicarán, razón por la cual no existe oposición alguna. Recomendaciones. - Atender la solicitud presentada por el Gobierno Provincial de Imbabura y el Consejo de Juntas del Proyecto Regional Pesillo-Imbabura y proceder al establecimiento de las servidumbres forzosas de acueducto necesarias en todo el recorrido del proyecto en sus ramales principales y secundarios, así como también de las obras especiales que se requerirán en este, de la forma como cons- 
ta en los estudios para los predios inmersos de las provincias de Imbabura y Pichincha.

En abril, el Jefe de la Agencia de Aguas de Ibarra, después de revisar el informe de Servidumbre Forzosa resuelve aceptar la petición y proceder al Establecimiento de las Servidumbres Forzosas del acueducto en todo el tendido de red del proyecto en sus ramales principales y secundarios, así como en las obras especiales que se requerirán, que permitan la conducción del agua proveniente de los ríos Montoneras, San Jerónimo y Cuscungo.

\section{Estudios técnicos (segunda etapa)}

En septiembre de 2005, en la Notaría Octava del cantón Quito, el MIDUVI e Ingenieros Civiles Asociados, ICA consultores, suscribieron un contrato para la ejecución de los estudios y diseños definitivos del proyecto por un valor de $\$ 259$ 953,33, luego de que la empresa ICA resultara ganadora en un concurso privado de consultoría llevado adelante por el MIDUVI.

El objeto del contrato contempla la revisión del anteproyecto elaborado por el Gobierno Provincial de Imbabura, la complementación de estudios básicos y la elaboración de los estudios definitivos del proyecto. Los trabajos se llevarán a cabo en dos etapas, la primera de estudios básicos y la segunda de diseños finales de la obra.

En diciembre, ICA-Consultores presentó el estudio de la primera etapa: hidrológico, oferta, demanda, y geología. El estudio de hidrología sostiene que lo hecho por CONSULPIEDRA aporta una información hidrométrica fundamentada en un número limitado de aforos y cambio en las fuentes. Las conclusiones y recomendaciones son:

Los análisis de caudales anteriores tienen errores y valores fuera de contexto. Se deben establecer ajustes necesarios, a fin de satisfacer todos los requerimientos técnicos en el área de hidrología, dentro de la etapa de los estudios básicos del PPI. Considerar como alternativa de diseño, el cálculo del escurrimiento anual al 90\% de probabili- 
dad, acogiendo la norma técnica que permite el uso de ese valor, para satisfacer el abasto de agua potable con una dotación necesaria de 80-100 litros/habitante/día para el sector rural.

El estudio de oferta y demanda arroja las siguientes conclusiones y recomendaciones:

1. La demanda de la ciudad de Ibarra es la más alta en el área del proyecto, requiere para el año $2032 \mathrm{de} 400$ l/s adicionales a los caudales actuales (...).

2. Aun cuando las ciudades de Cayambe y Tabacundo no requieren de caudales (...) es necesario dejar previsto el suministro complementario. En el caso de Cayambe un caudal de 100 1/s para sustituir o atender emergencias de su sistema de bombeo. Para Tabacundo un caudal de $30 \mathrm{l} / \mathrm{s}$ para sustituir o atender en forma complementaria su abastecimiento que tiene frecuentes daños por la antigüedad de su tubería. Para Atuntaqui se consideró el suministro completo para sus áreas rurales de 46 1/s liberando caudales que son entregadas desde las fuentes actuales, quedando para la ciudad la totalidad del caudal.

3. Para atender a las comunidades desde el PPI se cuenta con un caudal de hasta 350 l/s, al cual se incorporan 100 l/s de los caudales actuales que deben seguir prestando servicio.

\section{En total el PPI para atender con el servicio de agua potable a las comunidades rurales y en forma complementaria a las 5 ciuda- des hasta el año 2032 requiere 830 l/s.}

El estudio de geología arroja las siguientes conclusiones y recomendaciones:

El trazado del proyecto en las zonas de concesión de agua para el PPI debe ser estudiado por tramos, de esta manera se puede identificar las zonas inestables y que impliquen un riego para el proyecto.

En la fase de diseño definitivo se deberán dar las recomendaciones geotécnicas apropiadas, en base a investigaciones adicionales del subsuelo, que deberán incluir perforaciones, calicatas, geofísica, ensayos de laboratorio.

La alternativa alta de la línea de conducción de las captaciones que fue escogida en un estudio anterior es la menos recomendable, por- 
que contiene la mayor cantidad de aspectos desfavorables desde el punto de vista de la estabilidad, de la pendiente, etc.

El presupuesto para ejecutar el proyecto asciende a 41 millones de dólares y de acuerdo con el plano general del proyecto, la línea de conducción tiene una longitud total de $160 \mathrm{~km}$, habiéndose dividido la línea de conducción-distribución del agua en tres ramales principales.

De manera particular se detectaron diferencias en los caudales disponibles, los cuales eran sustancialmente menores a los previstos, la población a servirse era también menor, las condiciones geológicas de la zona impedían seguir el trazado de la línea de conducción, entre otras, lo cual obligó al MIDUVI a suspender los estudios el 19 de diciembre del 2005.

En informe presentado por la consultoría ICA llega a las siguientes conclusiones: (1) no existe caudal suficiente, (2) rediseñar el Proyecto Pesillo-Imbabura (Castañeda, 2009, p. 98).

En enero de 2006, técnicos de ICA, usuarios y dirigentes de comunidades ingresan a los ríos concesionados para realizar aforos de caudales y otros trabajos técnicos (Figura 11).

En el mes de julio de 2006, luego de un largo proceso en el que intervinieron el MIDUVI, Consejo Provincial de Imbabura y el Consejo de Juntas, llegan a un acuerdo para continuar los estudios con los siguientes alcances y modificaciones:

1. Tratar de utilizar parte de la infraestructura del proyecto de riego Tabacundo para no duplicar innecesariamente obras y costos, como es el caso del túnel de trasvase.

2. El levantamiento de la línea de conducción superior, desde las captaciones hasta la laguna de San Marcos y la entrada al túnel de trasvase, en una longitud aproximada de $22 \mathrm{~km}$.

3. El resto del proyecto se lo mantiene igual que el anteproyecto original, esto es la planta de tratamiento, conducción 
baja (aproximadamente $160 \mathrm{~km}$ ) y entregas en los sitios de reserva de las comunidades.

\section{Figura 11}

Colaboración de la comunidad en los estudios técnicos

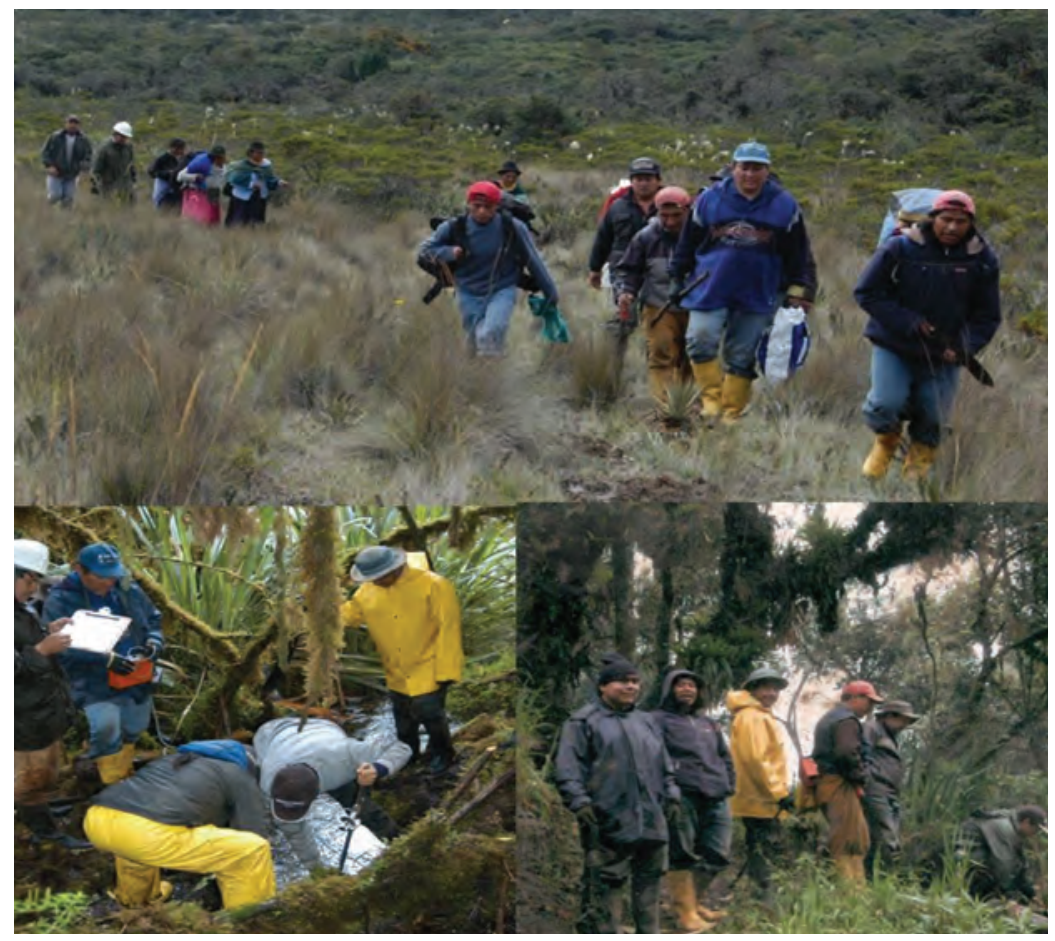

Fuente: Archivos PPI.

El MIDUVI y el Consejo Provincial de Pichincha también suscriben un convenio comprometiéndose a impulsar la implementación conjunta de los proyectos de riego Cayambe-Pedro Moncayo y de agua potable Pesillo-Imbabura.

En diciembre, en la Notaría décima séptima de la ciudad de Quito, el MIDUVI e ICA firman un contrato complementario para elaborar estudios de factibilidad, dentro de los cuales se contempla la 
realización de los estudios hidrológicos, los mismos que están enfocados en la determinación y actualización de los caudales de diseño, cálculo de volúmenes a captar por alternativa, así como el análisis de oferta y demanda.

En enero de 2007, ICA inicia la elaboración de los estudios de factibilidad del PPI. En abril presenta los estudios de factibilidad con dos alternativas:

Alternativa 1. Consiste en captar el caudal de los tributarios de los ríos San Jerónimo, Toldadas y Montoneras y conducirlos hasta el embalse San Marcos para regulación de caudales. En esta alternativa las estructuras de captación se ubicarán al alrededor de la cota $3460 \mathrm{~m} \mathrm{s.} \mathrm{n.} \mathrm{m.}$ Obras: Terrenos y servidumbres, vías de acceso, captaciones, conducción superior, presa/reservorio, planta de tratamiento, tanques de compensación, conducción inferior, manejo ambiental; ingeniería y administración; imprevistos generales. El presupuesto varía entre 44 hasta 68 millones de dólares.

Alternativa 2. Consiste en captar el caudal de los tributarios de los ríos San Jerónimo, Montoneras y Toldadas, para conducirlos directamente hasta la planta de Ismuquiru. En esta alternativa las estructuras de las captaciones se ubican alrededor de la cota de $3440 \mathrm{~m} \mathrm{~s}$. n. m.

Se considera el servicio únicamente a las comunidades rurales, el caudal demandado es de 298 l/s. El presupuesto varía entre 34 y 45 millones de dólares.

En junio, ICA presenta el estudio de factibilidad memoria técnica Alternativa 3:

Alternativa 3. Ante la limitación de recursos hídricos en la zona de estudio, ICA analizó varias fuentes de abastecimiento determinando que las más viable desde el punto de vista técnico son aquellas que se encuentran en el sector de Pesillo a la salida de túnel de trasvase del proyecto de riego Cayambe Pedro Moncayo y en los sectores del Lago San Pablo, vertiente de Araque. El presupuesto asciende a 19 millones de dólares.

La asamblea general de la organización (JAAP y comunidades) se opone a la Alternativa 3 y solicitan que el estudio de facti- 
bilidad tenga en cuenta atender solo al sector rural, excluyendo a los sectores urbanos como eran las recomendaciones de estudios de prefactibilidad anteriores.

En septiembre, ICA presenta al MIDUVI los estudios de factibilidad con la alternativa seleccionada por los beneficiarios y dirigentes del PPI, que el sistema de agua atienda solo al sector rural. El periodo de diseño adoptado es de 25 años. Si los estudios definitivos se concluían en el 2007 y la ejecución se terminaba en el 2010, el 2035 sería el horizonte del proyecto. La población a beneficiarse con el nuevo sistema es de 69865 habitantes y la población futura a beneficiarse (año 2035) de 97 058, y el costo estimativo de construcción ascendía a \$14 156579.73 .

El 20 de septiembre 2007, se firmó el Decreto Presidencial declarando prioritarios y emergentes al proyecto de agua potable Pesillo-Imbabura y de riego Cayambe-Pedro Moncayo. A partir de la suscripción del Decreto, el MIDUVI emprendió las siguientes acciones:

- Reformulación del Proyecto.

- Rehabilitación de los sistemas rurales o comunitarios de agua potable que se van a beneficiar del Proyecto, ya que estaban deterioradas.

- Apoyo al Consejo Provincial de Pichincha en la conclusión de los estudios de diseño para optimizar las obras de captación y trasvase de las aguas del río Azuela a embalsarse en la laguna de San Marcos.

Para la reformulación del proyecto se trazaron los siguientes objetivos:

- Atender a una cantidad mayor de población.

- Disminuir los costos de construcción de las obras.

- Garantizar la disponibilidad de un caudal regulado del orden de los 700 litros por segundo. 
Para cumplir con estos objetivos, el Proyecto Pesillo-Imbabura se integró con las obras de captación, regulación y trasvase del proyecto de riego Cayambe-Pedro Moncayo, de modo que las aguas adjudicadas al proyecto Pesillo-Imbabura también se regulen en la laguna de San Marcos.

El siguiente cuadro resume las características y los costos del proyecto como fue propuesto al año 2007, las características y los costos que tendría el proyecto reformulado. Los costos se obtuvieron de los estudios de factibilidad realizados por ICA (Tabla 10).

Tabla 10

Costos del proyecto según reprogramación

\begin{tabular}{|l|r|l|}
\hline \multirow{2}{*}{ Concepto } & Proyecto anterior (2006-2007) & Reformulación 2008 \\
\cline { 2 - 4 } & $\begin{array}{l}\text { Obras de captación y conducción } \\
\text { independientes de las obras del pro- } \\
\text { yecto de riego Tabacundo }\end{array}$ & $\begin{array}{l}\text { Obras de captación y } \\
\text { regulación comparti- } \\
\text { das con el proyecto de } \\
\text { riego Tabacundo }\end{array}$ \\
\hline $\begin{array}{l}\text { Población a beneficiarse } \\
\text { hasta el año 2035 }\end{array}$ & 160000 & 300000 \\
\hline Costo del proyecto & $\$ 48000000$ & $\$ 33000000$ \\
\hline $\begin{array}{l}\text { Costo por persona } \\
\text { atendida }\end{array}$ & 301 & 109 \\
\hline
\end{tabular}

Fuente: Ing. Vinicio Roldán, ayuda memoria proyecto regional de agua potable Pesillo-Imbabura

Sin embargo, el Consejo de Juntas, los dirigentes de las JAAP y comunidades siguen insistiendo en la Alternativa 2. En abril de 2008, los dirigentes del Consejo de Juntas, la ministra del MIDUVI y otras autoridades, acuerdan elaborar los Términos de Referencia para la elaboración de los estudios definitivos del sistema de agua potable Pesillo-Imbabura en base a la Alternativa 2 (Acta PPI, 10 de abril del 2008).

En julio, el MIDUVI entrega los Términos de Referencia para los estudios finales del PPI, que es una revisión y sistematización de los estudios realizados por CONSULPIEDRA e ICA consultores y solicita al Gobierno Nacional la contratación inmediata. 
Representantes del Consejo Provincial de Pichincha, MIDUVI, el Instituto Nacional de Riego, ASTEK Consultores, la Gobernación de Imbabura, presidente del PPI, y CODEMIA del canal de riego Cayambe-Pedro Moncayo se reúnen para suscribir el siguiente acuerdo:

El Honorable Consejo Provincial de Pichincha facilitará los estudios realizados por el MIDUVI para su revisión y complementación con los estudios realizados por ASTEK, para la unificación en un solo Proyecto.

\section{Acuerdos interinstitucionales para dotar agua al PPI desde la salida de túnel de trasvase del proyecto de riego Cayambe-Pedro Moncayo}

Desde los estudios de primera etapa, se había planteado como objetivo la atención a ambos proyectos, para ello, los gobiernos provinciales de Imbabura y Pichincha firmaron varios acuerdos de cooperación para implementar de forma conjunta.

En mayo de 2004, se firma un convenio de cooperación interinstitucional entre el Consejo Provincial del Pichincha e Imbabura, para dotar agua desde el embalse de la laguna de "San Marcos" del proyecto de riego Cayambe-Pedro Moncayo (Pichincha) al proyecto de agua potable Pesillo-Imbabura, en los siguientes términos:

Objeto: (...) el Consejo Provincial proporcionará a favor del Gobierno Provincial de Imbabura 1055 litros por segundo del caudal de agua almacenado en el embalse de la presa de "San Marcos" del proyecto de riego Cayambe-Pedro Moncayo, para satisfacer los requerimientos de agua potable de las poblaciones beneficiarias del proyecto regional Pesillo-Imbabura (...).

Obligaciones del Gobierno Provincial de Imbabura: 1. Proporcionar al Consejo Provincial de Pichincha los estudios definitivos del proyecto regional de agua potable Pesillo-Imbabura. 2. Construir las obras de conducción de los caudales asignados hasta los centros de distribución. Obligaciones del Gobierno Provincial de Pichincha: Construcción de la obra de toma a la salida del túnel de trasvase para la dotación de 1055 litros por segundo para el proyecto regional de agua potable Pesillo-Imbabura. 
Convenio de cooperación suscrito el 4 de julio de 2006 entre el MIDUVI, el Consejo Provincial de Pichincha e Imbabura.

Acuerdo del 02 de agosto del 2008 entre el MIDUVI, Ministerio de Agricultura, Consejo Provincial de Pichincha, Consejo Provincial de Imbabura, Municipio de Cayambe, Municipio de Otavalo y Municipio de Pedro Moncayo. El MIDUVI se compromete a realizar los estudios para concluir las obras de captación y trasvase del proyecto de riego Cayambe Pedro Moncayo, que también sirven para el proyecto Regional de Agua Potable Pesillo-Imbabura.

En enero de 2011, el MIDUVI y el Consejo Provincial del Pichincha firman un convenio interinstitucional para la ejecución de los proyectos de Riego Cayambe-Tabacundo y el Regional de Agua Potable Pesillo-Imbabura, tomando como antecedente el convenio firmado el 4 de julio del 2006, con los siguientes compromisos:

a. El MIDUVI solicitará a la Secretaría Nacional del Agua, SENAGUA, la reversión de las concesiones de las aguas de los ríos San Jerónimo, Cuscungo y Toldadas en un caudal de 660 1/s, para que sean concedidas a favor del Consejo Provincial de Pichincha. Estas aguas serán reguladas en la Laguna de San Marcos.

b. El H. Consejo Provincial del Pichincha se compromete a entregar un caudal regulado a la salida del túnel de trasvase. Este caudal será utilizado para dotar de agua potable a las comunidades beneficiarias del Proyecto Pesillo-Imbabura, de conformidad al siguiente detalle:

\begin{tabular}{|r|l|l|l|l|l|l|l|l|l|l|}
\hline AÑO & $\mathbf{2 0 1 0}$ & $\mathbf{2 0 1 1}$ & $\mathbf{2 0 1 2}$ & $\mathbf{2 0 1 3}$ & $\mathbf{2 0 1 4}$ & $\mathbf{2 0 1 5}$ & $\mathbf{2 0 1 6}$ & $\mathbf{2 0 1 7}$ & $\mathbf{2 0 1 8}$ & $\mathbf{2 0 1 9}$ \\
\hline $\begin{array}{l}\text { CAUDAL } \\
\left(\mathrm{m}^{3} / \mathrm{s}\right)\end{array}$ & 0,47 & 0,48 & 0,49 & 0,5 & 0,51 & 0,52 & 0,54 & 0,54 & 0,55 & 0,56 \\
\hline
\end{tabular}

\begin{tabular}{|l|l|l|l|l|l|l|l|l|l|l|l|l|}
\hline 2020 & 2021 & 2022 & 2023 & 2024 & $\mathbf{2 0 2 5}$ & $\mathbf{2 0 2 6}$ & $\mathbf{2 0 2 7}$ & $\mathbf{2 0 2 8}$ & $\mathbf{2 0 2 9}$ & $\mathbf{2 0 3 0}$ & $\mathbf{2 0 3 1}$ & $\mathbf{2 0 3 1}$ \\
\hline 0,57 & 0,58 & 0,59 & 0,6 & 0,61 & 0,62 & 0,63 & 0,64 & 0,65 & 0,66 & 0,67 & 0,68 & 0,69 \\
\hline
\end{tabular}


c. Respaldar la reformulación del Proyecto Regional de Agua Potable Pesillo-Imbabura, para que el MIDUVI que es el responsable del proyecto, pueda realizarlo en coordinación con las otras instituciones.

En base al Convenio con el Gobierno de la provincia de Pichincha, se realiza una proyección de caudales requeridos para el sector rural y urbano de los cinco cantones del PPI (Tabla 11 y 12).

Tabla 11

Caudal 1/s requeridos para sector rural y urbano 2042

\begin{tabular}{|c|c|c|c|c|c|c|c|c|c|c|c|}
\hline \multicolumn{10}{|c|}{ Cantones } & \multirow{2}{*}{\multicolumn{2}{|c|}{ Total }} \\
\hline \multicolumn{2}{|c|}{ P. Moncayo } & \multicolumn{2}{|c|}{ Cayambe } & \multicolumn{2}{|c|}{ Otavalo } & \multicolumn{2}{|c|}{ A. Ante } & \multicolumn{2}{|c|}{ Ibarra } & & \\
\hline Urbano & Rural & Urbano & Rural & Urbano & Rural & Urbano & Rural & Urbano & Rural & Urbano & Rural \\
\hline 23.57 & 23.64 & 39.29 & 42.29 & 33.57 & 120.57 & 47.86 & 12.86 & 103.14 & 55.29 & 246.43 & 254.65 \\
\hline & 47.21 & & 81.58 & & 154.14 & & 60.72 & & 157.43 & & 501.08 \\
\hline
\end{tabular}

Fuente: Ing. Vinicio Roldán, funcionario de MIDUVI responsable de PPI (2012)

Tabla 12

Caudal 1/s requeridos para sector rural y urbano 2042

\begin{tabular}{|c|c|c|c|c|c|c|c|c|c|c|c|}
\hline \multicolumn{10}{|c|}{ Cantones } & \multirow{2}{*}{\multicolumn{2}{|c|}{ Total }} \\
\hline \multicolumn{2}{|c|}{ P. Moncayo } & \multicolumn{2}{|c|}{ Cayambe } & \multicolumn{2}{|c|}{ Otavalo } & \multicolumn{2}{|c|}{ A. Ante } & \multicolumn{2}{|c|}{ Ibarra } & & \\
\hline Urbano & Rural & Urbano & Rural & Urbano & Rural & Urbano & Rural & Urbano & Rural & Urbano & Rural \\
\hline 33 & 33.1 & 55 & 59.20 & 47 & 168.8 & 67 & 18 & 143 & 77.4 & 345 & 356.5 \\
\hline & 66.1 & & 114.2 & & 215.8 & & 85 & & 220.4 & & 701.5 \\
\hline
\end{tabular}

Fuente: Ing. Vinicio Roldán, funcionario de MIDUVI responsable de PPI (2012)

\section{Estudios técnicos (tercera etapa)}

En el año 2011 el MIDUVI, en coordinación con el Consejo de Juntas, contrató a ACP consultores, para realizar los estudios de la Tercera Etapa del proyecto de agua Potable Pesillo-Imbabura. 
En enero de 2012, la SENAGUA y ACP consultores renuevan el contrato para realizar los estudios definitivos del proyecto: "realizar los diseños definitivos de la captación, planta de tratamiento de agua potable para 700 1/s, y la red principal de distribución a los tanques de reserva de las comunidades o ciudades que componen el sistema regional".

Acuerdan entregar por partes, ya que su diseño implica varios componentes: ambiental, capacidad de tanques, electromecánico Scada de la planta de tratamiento, estructural, geotécnico, hidráulico, mecánica de suelos, sistema eléctrico, topografía, y vial. En septiembre, octubre y diciembre, ACP consultores entregó al MIDUVI informe de alternativas con la cual se elabora los diseños definitivos correspondientes. La memoria del diseño electromecánico de válvulas y sistema Scada a implementarse.

En julio de 2013, ACP consultores entrega al MIDUVI los estudios definitivos de los diseños estructurales.

En enero de 2014, ACP consultores entrega a la SENAGUA y esta al Consejo de Juntas —en asamblea general, el informe consolidado de la (tercera etapa) del estudio de agua potable Regional Pesillo-Imbabura ${ }^{26}$ (Figura 12), repartidos en varios tomos. Uno de los funcionarios adelantó que:

La planta de tratamiento tendrá tecnología de punta con control informático. La red de distribución tiene 152 kilómetros que comprenden tubería de acero y PVC, y 29 tanques de reserva. El costo total del proyecto asciende a $\$ 47054000$, y que el plazo para ejecutar el proyecto es de dos años y medio, (Acta PPI, 2014, 25 de enero)

26 Luego de la entrega-recepción de los estudios definitivos, se realizaron alcances y modificaciones a varios componentes como la planta de tratamiento y líneas de conducción. 
88

Figura 12

Entrega-recepción de estudios definitivos del PPI

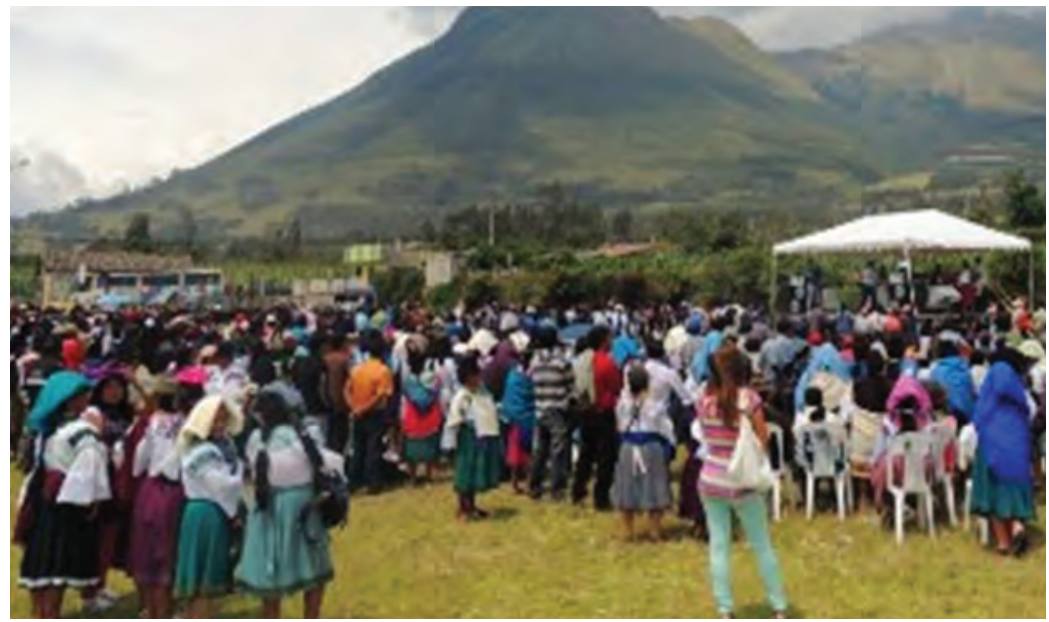

Fuente: Foto tomada por usuarios

\section{El financiamiento del proyecto y el modelo de ejecución}

La constancia de las comunidades agrupadas en la organización, presionan al Estado para que asuma sus compromisos y financien las dos etapas del proyecto: 1) financiamiento para los estudios y 2) financiamiento para la construcción de la infraestructura del sistema de agua potable. En el financiamiento de la infraestructura "último tramo del proyecto" participan de manera más protagónica los cinco municipios agrupados en una mancomunidad y el Banco del Estado.

De igual manera, el Estado a través del Banco de Estado acude a la cooperación internacional, a la Agencia Francesa de Desarrollo (AFD), quienes en coordinación con el resto de los actores logran negociar el financiamiento para la construcción de la infraestructura del sistema de agua potable. A continuación, se resume el proceso: 
Por los retrasos, la mañana del 21 de mayo de 2014, alrededor de cien personas del PPI y CODEMIA (proyecto canal de riego Cayambe-Pedro Moncayo) se reúnen en el sector de la Y de Tabacundo para caminar hacia la ciudad de Quito. La mañana del 22 de mayo, (aproximadamente ocho mil personas) se concentraron en el sector de Carcelén, norte de Quito para dirigirse hacia la Plaza Grande (Figura 13) para exigir al gobierno el financiamiento para construir el proyecto Pesillo-Imbabura y proyecto canal de Riego Cayambe- Pedro Moncayo:

1. Se respete la gestión comunitaria del agua, de acuerdo con el artículo 318 de la Constitución de la República.

2. Culminación inmediata del túnel de trasvase y canales secundarios.

3. Presupuesto necesario para los estudios definitivos, implementación y ejecución del proyecto de agua de consumo Pesillo-Imbabura y riego Cayambe-Pedro Moncayo.

En la tarde, asesores del Presidente de la República, Ministros de Estado entre otras autoridades recibieron a los representantes, comprometiéndose a atender las propuestas presentadas y buscar fórmulas de financiamientos para ejecutar ambos proyectos.

\section{Modelo de ejecución del proyecto y el financiamiento}

La forma de participación de la organización en la fase de implementación del proyecto y el modelo de gestión se tornó muy importante ya que de ello dependía el financiamiento para la ejecución, por una parte, el Consejo de Juntas aspiraba un modelo basado en los principios y prácticas comunitarias, y por otra parte los municipios se interesan e impulsan la gestión pública.

El 29 de noviembre de 2014, en la parroquia de San Pablo de Lago, en presencia del vicepresidente de la República Jorge Glas, y cerca de cinco mil personas (Figura 14), los alcaldes: Fabián Poso de Antonio Ante, Gustavo Pareja de Otavalo, Álvaro Castillo de Ibarra, Frank Gualsaquí de Pedro Moncayo, y Guillermo Churuchumbi 
de Cayambe, solicitan al Banco del Estado el financiamiento para construir el "Proyecto Regional de Agua Potable Pesillo-Imbabura", mismo que cuenta con el informe de aprobación y viabilidad técnica por parte de SENAGUA.

\section{Figura 13}

Marcha de beneficiarios del proyecto de agua potable Pesillo-Imbabura y canal de riego Cayambe Pedro Moncayo

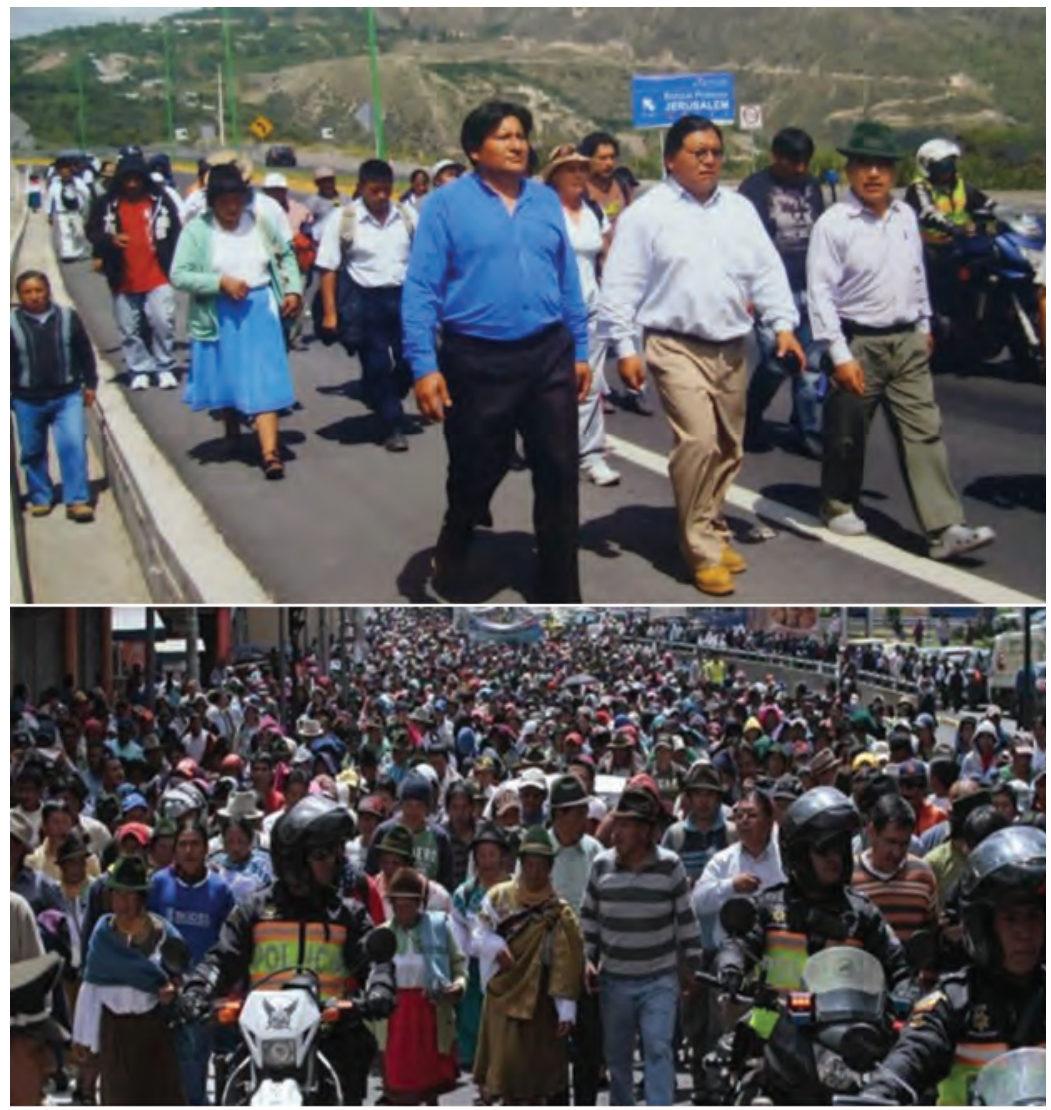

Fuente: Archivo PPI. 
Figura 14

Delegaciones de las juntas regionales consiguiendo el financiamiento del proyecto

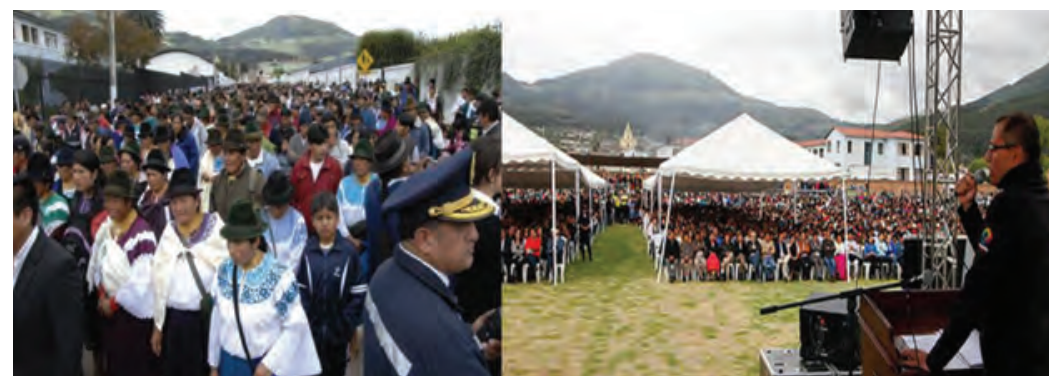

Fuente: Archivo PPI

Así, se llega a un acuerdo en primera instancia en un modelo para la ejecución del proyecto en donde garantice la participación de todos los actores y se viabilice el financiamiento del proyecto.

En enero de 2015, Verónica Gallardo, Gerente General del Banco del Estado, socializa el proyecto "Sistema Regional de Agua Potable Pesillo-Imbabura”, donde informa las características, el esquema de financiamiento. También anuncia la suscripción del:

Acuerdo sobre la participación público-comunitario para la implementación y gestión del proyecto, y que el costo del proyecto asciende a $\$ 47500000$ dólares, de los cuales $\$ 31000$ 000, equivalentes al $65 \%$, serán aportados directamente por el Gobierno Nacional como fondos no reembolsables y $\$ 16600$ 000, equivalentes al 35\%, serán financiados por los municipios, a través de créditos con el Banco del Estado. (GAD Otavalo, publicado 15 abril de 2015)

El 13 de abril, en la ciudad de Atuntaqui, los gobiernos Autónomos Descentralizado Municipales de: Antonio Ante, Otavalo, Ibarra, Pedro Moncayo, y Cayambe; el Consejo de Coordinación de Juntas Administradoras de Agua Potable Pesillo-Imbabura; y los presidentes de los sistemas regionales beneficiarios, suscriben el "Acuerdo 
sobre la participación Publico-Comunitario para la implementación y gestión del proyecto regional de agua potable Pesillo-Imbabura":

PRIMERO. Modelo de Implementación: La Mancomunidad constituida creará la Unidad de Gerenciamiento del proyecto para los procesos de construcción y fiscalización de las mismas. Para garantizar los procesos de participación ciudadana y comunitaria se conformará un Comité Técnico de Seguimiento.

A fin de garantizar los procesos de participación ciudadana y comunitaria, en esta etapa constructiva, para el monitoreo y supervisión del Proyecto, se conformará un Comité Técnico de Seguimiento, como expresión organizativa de la veeduría ciudadana, que se integrará por delegados técnicos de los 5 GADM y representantes del Consejo de Juntas.

SEGUNDO. Modelo de Gestión: Para la administración, operación y mantenimiento del sistema regional de agua potable PesilloImbabura, se acuerda que la mancomunidad creará la denominada Empresa Pública de Agua Potable Pesillo-Imbabura (EPAP PesilloImbabura), con participación comunitaria (...). Esta empresa se dirigirá a través de un Directorio integrado por un máximo de 5 miembros, entre los cuales estarán tres representantes de los municipios y dos representantes de las juntas administradoras de agua potable. TERCERO. Alianza Público-Comunitaria: Los intervinientes reconociendo la gestión comunitaria y su autonomía administrativa, acuerdan suscribir convenios para el establecimiento de alianzas público-comunitarias, entre cada GADM y los representantes de las Juntas Administradoras de Agua Potable en cada cantón, tendientes al fortalecimiento técnico y operativo de las JAAP (...).

\section{Fórmula para el financiamiento y contratación de la empresa constructora}

El 3 de junio del 2015 en el cantón Antonio Ante, con la presencia de aproximadamente cinco mil personas, los municipios de Cayambe, Pedro Moncayo, Otavalo, Antonio Ante e Ibarra, firmaron un convenio de crédito por 47.6 millones de dólares con el Banco del Estado (BDE) para la construcción del proyecto (Figura 15). 
Figura 15

Firma de convenio de crédito para ejecutar el PPI

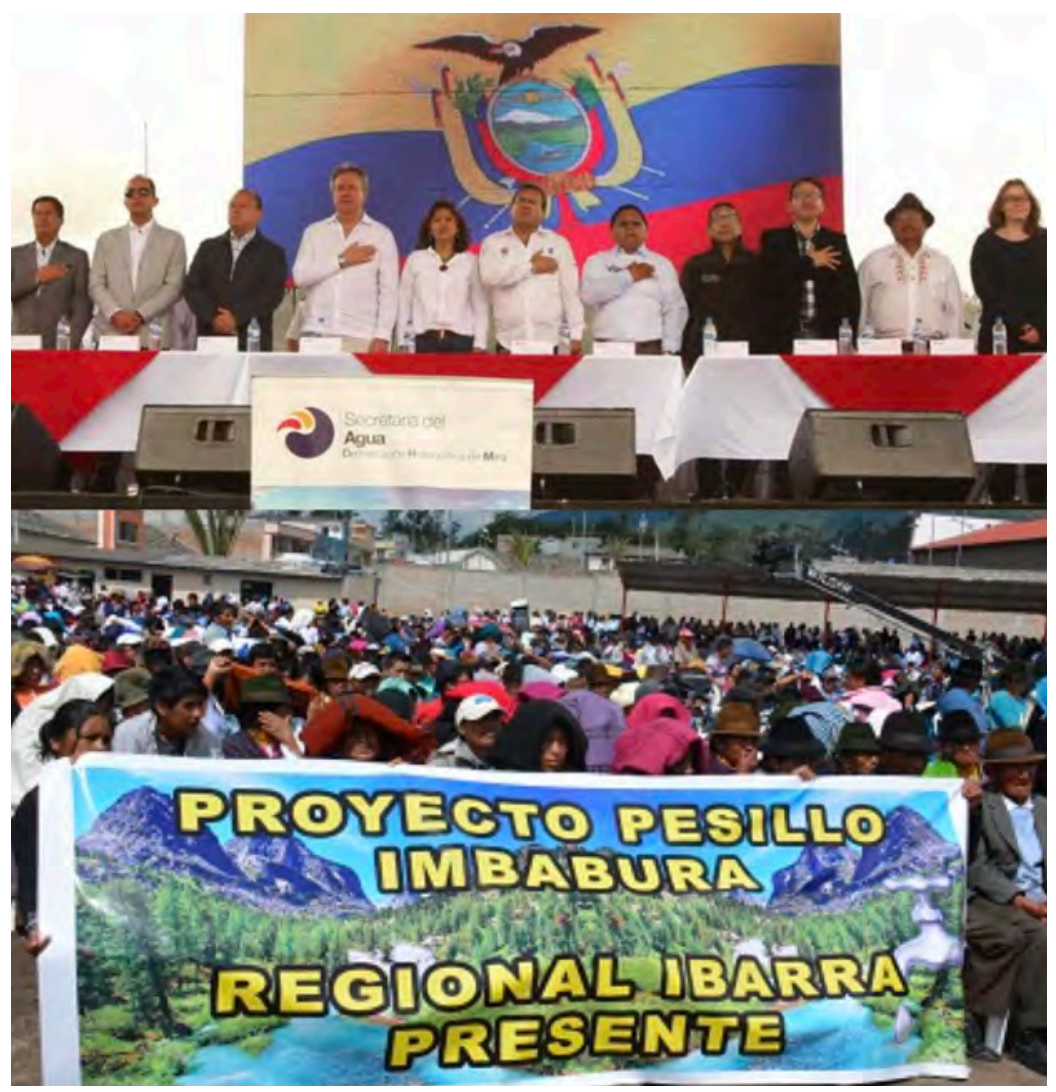

Fuente: BEDE

En marzo de 2016, los alcaldes que conforman la mancomunidad del PPI, el subgerente de Banco de Desarrollo Gonzalo Núñez, la viceprefecta de Pichincha Marcela Costales, Juan Serrano presidente del PPI y otros dirigentes (Figura 16), visitaron el túnel trasvase en la represa San Marcos, para verificar el avance de la obra, ya que de esta depende la dotación del agua para el PPI (Acta-informe del PPI, 2016, 2 de marzo). 
94

Figura 16

Autoridades en la laguna de San Marcos verificando avance de obras

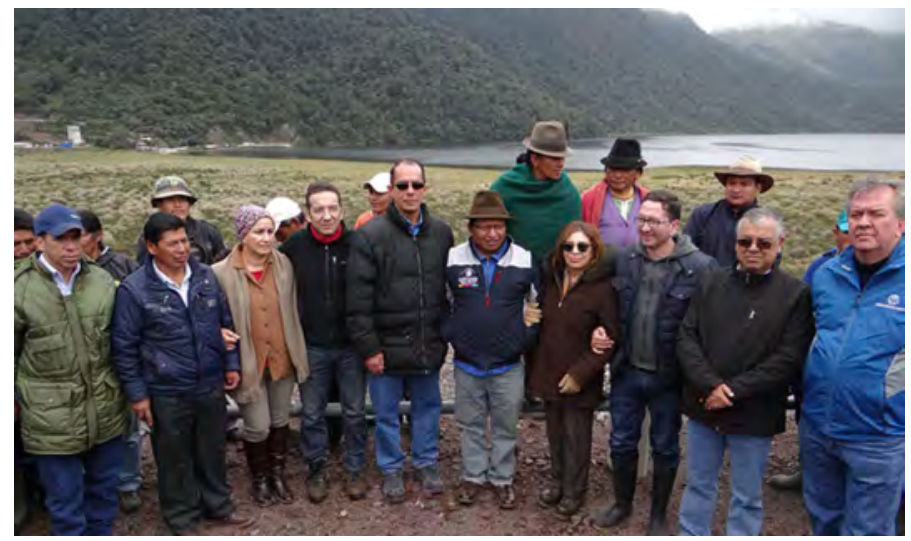

Fuente: Archivos PPI.

En abril, en la ciudad de Ibarra, el Consejo Nacional de Competencias, CNC, inscribe la Mancomunidad del proyecto de agua potable Pesillo-Imbabura, publicado en el Registro Oficial, Edición Especial No. 638, de fecha 18 de julio de 2016:

2.1. Por medio del presente instrumento se constituye la MANCOMUNIDAD DEL PROYECTO DE AGUA POTABLE PESILLO-IMBABURA, conformada por los GAD Municipales: Antonio Ante, Otavalo, San Miguel de Ibarra, Pedro Moncayo y San Pedro de Cayambe, como una persona jurídica de derecho público para el cumplimiento de los fines dispuestos en el presente instrumento.

2.3. La Mancomunidad tiene por objeto o finalidad específica gestionar de manera efectiva y eficiente la implementación de obras y gestión de servicio del proyecto de agua potable Pesillo-Imbabura, para suministrar del líquido vital a todos los cantones mancomunados. La implementación de las obras que implica su contratación, fiscalización, así como la administración de los contratos, hasta la entrega recepción de las obras concluidas, que serán ejecutados por el GADM de Ibarra delegado para el efecto.

Objetivos: 
2.4.1. Generar espacios participativos de gestión, control y monitoreo de los planes, programas y proyectos relacionados y previstos en el proyecto de agua Pesillo- Imbabura.

2.4.2. Generar planes, programas y provectos de conservación y aprovechamiento racional y sustentable de los recursos naturales.

2.4.3. Identificar y acceder a recursos de financiamiento, públicos y privados, nacionales o internacionales para las actividades contempladas en los planes, programas y proyectos que se definan al interior de la Mancomunidad (Registro Oficial No 638).

Para efectivizar el financiamiento, el Estado a través del Banco de Desarrollo del Ecuador presentó un paquete de proyectos a la Agencia Francesa de Desarrollo (AFD). La Agencia, después de analizar todos los proyectos, eligió el Pesillo-Imbabura como beneficiaria. En mayo, se obtuvo la No Objeción de la Agencia Francesa de Desarrollo, para el financiamiento de crédito de 16 millones de dólares a los municipios.

En junio, en la ciudad de Ibarra: el GAD Municipal de Ibarra, la Mancomunidad Pesillo- Imbabura, el Banco de Desarrollo del Ecuador, y la Agencia Francesa de Desarrollo, emiten documentos de licitación para la Contratación de la infraestructura:

Construcción del sistema de agua potable Pesillo-Imbabura, en las provincias de Pichincha e Imbabura; contratante: Gobierno Autónomo Descentralizado Municipal de San Miguel de Ibarra en representación de la Mancomunidad del proyecto de agua potable Pesillo-Imbabura.

En julio, el GAD Municipal de Ibarra, la Mancomunidad Pesillo-Imbabura, el Banco de Desarrollo del Ecuador, y la Agencia Francesa de Desarrollo, invitan a presentar expresiones de interés de servicios de consultoría para la:

Fiscalización de la construcción del sistema de agua potable PesilloImbabura. Los servicios de la consultoría comprenden la fiscalización de la construcción del sistema de agua potable Pesillo-Imbabura y el presupuesto referencial de la fiscalización alcanza la suma de: UN 
MILLÓN DOSCIENTOS CINCUENTA MIL DOSCIENTOS CON 00/100 dólares de los Estados Unidos de América (US\$1 250 200,00).

En agosto, el GAD Municipal de Ibarra (en representación de otros municipios), la Mancomunidad Pesillo-Imbabura, el Banco de Desarrollo del Ecuador, y la Agencia Francesa de Desarrollo, realiza el llamado a Licitación:

La República del Ecuador, ha recibido un préstamo del Agence Française de Développement (AFD) para financiar el PROGRAMA NACIONAL DE INVERSIONES EN AGUA, SANEAMIENTO Y RESIDUOS SÓlIDOS, PROSANEAMIENTO, cuyo Organismo Ejecutor es el Banco de Desarrollo del Ecuador, con aplicación al cual ha suscrito con los Gobiernos Autónomos Descentralizados Municipales de Ibarra, Otavalo, Antonio Ante, Pedro Moncayo y Cayambe, un Contrato de Financiamiento y Servicios Bancarios, para financiar las obras de CONSTRUCCIÓN DEL SISTEMA DE AGUA POTABLE PESILLOIMBABURA, EN LAS PROVINCIAS DE PICHINCHA E IMBABURA, y se propone utilizar parte de los fondos de este Préstamo para efectuar los pagos estipulados en el Contrato de obra.

Para el efecto los Gobiernos Autónomos Descentralizados Municipales de Ibarra, Otavalo, Antonio Ante, Pedro Moncayo y Cayambe conformaron la Mancomunidad del Sistema de Agua Potable PesilloImbabura, y delegaron al Gobierno Autónomo Descentralizado del Municipio de Ibarra para que en representación de los cantones realice los procesos precontractuales y de contratación para la implementación de las obras. Con este antecedente se invita a los oferentes elegibles a presentar ofertas selladas para el contrato que integra la Licitación Pública Internacional.

Luego se organiza una visita técnica con las empresas interesadas en participar en la licitación a los sitios donde se realizarán los trabajos.

A fines de agosto, en el centro de exposiciones del cantón Pedro Moncayo, Verónica Gallardo, Gerente General del Banco de Desarrollo del Ecuador, expuso los avances realizados en conjunto con la Agencia Francesa para el Desarrollo (AFD), e hizo conocer un cronograma de actividades destacando el inicio del proceso de licitación internacional 
para contratar a la empresa constructora que ejecute las obras civiles. 17 empresas: 10 extranjeras y 7 nacionales estaban interesadas.

El 20 de octubre del 2016, el GAD municipal de Ibarra, la Mancomunidad Pesillo-Imbabura, el Banco de Desarrollo del Ecuador, y la Agencia Francesa de Desarrollo, invitan a la apertura de ofertas de licitación de obra: Construcción del sistema de agua potable Pesillo-Imbabura, en las provincias de Pichincha e Imbabura:

Se comunica e invita a los Oferentes que estén interesados en presentar su oferta para este proceso Internacional de Licitación de Obra, que la apertura de ofertas será realizada el martes 25 de octubre de 2016 a las 16:00 en el salón del despacho de la Alcaldía de Ibarra, calle García Moreno y Bolívar 2do piso antiguo Edifico Municipal.

La licitación se realizó conforme a los procedimientos de Licitación Pública Internacional establecidos en la publicación de la Agencia Francesa de Desarrollo. El precio referencial para licitación fue 41674 988,77 millones de dólares sin incluir Impuesto al Valor Agregado IVA. Las empresas oferentes fueron: 1. Hidalgo e Hidalgo S.A \$29 546 056.49; 2. Consorcio AV-Pesillo $\$ 34855$ 100.91; 3. Consorcio Pesillo \$35 284 129.18; 4. Sinohydro \$35 917 395.46; 5. Eceico \& Rodas \$37 316418 81; 6. Enserving EP \$39923 849.79; 7. Consorcio SVS \$41382 333.76.

Para la calificación se creó una comisión técnica conformada por los gerentes de las Empresas Públicas de Agua Potable de los cinco municipios beneficiarios. En este proceso los representantes de la organización se mantuvieron como testigos, sin participar en la toma de decisiones. La empresa ganadora fue Hidalgo e Hidalgo Constructores S.A. que ofertó \$29 546 056.49. ${ }^{27}$

27 La diferencia entre el precio referencial del costo del proyecto \$41 674 988,77 millones de dólares, y la oferta de Hidalgo e Hidalgo Constructores S.A. de \$29 546056.49 , es porque a nivel mundial hubo un descenso del kilo de acero, eso beneficia el proyecto porque las redes de conducción (tubería) son el componente más grande y costoso. La diferencia servirá para realizar estudios y mejoras de los sistemas comunitarios de agua existentes, una vez que reciban las aguas del Pesillo no tengan problemas de funcionamiento 
El 24 de octubre, se realiza la apertura de Ofertas para la Fiscalización de la construcción del sistema de agua potable Pesillo-Imbabura en las provincias de Pichincha e Imbabura, resultando ganador la empresa Kunhwa Engineering \& Consulting Co. Ltd.

En diciembre, se concluyen las obras en el túnel de trasvase:

El prefecto de Pichincha Gustavo Baroja, asistió al empate del túnel y destacó el esfuerzo de técnicos y trabajadores para concluir esta parte del proyecto, que presentó constantes inconvenientes de carácter geológico. Hasta el momento, el Gobierno Nacional invirtió $\$ 81$ millones en la obra; mientras que el aporte del ejecutivo provincial es de \$ 18 millones. Según las proyecciones, la obra dotará de riego a 14000 hectáreas de las parroquias: Olmedo, Ayora, La Esperanza, Tupigachi, Tabacundo, Tocachi y Malchinguí. Además, proporcionará agua potable a comunidades de la provincia de Imbabura. (Diario El Telégrafo, 2016)

El 11 de enero de 2017, en el Auditorio Monseñor Leonidas Proaño de la ciudad de Ibarra se firma el contrato para la ejecución del proyecto de agua potable Pesillo-Imbabura, con la empresa Hidalgo e Hidalgo por un monto de USD29 546 056,49 a un plazo de 24 meses. El 29 de enero, el Municipio de Ibarra, en representación de la Mancomunidad Pesillo-Imbabura en coordinación con los dirigentes del PPI, organizó un evento para celebrar el inicio de obra del proyecto en el estadio municipal de Otavalo (Figura 17).

La primera semana de marzo, se suscribió el contrato de fiscalización con la empresa Kunhwa Engineering \& Consulting Co. Ltda, por un monto de USD 1249 398,91 y un plazo de ejecución de 25 meses, de los cuales 24 meses comprende la ejecución de la obra y 1 mes para preparar liquidación provisional del contrato y suscripción del acta de recepción definitiva del contrato.

(Álvaro Castillo, alcalde de Ibarra, reunión mantenida en Ibarra con los representantes de las JAAP regionales el 3 de enero de 2019). 


\section{Figura 17}

Autoridades y usuarios al acto de inicio de obra del proyecto, en el estadio de Otavalo

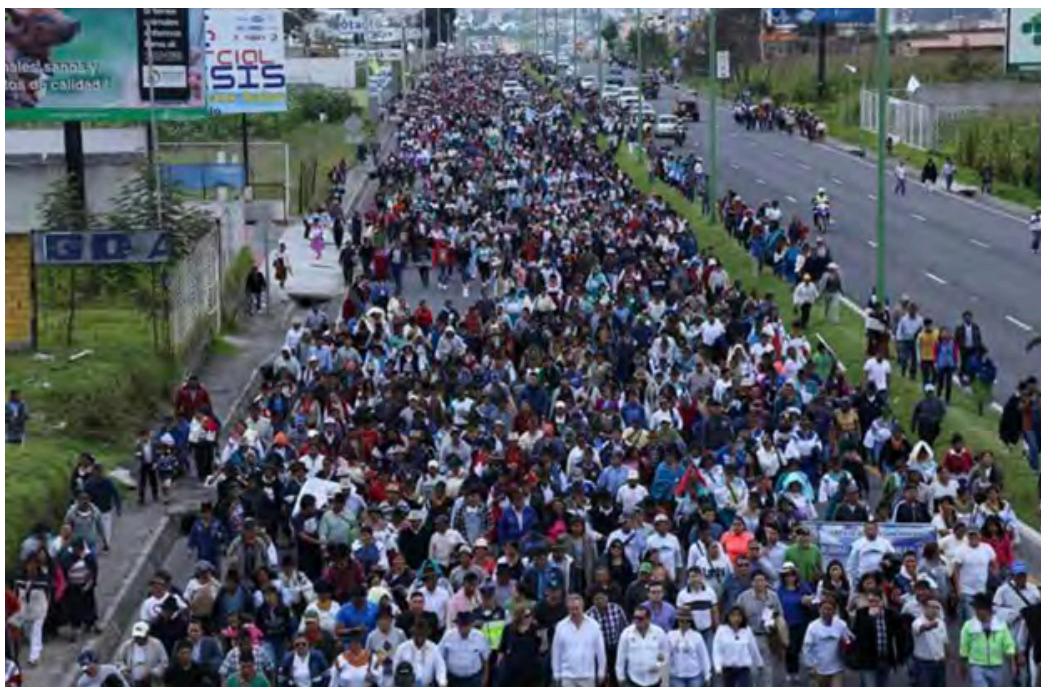

Fuente: Archivo PPI

\section{La ejecución de la infraestructura del proyecto Pesillo-Imbabura}

La organización está presente en la etapa de ejecución del proyecto de forma indirecta, cumpliendo un papel de veedor de ejecución de la infraestructura del PPI (obra física) y de presión ante las instituciones para que se cumpla con las planificaciones y cronogramas. También es parte de las negociaciones con los otros actores de uso del agua (Canal de riego Cayambe-Pedro Moncayo). Se genera una organización articulando la dinámica de las instituciones públicas y de las comunidades, esto permite que la organización conozca los avances del proyecto, pero también pierde protagonismo en las comunidades de base (regionales de juntas de agua potable) y en la toma de decisiones en la ejecución del proyecto (Figura 18). 
100

Figura 18

Involucramiento de actores en la ejecución del proyecto previo a su financiamiento

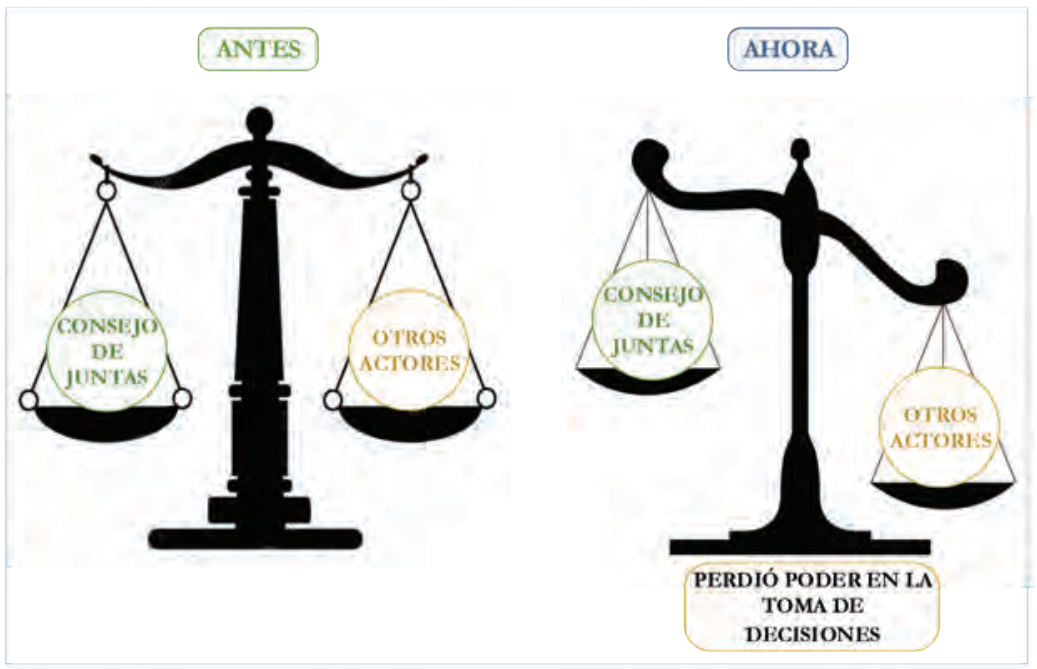

Fuente: Elaboración propia

\section{Modelo de implementación del proyecto $y$ participación de la comunidad}

Para la ejecución del proyecto es necesario contar con una propuesta de gestión de la ejecución en donde los actores se involucren en la toma de decisiones, así, se genera una propuesta de modelo de implementación de la obra física (Figura 19).

En general el modelo de implementación del proyecto pasa por los siguientes acontecimientos de participación:

PARTICIPACIÓN DE LOS MUNICIPIOS

En el "Acuerdo sobre la participación Publico-Comunitario para la implementación y gestión del proyecto" los municipios con- 
101

forman la Mancomunidad y esta creará la Unidad de Gerenciamiento del proyecto (Figura 20) y manifiesta que:

Los GAD Municipales convinieron crear una Unidad de Gerenciamiento del Proyecto (UGP-PI) encargada del proceso de Implementación del proyecto hasta su entrega recepción de las obras concluidas con profesionales técnicos de amplia experiencia; y la implementación del modelo de gestión del servicio público con participación (comunitaria) de la JAAP.

Funciones de la (UGP-PI) en general son las siguientes:

Realizar actividades de administración y supervisión de los contratos de obra, fiscalización, consultoría y bienes, del sistema de agua potable hasta la entrega y funcionamiento a la Empresa mancomunada de Agua Potable Pesillo- Imbabura.

Coordinar acciones permanentes con las áreas del GAD Municipal de Ibarra quien llevará adelante los procesos precontractuales, contractual, administrativo, financiero, requeridos en la implementación y ejecución del proyecto (...).

Figura 19

Acuerdo de participación Público-Comunitario para ejecución de la obra física del PPI

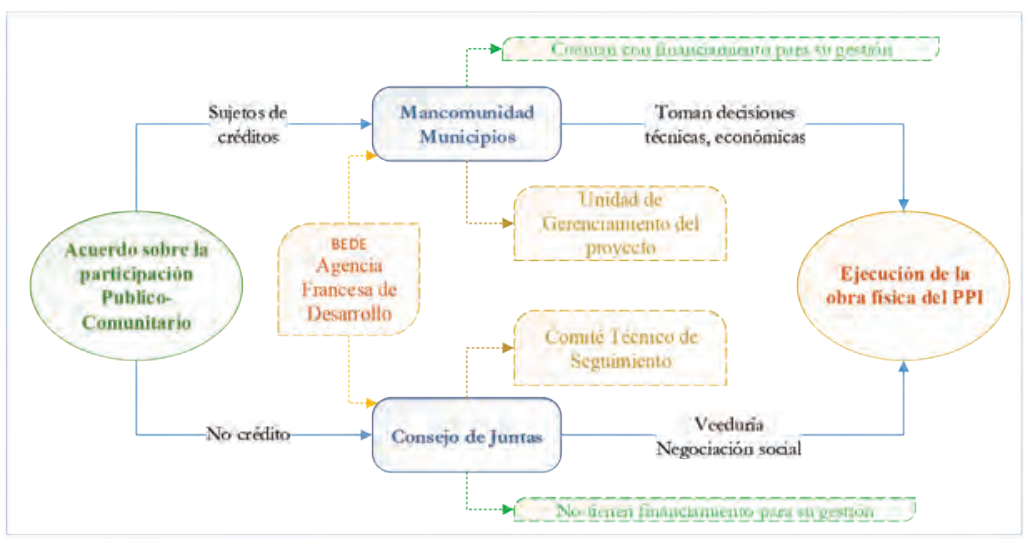


102

Figura 20

Estructura Orgánica de la UGP-PI

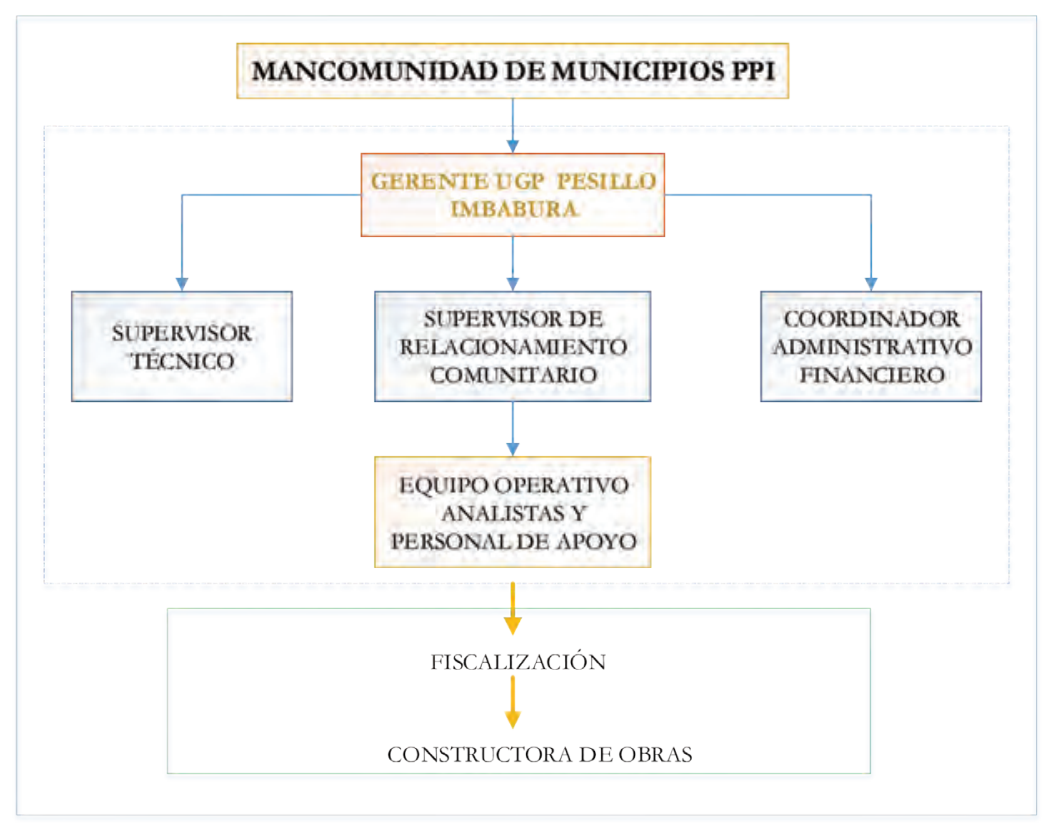

Fuente: UGP-PI

La UGP-PI está constituida por profesionales con trayectoria y amplios conocimientos en hidráulica, por el tipo de proyecto que se ejecuta. Por su trabajo perciben un salario, contando con los recursos humanos, técnicos y logísticos para ello. Según Álvaro Castillo, expresidente de la Mancomunidad del proyecto Pesillo-Imbabura, para financiar los pagos a las personas que trabajan en la Unidad de Gerenciamiento, han tenido que acudir a una nueva deuda, además compraron dos camionetas y contrataron dos choferes para facilitar la movilización en toda el área del proyecto (extracto reunión, enero 2019).

PaRTicipación DE LAS COMUNIDAdeS

En el "Acuerdo sobre la participación Publico-Comunitario para la implementación y gestión del proyecto" consta la conforma- 
ción de un Comité Técnico de Seguimiento para el monitoreo y supervisión del proyecto en la fase de ejecución:

A fin de garantizar los procesos de participación ciudadana y comunitaria, en esta etapa constructiva, para el monitoreo y supervisión del Proyecto, se conformará un Comité Técnico de Seguimiento, como expresión organizativa de la veeduría ciudadana, que se integrará por delegados técnicos de los 5 GADM y representantes del Consejo de Juntas.

De parte del Consejo de Juntas, los primeros miembros que conformaron el Comité Técnico de Seguimiento fueron elegidos el 14 de octubre de 2015, siendo Alberto Yánez en representación de la regional Angla, José Manuel Criollo de la regional San Rafael, Anita Quilumbaquí de la regional Yana Urco, y Fernando de la Torre de la regional Antonio Ante. Acuerdan que las regionales apoyen con recursos económicos para que realicen adecuadamente el trabajo de veeduría (Acta PPI, 14 de octubre de 2015).

En el año 2017, se nombra nuevos representantes de Comité Técnico de Seguimiento, esta vez uno por cantón: de Pedro Moncayo Roberto Robalino, de Cayambe Gonzalo Perugachi, de Otavalo Alberto Yánez, de Antonio Ante Alejandro Maldonado, e Ibarra Roberto Farinango. No son profesionales con conocimientos técnicos, pero si cuentan con amplia experiencia como dirigentes de comunidades y JAAP en sus respectivos cantones.

De parte de los GAD Municipales hay otros cinco representantes en el Comité, siendo a veces los gerentes de las empresas públicas de agua potable con conocimientos en hidráulica.

Las principales funciones que tienen son las de monitorear y realizar veedurías para que la empresa constructora cumpla el contrato de ejecución de obra (septiembre 2019). Para ello hacen seguimientos constantes a las planificaciones, cronogramas y ejecución de los trabajos en los diferentes componentes del proyecto. 
104

Además, deben informar al Consejo de Juntas y sus organizaciones sociales de base sobre los cumplimientos de sus actividades y lo relacionado con los avances y problemas que se dan durante la ejecución. Pueden solicitar documentos e información a la Unidad de Gerenciamiento todo lo relacionado con el proyecto.

Según Alberto Yánez (entrevista mayo 2019), el Consejo de Juntas que está en transición para llamarse Organización Pesillo-Imbabura, la Unidad de Gerenciamiento del Proyecto UGP-PI y el Comité Técnico de Seguimiento están en la misma jerarquía, ninguna está por debajo o por encima de otra.

Sin embargo, los miembros del Comité en representación de la organización no perciben ningún ingreso económico por la labor que desempeñan, no cuentan con recursos para movilizarse ni medios de transporte en una geografía tan amplia, por lo que solo dos del Comité realizan sus funciones y los otros se han ausentado. Estas son las principales limitaciones a las que se han enfrentado la organización y eso disminuye su participación en esta etapa del proyecto.

\section{La construcción de la infraestructura}

La construcción de la infraestructura del sistema de agua potable está a cargo de la empresa Hidalgo e Hidalgo, de la fiscalización la empresa Kunhwa Engineering \& Consulting Co. Ltd. Los avances y la fecha de culminación se han retrasado por falta de materiales, principalmente las tuberías que, dadas las dimensiones, fueron fabricados en Turquía.

El Comité Técnico realiza el seguimiento y veeduría en la etapa de construcción. Los representantes de las organizaciones informan de sus actividades y avances a los beneficiarios en los espacios que sean necesarios, aunque su labor está limitada por la falta de recursos económicos, logística y movilización. 
105

Los GAD Municipales, la empresa constructora como el Consejo de Juntas han mantenido permanente coordinación, pese a las dificultades de carácter organizativo de esta última, para verificar los avances de obras en sitio, las JAAP regionales han entrado constantemente (durante el año 2018) al embalse de la laguna San Marcos, el túnel y varios componentes que estaban en construcción para constatar los avances respectivos (Figura 21).

\section{Figura 21}

Dirigentes y usuarios de las regionales Tabacundo y Tupigachi en visita de campo (planta de tratamiento, noviembre 2018)

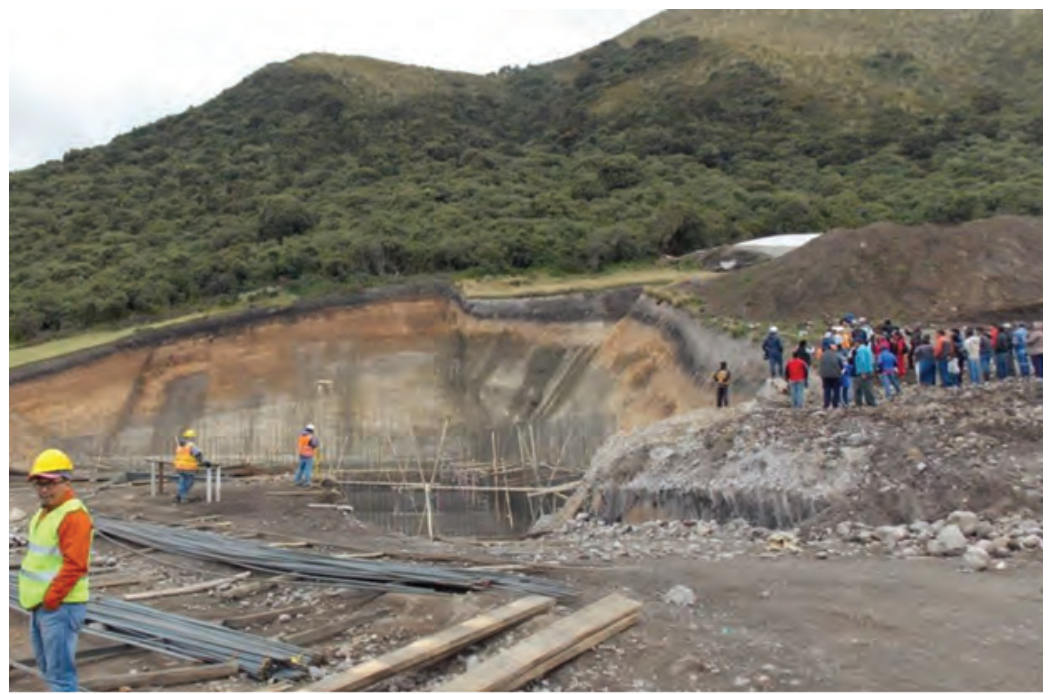

Fuente: Archivos PPI

El involucramiento de los dirigentes y futuros beneficiarios del PPI ejerce presión social a la empresa constructora, a las diferentes instituciones y a sus funcionarios, para que aceleren los trabajos y disponibilidad de los recursos (Figura 22). 


\section{6}

\section{Figura 22}

Autoridades, dirigentes y futuros usuarios verificando avances de obras en junio 2019

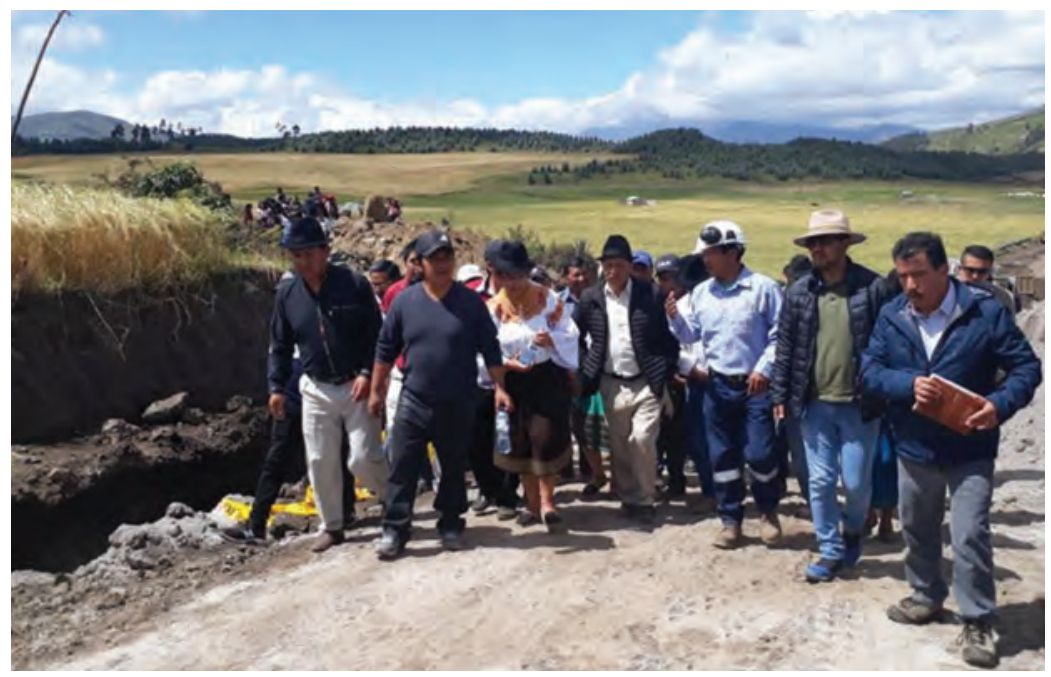

Fuente: Amadeo Casco

\section{Componentes del sistema de agua potable Pesillo-Imbabura}

Uno de los elementos de un sistema de agua potable es la infraestructura, misma que se divide en 5 componentes (Figura 23). 1) captación del embalse laguna San Marcos, 2) planta de tratamiento, 3) tanques de reserva, 4) líneas de conducción y transmisión, 5) automatización y sistema de control..$^{28}$ Como segundo elemento del sistema se consideró el modelo de gestión y manejo del sistema.

28 Los estudios definitivos que ACP consultores entregó en enero de 2014 estaban incompletos. Se rediseñó los pasos elevados en quebradas para bajar costos. Se rediseñó la planta de tratamiento. Se ha rediseñado los tanques de reserva porque las alturas no coincidían. La empresa Hidalgo e Hidalgo hizo una nueva topografía de toda la línea de conducción. A medida que hacen los trabajos también están arreglando los errores de diseño. 


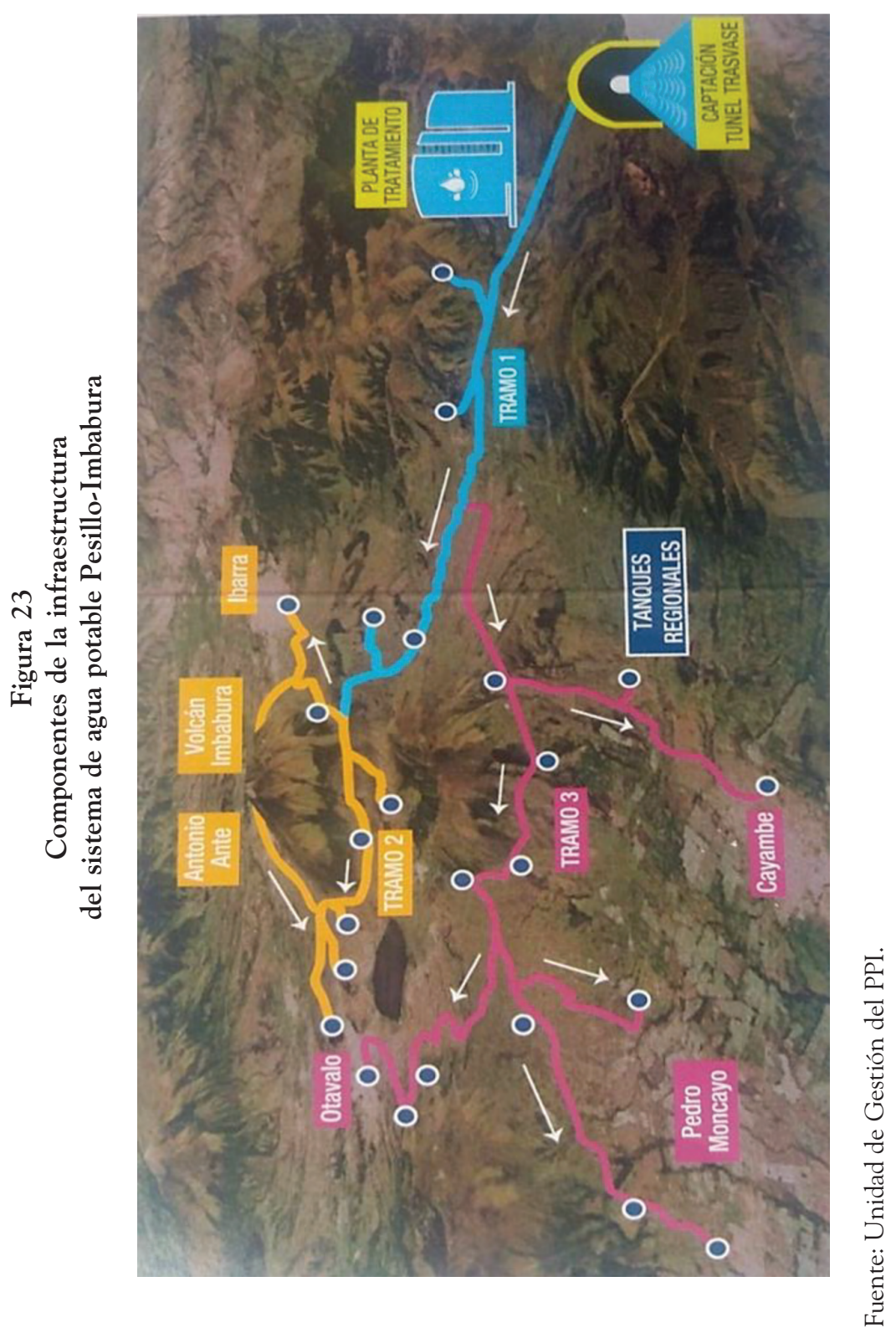




\section{8}

\section{Captación y embalse en la laguna San Marcos}

En la Laguna de San Marcos se construyó una presa de aproximadamente 679 metros de longitud y una altura de 20 metros con el propósito de embalsar el agua y poder captarla para los dos proyectos, canal de riego Cayambe-Pedro Moncayo y sistema de agua potable Pesillo-Imbabura. Se corta el curso natural de los ríos Arturo, Boquerón y San Pedro, ubicados atrás del nevado Cayambe que caen a la cuenca amazónica para conducirlos a la laguna. Se estima que la laguna de San Marcos tiene aproximadamente dos millones de metros cúbicos de agua y se espera que una vez embalsada el agua se almacene aproximadamente diez millones de metros cúbicos de agua, que abastecerá para los dos proyectos, riego y agua potable (Figura 24).

\section{Figura 24}

\section{Embalse de la Laguna San Marcos}

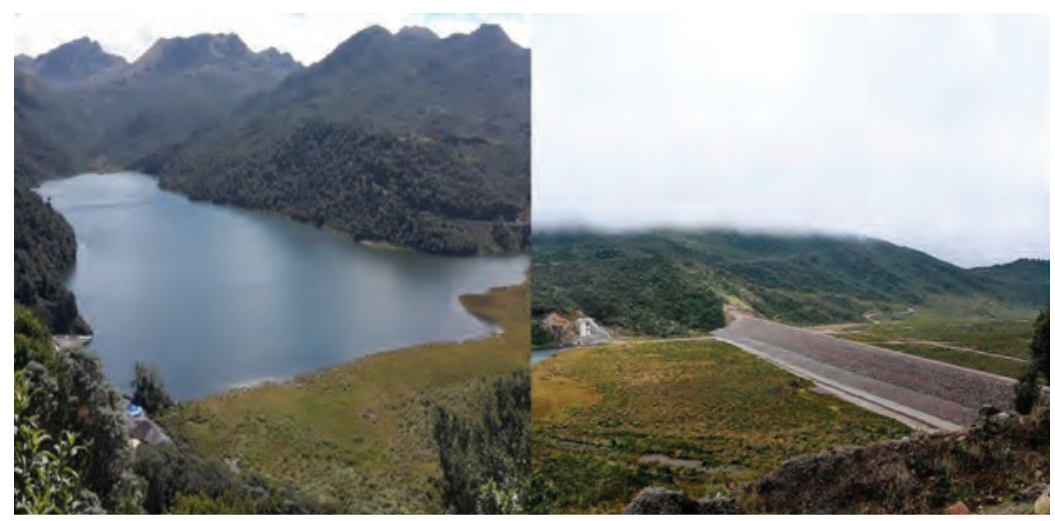

Fuente: Marcelo Quinteros Mena

Para que el agua llegue a los beneficiarios finales, se construye la captación de entrada al túnel de trasvase que tienen una longitud de $5 \mathrm{~km}$ que traslada el agua de la cuenca oriental a la cuenca del río La Chimba (Figura 25). 
109

Figura 25

Entrada del agua al túnel de trasvase en la laguna San Marcos, enero 2019

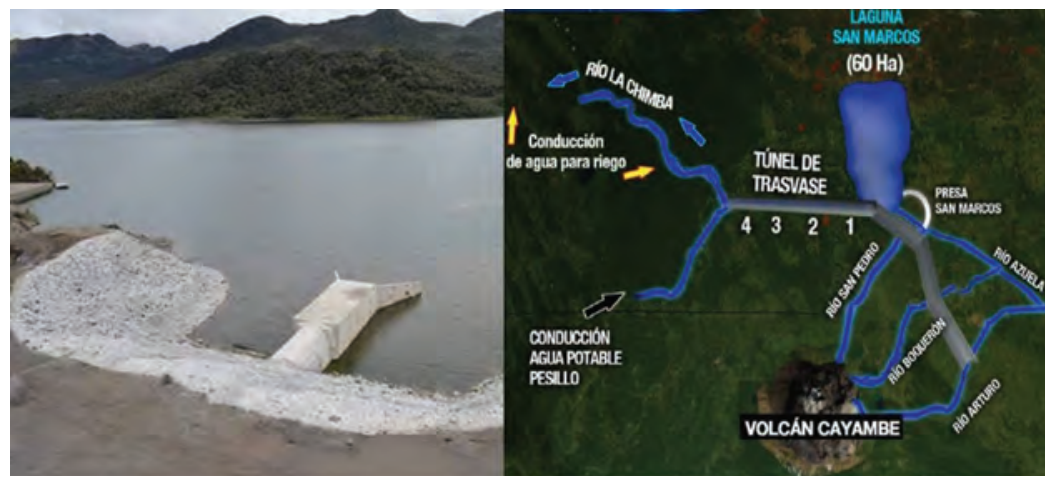

Fuente: GAD Pichincha

El proyecto de agua potable Pesillo-Imbabura inicia a la salida del túnel de trasvase de la laguna San Marcos (cantón Cayambe) cota (3402,85 m s. n. m.). En la salida del túnel está construido un repartidor de caudales para el canal de riego Cayambe-Pedro Moncayo y para el proyecto de agua potable Pesillo-Imbabura (Figura 26), que permitirá captar caudales en un rango de 540 l/s (año 2017) y 700 l/s (año 2032).

LÍNEA DE CONDUCCIÓN Y PLANTA POTABILIZADORA

El agua captada será transportada por la línea de conducción en una longitud de $800 \mathrm{~m}$, hasta la planta potabilizadora ubicada en la cota (3395 m s. n. m.). La planta potabilizadora prevista de tipo convencional (Floculación, Sedimentación-Filtración) tiene una capacidad máxima de tratamiento de $700 \mathrm{l} / \mathrm{s}$ (Figura 27). A la salida de la planta se construirá dos tanques de $5.000 \mathrm{~m} 3$ cada uno, a estos tanques se suman los 29 tanques de reserva (construidos con el proyecto), 24 de los cuales ya existen a lo largo del área de cobertura del proyecto. 
110

Figura 26

Repartidor de caudal a la salida del túnel cerca de Pesillo, (el de la izquierda para el PPI y el de la derecha para el canal de riego Cayambe-Pedro Moncayo)

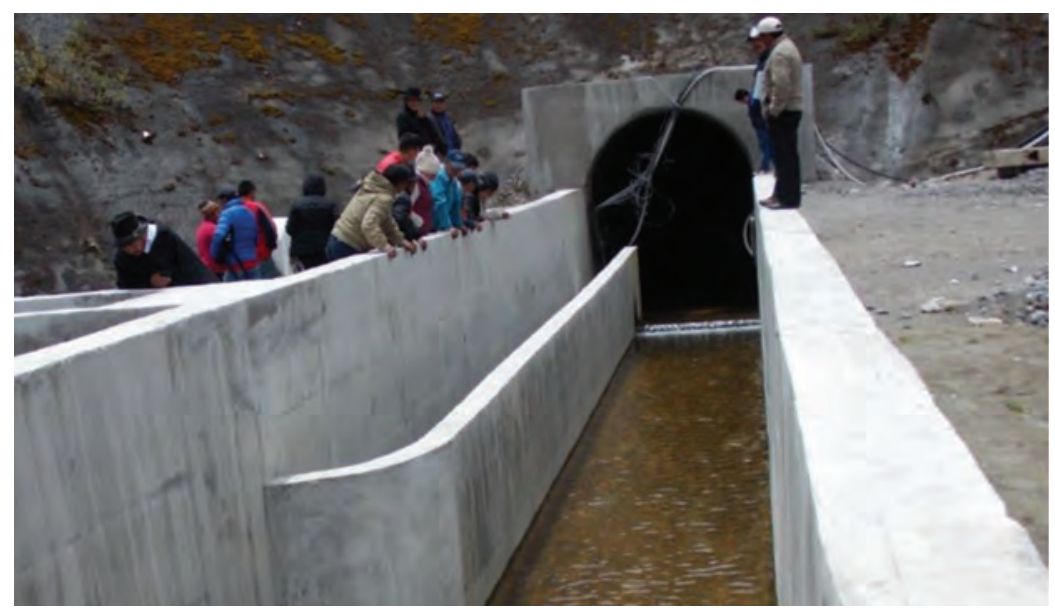

Fuente: José Manuel Perugachi

Figura 27

Planta de tratamiento, avances febrero 2019

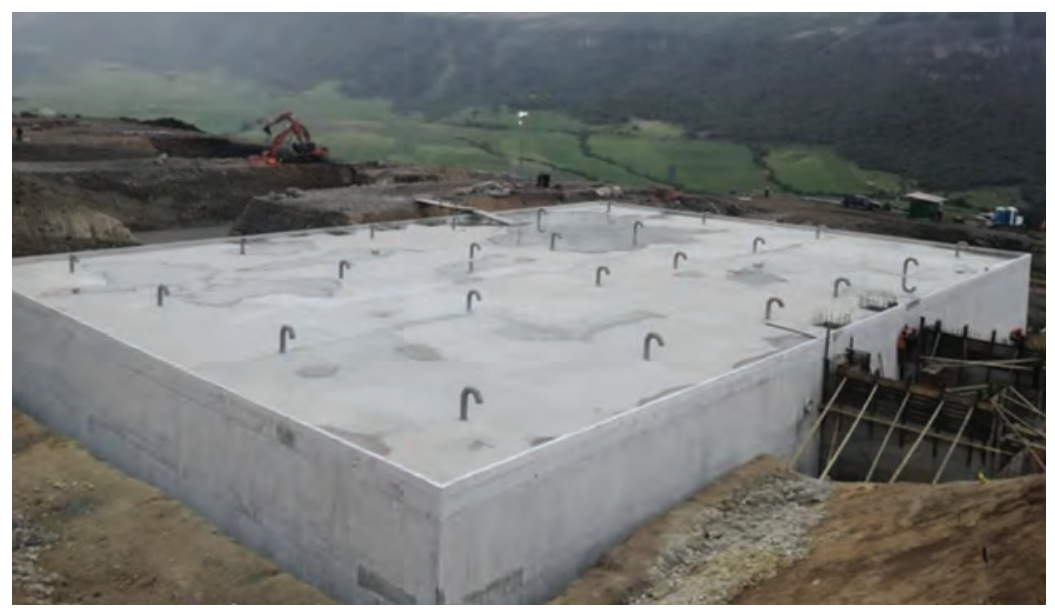

Fuente: Maritza Tocagón 


\section{LÍNEAS DE CONDUCCIÓN Y DISTRIBUCIÓN}

La tubería de distribución principal está diseñada en material de acero en una longitud de 96,7 km y 57,5 km en PVC, (que ya están instaladas) (Figura 28).

\section{Figura 28}

Avances de trabajos en la línea de conducción instalando tubería de acero por parte de la empresa Hidalgo e Hidalgo recibiendo visita de autoridades, dirigentes y usuarios, en junio de 2019

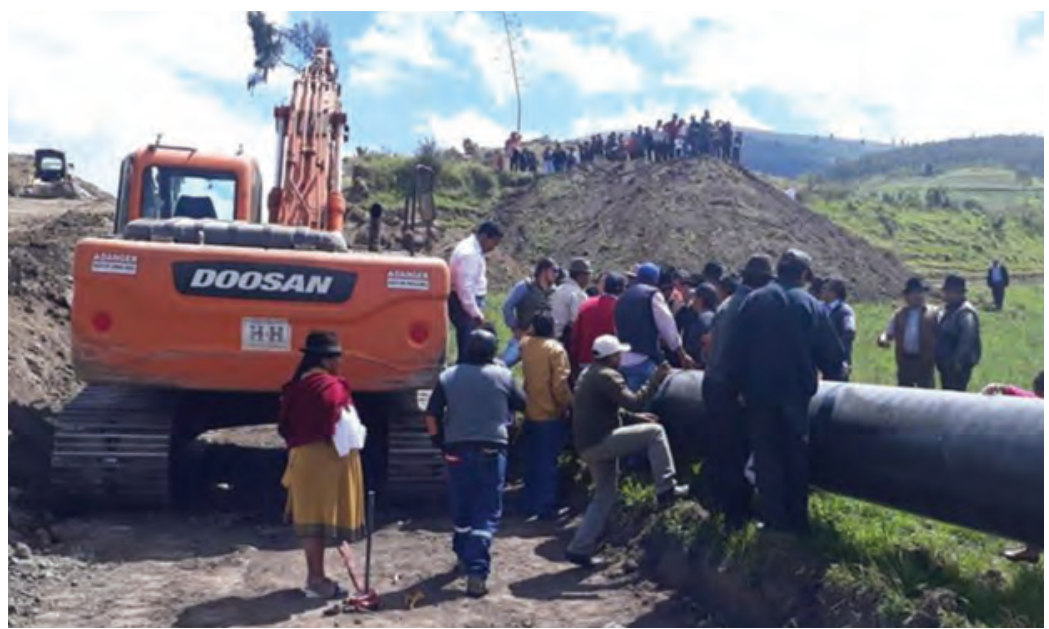

Fuente: Amadeo Casco

A partir de la planta de tratamiento, la tubería de distribución principal recorrerá un tramo de $10 \mathrm{~km}$ y se dividirá en dos ramales principales: el primero, desde la zona de Pesillo hacia el sur para conducir el agua a la parte de Cayambe y Pedro Moncayo, desde el sector de Cajas, límite provincial entre Pichincha e Imbabura, continua hacia el este, sirviendo a las comunidades de González Suárez, San Rafael, Eugenio Espejo y termina al sur de Otavalo; y el segundo va desde Pesillo hacia el norte para formar un anillo de distribución alrededor del cerro Imbabura que cubrirá parte de los cantones de Otavalo, Antonio Ante e Ibarra (Figura 29). 
Figura 29

Líneas de conducción y distribución de agua (en puntos rojos los tanques de almacenamientos y distribución de las regionales)

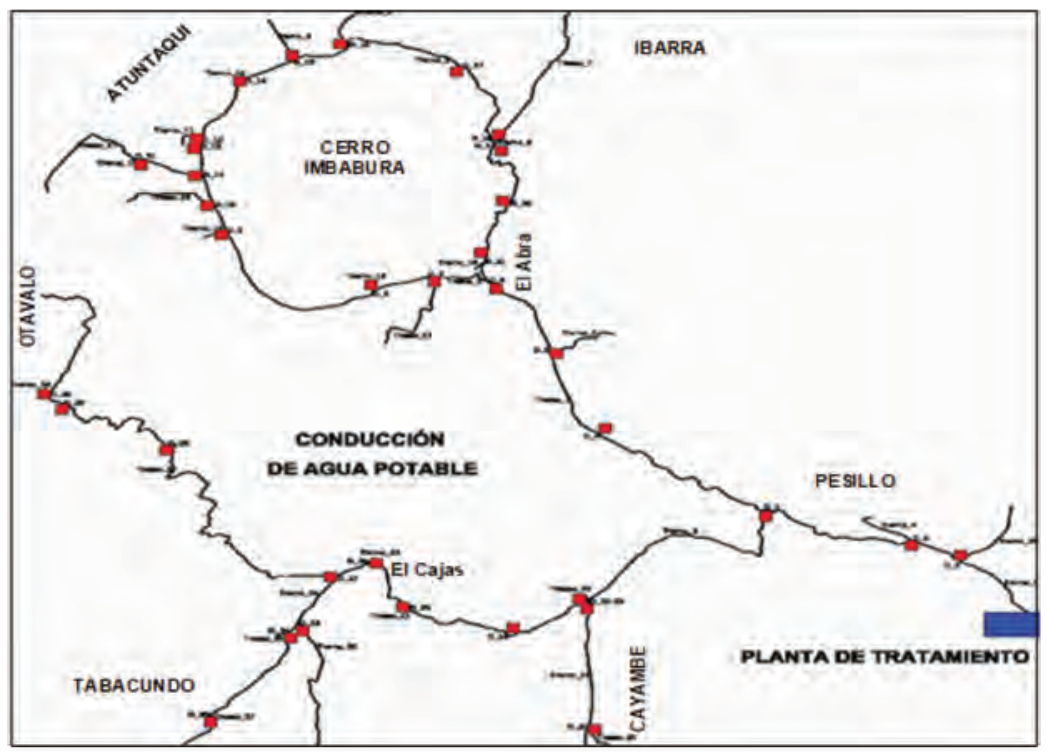

Fuente: Informes estudios tercera etapa 2014

\section{Beneficiarios del PPI}

El PPI abastecerá de agua potable a la población urbano marginal de los cantones de: Pedro Moncayo, Cayambe, Otavalo, Antonio Ante e Ibarra; la mayoría de las cabeceras parroquiales que están dentro del área o territorio del proyecto y a aproximadamente 164 comunidades rurales de los cinco cantones, cuyo servicio es prestado actualmente a través de 55 Juntas Administradoras de Agua Potable, distribuidas de la siguiente manera: Pedro Moncayo (14 JAAP), Cayambe (12 JAAP), Otavalo (16 JAAP), Antonio Ante (1 JAAP), Ibarra (12 JAAP).

Los beneficiarios del proyecto en la actualidad son usuarios de las juntas de agua potable comunitarias mismas que están agrupadas en las regionales que geográficamente se ubican por cantones y parroquias (Tabla 13). 
Tabla 13

Comunidades beneficiarias del PPI por cantón

\begin{tabular}{|c|c|c|}
\hline Cantones & Regional & Comunidades \\
\hline Cayambe & Pesillo & $\begin{array}{l}\text { Turucucho, Santa Rosa, Muyurco, La Chimba, San Pa- } \\
\text { blo Urco, Chaupi, Albas, Guayllabambilla, San Fran- } \\
\text { ciso, Molinos, Queseracucho, Arrayancucho, Pucará } \\
\text { Alto, Llanos de Alba, El Rosal Alto y Bajo, Panecillo, } \\
\text { Capas Alto y Bajo, San Antonio, Pesillo, Huagracielo, } \\
\text { Olmedo, Organizacion UNOPAC, San Francisco de } \\
\text { Cajas, Santa Monica, San Esteban, San Francisco de la } \\
\text { Compania, Santa Rosa de la Compania, Buena Espe- } \\
\text { ranza, San Miguel del Prado, Santa Lucia del Tejar, } \\
\text { Cadena, La Faccha, Mojandita, Miravalle. }\end{array}$ \\
\hline Pedro Moncayo & $\begin{array}{l}\text { Tupigachi y } \\
\text { Tabacundo }\end{array}$ & $\begin{array}{l}\text { Loma Gorda, Cajas Jurídica, San José Grande, San } \\
\text { Juan Loma, San José Alto, San Pablito de Agualongo, } \\
\text { Florencia, La Libertad, Chaupiloma, Nañoloma, Tupi- } \\
\text { gachi, Luis Freire. }\end{array}$ \\
\hline \multirow{9}{*}{ Otavalo } & Yana Urco & $\begin{array}{l}\text { San Agustin de Cajas, Eugenio Espejo de Cajas, Ma- } \\
\text { riscal Sucre, Asociación Atahualpa, Asociación Rumi- } \\
\text { ñahui, Asociación Apangoras, Caluquí, Pijal. }\end{array}$ \\
\hline & Moraswayco & Abatag, Gualaví, Cusinpamba \\
\hline & Angla & $\begin{array}{l}\text { Imbaburita, Cocha Loma, Casco Valenzuela, El Topo, } \\
\text { Primavera Uksha, Angla }\end{array}$ \\
\hline & Sumak Yaku & $\begin{array}{l}\text { Agato, Camuendo, Runasapi, Quinchuquí, Yacupata, } \\
\text { Arias Uco, Compania Alta, Compania Centro, Compa- } \\
\text { nia Baja, Pucará Alto, Pucará de Velasquez. }\end{array}$ \\
\hline & San Rafael & $\begin{array}{l}\text { Tocagón, Huaycopungo, Cachiviro, San Miguel Alto, } \\
\text { San Miguel Bajo, Cachimuel, Sanchez Pugro, Huaco- } \\
\text { pungo Chico, San Rafael, Cuatro Esquinas. }\end{array}$ \\
\hline & $\begin{array}{l}\text { Eugenio } \\
\text { Espejo }\end{array}$ & $\begin{array}{l}\text { Calpaquí, Chuchuquí, Cuaraburo, Puerto Alegre, } \\
\text { Eugenio Espejo, Rey Loma, Privarence. }\end{array}$ \\
\hline & La Bolsa & $\begin{array}{l}\text { Peguche, Faccha Llakta, Atahualpa, Provivienda, Obra- } \\
\text { je, La Bolsa, Guananci, Cotama, San Esteban. }\end{array}$ \\
\hline & Carabuela & $\begin{array}{l}\text { Sinsiuco, Cinco de marzo, Sigsichaca, Picuasi Pugro, } \\
\text { Carabuela Central, Jahuapamba }\end{array}$ \\
\hline & Ilumán & $\begin{array}{l}\text { Pinsaquí, Hualpo, Azares, Condor Mirador, San } \\
\text { Carlos, Ilumán Alto, Ilumán Bajo, Angelpamba, Ran- } \\
\text { cho Chico, Guabo, Santa Teresita, Rumilarka, San } \\
\text { Luis de Agualongo, Santo Domingo, Barrio Central, } \\
\text { Curillacta. }\end{array}$ \\
\hline
\end{tabular}


114

\begin{tabular}{|c|l|l|}
\hline Antonio Ante & $\begin{array}{l}\text { Antonio } \\
\text { Ante }\end{array}$ & $\begin{array}{l}\text { Pucará Bajo, Santa Isabel, La Esperanza, Cerotal, Los } \\
\text { Ovalos, Carmelo Alto, Agualongo de Paredes, Santa } \\
\text { Bernardita, Pucará de San Roque, Jatun Rumi, Nuevos } \\
\text { Horizontes. }\end{array}$ \\
\hline Ibarra & Ibarra & $\begin{array}{l}\text { Chilco, Cochas-La Merced, Zuleta, Angochahua, La } \\
\text { Rinconada, La Magdalena, Jurapango, Inga Tola, } \\
\text { Paniquindra, El Abra, Chirihuasi, Rumipamba Chico, } \\
\text { Rumipamba Grande, Cadena, Naranjito, San Crsi- } \\
\text { tobal, Florida, San Vicente, Chorlavisito, Compania } \\
\text { de Jesus, Pucahuayco, Punguhuayco, San Francisco } \\
\text { de Catzoloma, San José de Cacho, Santa Marianita, } \\
\text { Cashaloma, Santa Rosa, San Clemente, Manzanal, } \\
\text { Turupamba, Chapilan. }\end{array}$ \\
\hline
\end{tabular}

Fuente: Archivos PPI.

\section{La administración del proyecto Pesillo-Imbabuara}

A mayo-junio del 2019, las obras de infraestructura tenía un avance del $40 \%$, se presentan retrasos porque el acero para la tubería de los ramales principales se trae de España, se estimaba que todos los componentes del proyecto serán concluidas y entregados a finales de 2019, según (Álvaro Castillo, alcalde de Ibarra, 2019).

El conciliar una propuesta de manejar el PPI cuando existe una visión tecnocrática y centrada únicamente en la administración y no en la gestión y manejo del sistema en forma integral e intercultural (Figura 30), el Consejo de Juntas como organización logra al menos se considere su participación razón por la cual se piensa en una propuesta de realizar una alianza público comunitario.

Pero, por el peso de los municipios, por adquirir la deuda para financiar el proyecto, se creó la "empresa pública con participación comunitaria”, que es muy distinto a una alianza público comunitario. Las decisiones serán compartidas (gestión pública y gestión comunitaria a través de la Empresa) a nivel de la conducción principal y la distribución a las regionales; y a nivel de la infraestructura existente que es gestionada y manejada por las regionales de agua potable de las comunidades representadas por el Consejo de Juntas se mantiene la gestión comunitaria. 
Figura 30

Sistema de administración del PPI

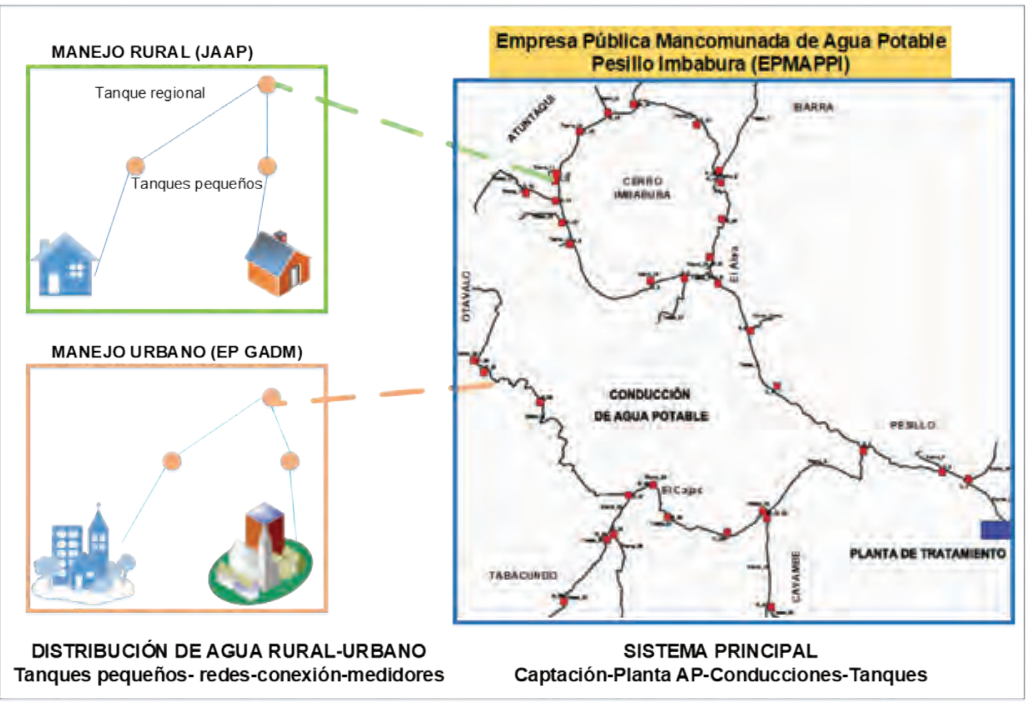

Fuente: UGP-PI

\section{El modelo de gestión para la administración del sistema de agua potable}

Como parte de los acuerdos para desarrollar el modelo de gestión para la administración y operación del sistema de agua potable Pesillo-Imbabura, la mancomunidad creará la Empresa Pública de Agua Potable Pesillo-Imbabura con participación comunitaria, el directorio estará integrado por 5 miembros (2 GADM, 2 JAAP, 1 presidente de la Mancomunidad).

También firmarán acuerdos los GAD Municipales y las Juntas Administradoras de Agua Potable, tendientes al fortalecimiento técnico y operativo de las JAAP. Para ello, en el marco de la Ley Orgánica de Recursos Hídricos, Usos y Aprovechamiento del Agua, y su reglamento, se establecerán los alcances, plazos y recursos necesarios para alcanzar las metas propuestas. 
De conformidad con la Ley Orgánica de Recursos Hídricos y el Código Orgánico de Organización Territorial, Autonomía y Descentralización (COOTAD), acuerdan que las tarifas deberán asegurar la sostenibilidad de los servicios de agua potable y saneamiento, de tal manera que se cubran como mínimo los costos de administración, operación, mantenimiento y reposición de los equipos. Durante el año 2019, se debía definir el modelo de gestión a través de una consultoría, para definir las tarifas a implementarse por el servicio de agua (asunto que también está retrasado).

Los ramales principales hasta los tanques de reserva y distribución serán administrados por la Empresa Pública. Se construirán redes secundarias que conectarán los tanques regionales con los tanques comunitarios y luego redes que llega a los usuarios finales, que serán administradas por las comunidades (gestión comunitaria).

Durante el 2019 debía elaborarse estudios y obras para realizar las conexiones desde los ramales principales del proyecto hacia los tanques regionales, en algunos sectores estos trabajos de conexión pueden demorarse hasta el año 2020.

\section{La toma de decisiones en la administración del sistema de agua}

El modelo de la gestión y administración tiene inconformes a los dirigentes de la organización que ideó el proyecto, así como a sus beneficiarios. Ya que el sueño era que las comunidades administren todos los componentes que conforman el sistema: desde la salida del túnel, los tanques de tratamiento y almacenamiento, y las redes de conducción. Pero el acuerdo firmado en el año 2015 deja en un plano secundario a la organización pese a que esta fue la principal protagonista por más de veinte años en la lucha por el agua.

Lo que explica Juan Serrano (2018), es que para ejecutar e implementar el proyecto, los otros actores presionaron para imponer un modelo de acuerdo con sus visiones e intereses, pero desplazando los 
sueños y visiones de gestión del agua que han ejercido las comunidades, y que pensaban poner en práctica en un proyecto de tal magnitud.

Si no aceptaban dicha propuesta, tampoco entregaban los recursos para la ejecución e inicio de obras, por el miedo de quedar nuevamente sin agua, aceptaron y firmaron el acuerdo de participación público-comunitario que crea la empresa pública con participación comunitaria para la gestión del agua.

Desde la visión de lo público, la gestión y manejo del agua que realizan las comunidades es menospreciada o catalogada de segundo orden, se cree que la gestión y manejo se lo realiza de forma intuitiva y de corazón, dejando un lado los procesos técnicos y científicos, por eso para la gestión y administración acordaron crear la empresa pública, para supuestamente dar un enfoque técnico. Para ser incluyentes e interculturales se incluye a representantes de la organización, es decir, un premio consuelo.

Es verdad que hay debilidades en la gestión comunitaria por los escases de recursos económicos, el mal estado de los sistemas de agua y la calidad de agua; pero también hay profesionales que pueden conjugar los conocimientos técnicos-científicos con la experiencia empírica-organizativa. Por eso la mayoría de las personas, si antes sentían que el proyecto era de los comuneros (de nosotros), de todos los que empujaron su proceso, ahora sienten que no es, ni será de (nosotros). Mientras la mayoría de los beneficiarios son poblaciones de las comunidades, los que administren y tomen las decisiones serán los personeros de la empresa pública ajenas a los usuarios del agua de las comunidades.

No obstante, Juan Serrano ha señalado que se debe luchar para que la ahora empresa pública sea comunitaria, en el sentido que las comunidades tengan presencia con su visión en el manejo del agua dentro de la empresa y que las autoridades impongan una visión de gestión y manejo del agua en donde prime la rentabilidad financiera del proyecto. 
118

El modelo de gestión y manejo del sistema es un reto que las comunidades y JAAP tienen que trabajar a futuro y que las alianzas público-comunitario en cada cantón sea en igualdad de condiciones, que incluso la gestión comunitaria tiene potencialidades que otros pueden aprender para implementar en las localidades urbanas. Es decir, después de que se concluya las obras e inicie a brindar el servicio, el gran reto es la gestión y administración del sistema de agua con sus componentes. Reto que invita a otra minga de ideas y compromisos de la mayoría, ya que la organización en un proyecto tan grande presenta debilidades y necesita coordinar y tomar decisiones acertadas para el futuro.

Finalmente, Alberto Yánez miembro de la Comité Técnico de Seguimiento sostiene que las obras están retrasadas, por lo que no podrán terminar en el plazo señalado (septiembre 2019), y que necesariamente se deberá otorgar una ampliación del plazo para unos seis meses más, es decir, las obras podrían concluirse durante el primer trimestre del año 2020. Mientras tanto se debe seguir dialogando sobre el modelo de gestión. 


\section{Capítulo III La gestión comunitaria del agua, garantía para su acceso, control, distribución y uso eficiente en las comunidades indígenas}

El ejercicio pleno del derecho humano al acceso al agua enfrenta limitaciones políticas, técnicas y organizativas, especialmente en las zonas rurales y periurbanos (Foro de los Recursos Hídricos, 2015). Por eso la mayoría de las soluciones para acceder al agua en las comunidades son iniciativas locales que en base a su constancia y con el apoyo de instituciones públicas y privadas construyen sistemas de agua entuba$\mathrm{da}$, cuyas fuentes pueden o no encontrarse en sus territorios.

Los proyectos en territorios comunitarios se construyen de forma comunitaria, con la participación de los potenciales beneficiarios, inician generalmente con mingas de ideas que solucionen sus problemas, para que estos sean factibles las organizaciones buscan el acompañamiento técnico de instituciones que compartan sus visiones e intereses. Los proyectos son presentados a las instituciones representantes del Estado según sus competencias para que sean evaluadas su factibilidad, pero muchas veces estas instituciones tienen limitaciones técnicas y económicas, por lo que las comunidades también invierten recursos económicos contratando profesionales para realizar estudios técnicos preliminares y/o definitivos, como aconteció con las comunidades del Consejo de Juntas. 


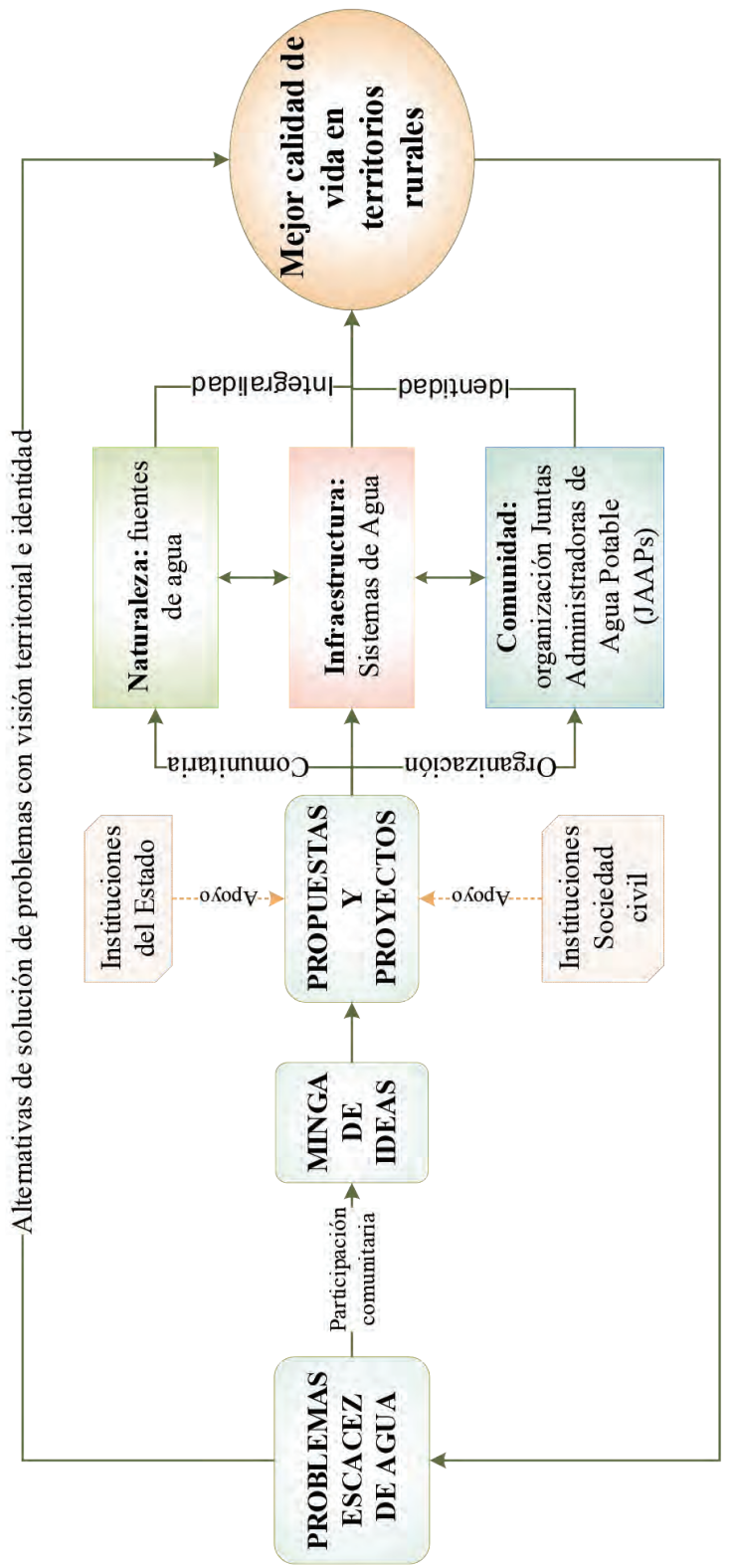


Según Cachipuendo (2017), cuando se analiza un proyecto, las comunidades no solo piensan en la infraestructura física, sino también de dónde viene el agua y cómo la organización va manejarla, así, se consideran a un sistema con una visión de integralidad donde existen relaciones entre la naturaleza, la comunidad y la infraestructura física como tal, razón por la cual las necesidades de abastecimiento de agua obliga a las comunidades proponer proyectos que según sus dinámicas solucionen sus problemas de forma sostenible en el tiempo (Figura 31).

En la fase de ejecución de proyectos, los futuros usuarios también aportan dinero, colaboran con materiales y participan en mingas. Cuando los sistemas de agua están en operación participan en la gestión, administración, vigilancia, control social y veedurías comunitarias de tal forma que se garantice el acceso al agua a todos sus comuneros. Los grupos vulnerables adultos mayores y/o madres solteras, personas con capacidades especiales se benefician con tarifas especiales; es decir, tienen derechos y obligaciones a lo largo de sus vidas, de esta manera se practica la solidaridad, principio fundamental de la gestión comunitaria del agua.

Una de las actividades importantes del Consejo de Juntas fue que involucró en el proyecto de consecución del PPI planes de gestión ambiental en las zonas de captación del agua. Por lo tanto, existe una intervención social en el territorio a través de mingas para minimizar los impactos de las sequias. Así, el agua, como un elemento dinámico circula a través del ciclo hidro-social, mediante una compleja red de infraestructura que capta el agua luego es conducida y distribuida en los diferentes sectores beneficiarios, es decir, para acceder al agua se requiere una relación entre la naturaleza y la acción social (Perreault, 2015).

La comunidad contribuye a mejorar sus condiciones de vida cuando acceden al agua, y últimamente también son encargadas de la disposición final de las aguas residuales "saneamiento", acciones que son gestionadas y manejadas por las organizaciones basadas en 
122

la participación desde su construcción, por lo que la comunidad se encuentra comprometida en su funcionamiento y administración (Bastidas \& García, 2002).

Las prácticas implementadas por las organizaciones comunitarias para acceder, controlar, distribuir y usar el agua se fundamentan en la participación de todo/as, en la capacidad de diálogo al interno y al externo de la organización, manteniendo una visión territorial y de interculturalidad. En este sentido, sí, la gestión comunitaria del agua garantiza el acceso al agua a todos/as, también está la organización en la capacidad de ejercer sus derechos, mantener una visión territorial, construcción de un tejido social, en la puesta en práctica principios de gobernanza y gobernabilidad con identidad según las realidades locales.

\section{El derecho al agua y la organización comunitaria}

A finales del 2015 fueron aprobados los Objetivos de Desarrollo Sostenible por parte de las Naciones Unidas, mismos que cada país que firma el acuerdo debe cumplirlos hasta el año 2030. El objetivo 6 agua limpia y saneamiento, pretende "garantizar la disponibilidad de agua y su gestión sostenible y el saneamiento para todos", pese de existir estos postulados a nivel global no necesariamente garantizan el acceso universal al agua, y no existe una organización internacional que afronte los desafíos que supone la gestión eficiente del agua y del medio ambiente (Hortelano Villanueva, \& Hidalgo García, 2016).

El Consejo de Juntas para exigir al Estado el financiamiento del PPI se respalda en la Constitución del 2008 que plantea algunos postulados para garantizar el derecho al agua. Así, en el artículo 3, se estableció como el primer deber primordial del Estado: "Garantizar sin discriminación alguna el efectivo goce de los derechos establecidos en la Constitución y en los instrumentos internacionales, en particular la educación, la salud, la alimentación, la seguridad social y el agua para sus habitantes". Mientras que el artículo 12 determina que "el derecho humano al agua es fundamental e irrenunciable. El 
agua constituye patrimonio nacional estratégico de uso público, inalienable, imprescriptible, inembargable y esencial para la vida". Para la gestión y manejo del agua en el artículo 411 manifiesta que:

El Estado garantizará la conservación, recuperación y manejo integral de los recursos hídricos, cuencas hidrográficas y caudales ecológicos asociados al ciclo hidrológico. Se regulará toda actividad que pueda afectar la calidad y cantidad de agua, y el equilibrio de los ecosistemas, en especial en las fuentes y zonas de recarga de agua.

Las comunidades andinas para acceder al agua implementan sistemas de gestión y manejo del agua según sus dinámicas socio culturales y ambientales, y por sus constantes reclamos logran que en la Constitución del 2008 se reconozca sus formas de gestión, así en el artículo 318 manifiesta:

El agua es patrimonio nacional estratégico de uso público, dominio inalienable e imprescriptible del Estado, y constituye un elemento vital para la naturaleza y para la existencia de los seres humanos.... La gestión del agua será exclusivamente pública o comunitaria. El servicio público de saneamiento, el abastecimiento de agua potable y el riego serán prestados únicamente por personas jurídicas estatales o comunitarias. (Constitución, 2008)

Para operativizar los postulados de la Constitución, en el Código Orgánico de Organización Territorial, Autonomía y Descentralización (COOTAD), la competencia para dotar de agua segura recae a los gobiernos municipales como lo manifiesta el artículo 137:

Los gobiernos autónomos descentralizados municipales planificarán y operarán la gestión integral del servicio público de agua potable en sus respectivos territorios, y coordinarán con los gobiernos autónomos descentralizados regional y provincial el mantenimiento de las cuencas hidrográficas que proveen el agua para consumo humano.

Pero desde décadas pasadas, dada la debilidad del Estado y los gobiernos municipales, no atiende las necesidades de las comunidades andinas y en particular a las filiales del Consejo de Juntas, por lo que los comuneros se organizan y generan alternativas que al menos permiten 
124

acceder al agua entubada. Entonces se debe entender a las organizaciones comunitarias como entidades que buscan resolver problemas que afectan a su población, desarrollando iniciativas en constante relación con su espacio territorial. Esto exige que la participación sea permanente y exista una articulación con los diversos actores bajo lazos de confianza, reciprocidad, cooperación y armonía, principios fundamentales del Buen Vivir y aplicados en la gestión comunitaria del agua.

Las JAAP además de ser entidades constituidas jurídicamente y en algunos casos únicamente legítimas, son organizaciones comunitarias que buscan dotar de agua a todo/as los miembros de la comunidad, enfrentando así, la marginación de las entidades del Estado quienes tienen estas competencias. Estos procesos organizativos a nivel de comunidad trascienden en las instituciones públicas cuando el problema no es únicamente en una comunidad, sino que se extiende a territorios más amplios como el caso del PPI, por lo que es necesario la existencia de procesos organizativos intracomunitarios como intercomunitarios, este tipo de organización tiene mayor poder de reclamar sus derechos, y poder impulsar y exigir al Estado la concreción de proyectos regionales que doten de agua a sus pobladores.

La participación de los miembros de la organización exige al Estado cumplir con sus roles permitiendo plasmar la ejecución de los proyectos como es el caso del PPI, donde se lo realizó de forma conjunta. Así, las organizaciones comunitarias se dan a conocer ante las diferentes instituciones como actores fundamentales que tienen intereses y demandas comunes, convirtiendo sus formas de actuación comunitaria en procesos con cierta autonomía y articulan con otros actores sociales y de las instituciones públicas, en búsqueda del bienestar de su población (Bastidas \& García, 2002).

En la década de 1990 era difícil pensar en una articulación inter cantonal e interprovincial de las organizaciones comunitarias. Los únicos ejemplos hasta ese entonces fueron el de las comunidades y unión de comunidades indígenas agrupados en la Federación Indígena y Campesina de Imbabura, cumpliendo importantes jornadas de lucha por los derechos colectivos y el acceso a la tierra. 
$\mathrm{Al}$ ser el agua un elemento que no reconoce fronteras, la articulación entre las JAAP comunitarias se convierte en un sistema organizativo que genera poder, en muchas ocasiones sirve como bandera de lucha del movimiento indígena y sectores rurales, enfocándose principalmente en reclamar el derecho de acceder al agua. En este proceso prevalece la participación y articulación entre los actores mediante el diálogo, los lazos de confianza, la reciprocidad, la armonía y la cooperación en sus reclamos; así, a partir de las organizaciones comunitarias de base se construyó un símbolo social llamado Consejo de Juntas que impulsó la construcción del Proyecto de Agua Potable Pesillo-Imbabura.

En función de objetivos comunes y principios comunitarios, la unidad de las organizaciones comunitarias ha permitido que los límites geográficos comunales, parroquiales, cantonales y provinciales no tengan importancia en la consecución de acuerdos. El PPI es resultado de procesos que se han construido a lo largo de años, logrando unir y reunir miles de personas de diferentes comunidades y centros poblados, dejando de un lado las visiones políticas o intereses personales, un proceso de reconocimiento de sus problemas y potencialidades, que bien se puede llamar interculturalidad, porque las diferentes instituciones públicas, privadas y de la sociedad civil se involucran y aportan en la ejecución de proyecto (Figura 32).

Los intereses y realidades entre los beneficiarios del proyecto: juntas comunitarias, regionales y empresa pública, midió la capacidad de negociación y llegar a acuerdos para lograr la ejecución de la infraestructura, quedando aun el análisis del modelo de gestión y manejo del sistema. Pese a los problemas y diferencias, así como los disensos en el camino transitado desde los inicios del proyecto, a decir de Bastidas y García (2002), lo que mantiene a las organizaciones unidas es el propósito de acceder al agua sin perder el horizonte ni las esperanzas. 
126

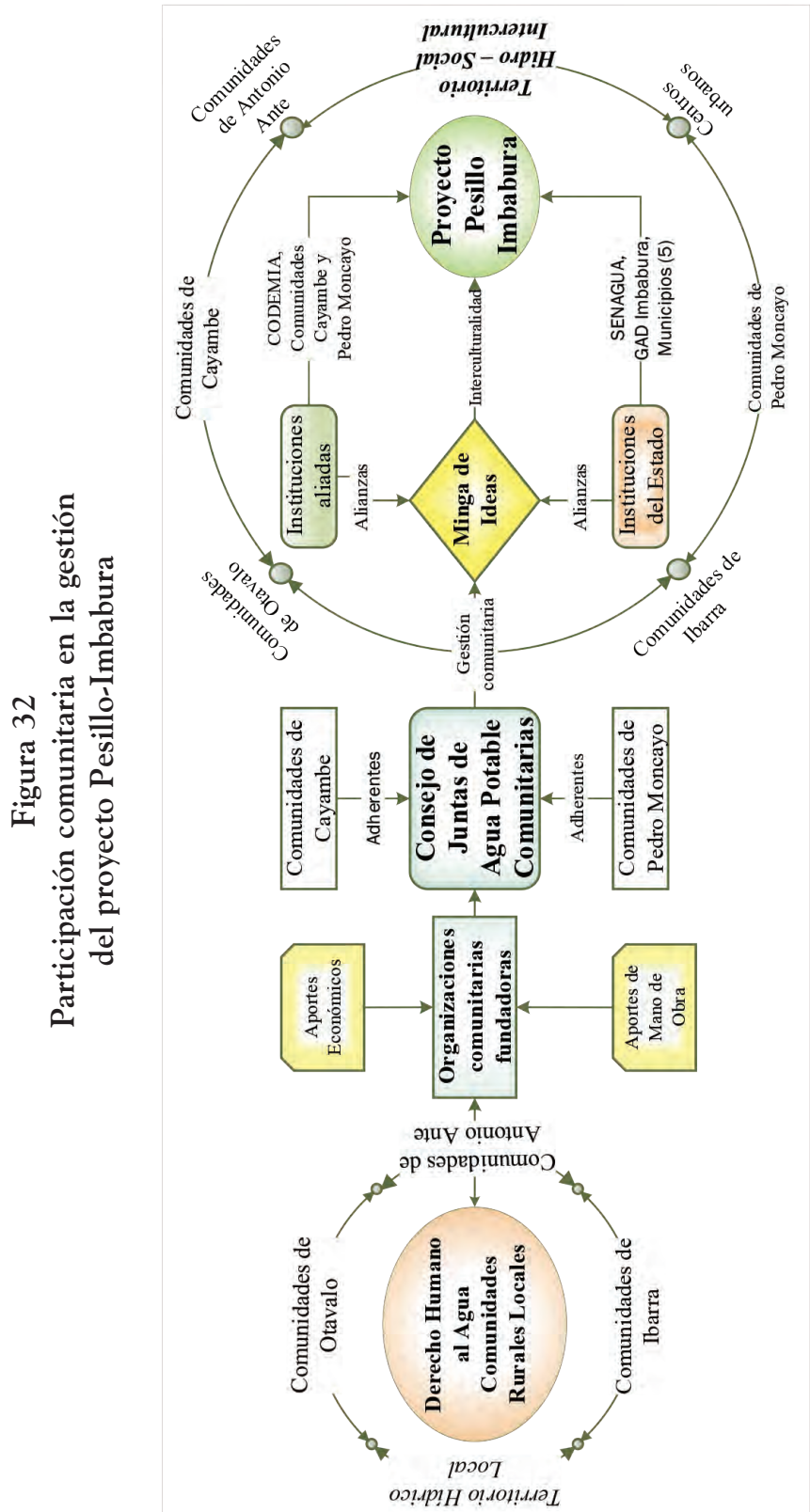


La participación comunitaria en las asambleas y reuniones de trabajo sirven para evidenciar las realidades en las diferentes comunidades y JAAP. Los problemas comunes en vez de distanciarlos los han unido, prácticas de diálogo que permiten llegar a consensos superando las diferencias entre comunidades y pueblos indígenas: Kayambis, Karankis, Otavalos, Natabuelas y pueblo mestizo. Estos espacios de diálogo enfocados en la ejecución del proyecto se convierten en escenarios que fomentan la interculturalidad y los principios de acción colectiva y comunitaria.

Los beneficiarios del PPI se encuentran agrupados en diversas organizaciones de gestión y manejo de los sistemas de agua de consumo humano: 1) empresas públicas, 2) organizaciones colectivas y 3) organizaciones comunitarias. Cada una de estas organizaciones se encuentra dentro de la Ley de Recursos Hídricos, y tienen sus propias características. Sin embargo, a nivel nacional se puede identificar un cuarto tipo de organización, la privada como es el caso de Interaguas de Guayaquil (Figura 33).

Desde la legalidad, las organizaciones colectivas y comunitarias son reconocidas como Juntas de Administradoras de Agua, pero existen diferencias entre estas por el tipo de gestión y manejo del sistema.

Las organizaciones comunitarias de gestión y manejo de agua de consumo humano, se estructuran mediante una JAAP o a través del gobierno comunitario; sin embargo, cualesquiera que sean estas, tienen como característica que sus usuarios viven en un sistema comunitario, en donde se practican principios y valores de la cosmovisión indígena andina como: la toma de decisiones comunitarias en "asambleas", aportes de mano de obra mediante las "mingas", aportes económicos denominados "tarifas" y relación de armonía con la naturaleza (cuidado de las fuentes de agua). Existe un proceso democrático para elegir a sus dignatarios (dirigentes), y la exigencia de rendición de cuentas de gestión y administración financiera a los dignatarios de turno son prácticas generalizadas en este tipo de organizaciones. 


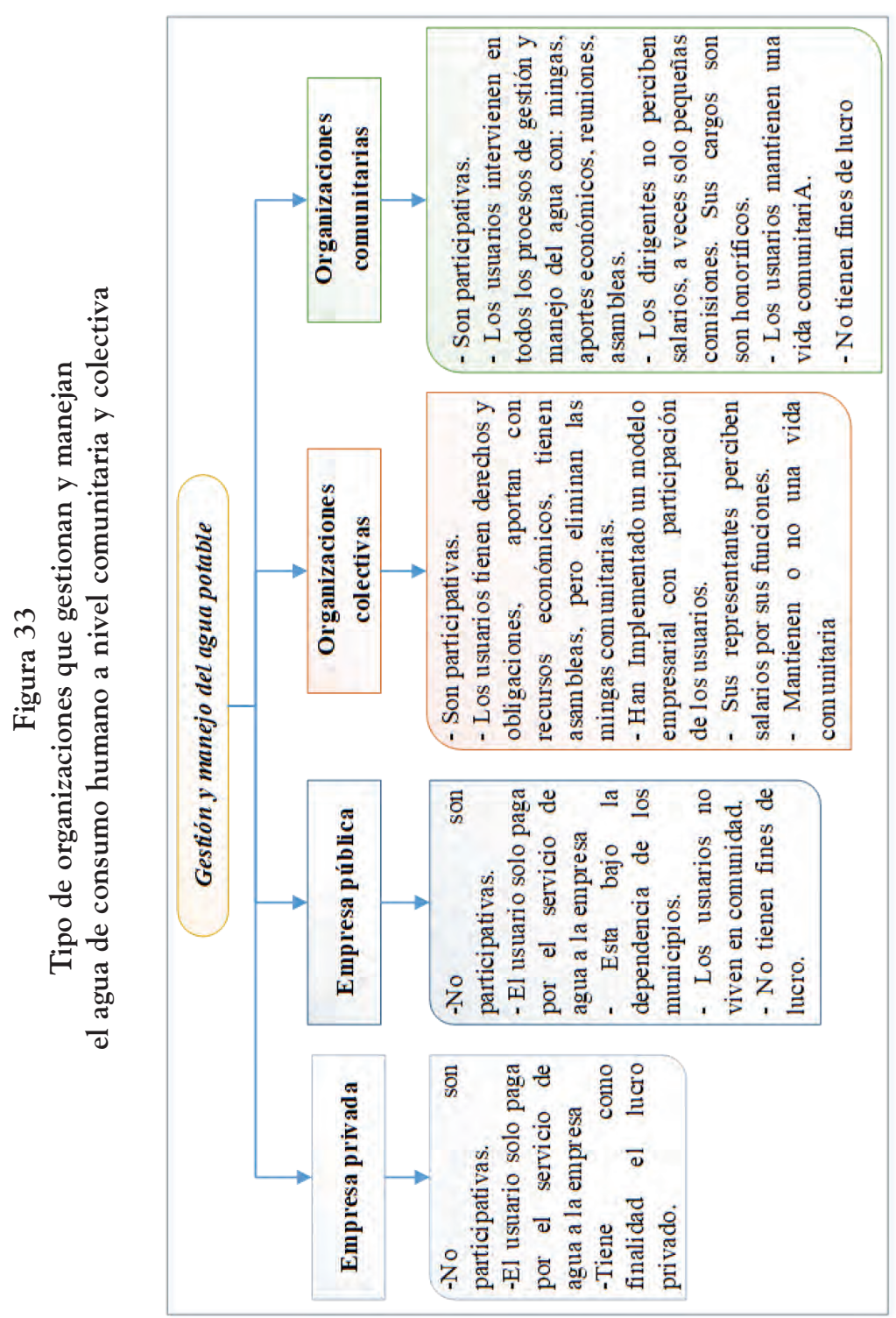


Las organizaciones colectivas, este tipo de organizaciones se encuentran en las cabeceras parroquiales (centros poblados), su gestión y manejo se lo realiza a través de la JAAP, cuya visión es como una empresa de prestación del servicio, se practica la elección de sus representantes de manera democrática, se realizan asambleas para la rendición de cuentas, pero tienen trabajadores por lo que las mingas comunitarias no son usuales.

Las empresas públicas, generalmente prestan el servicio a las cabeceras cantonales y son adscritas a los Gobiernos Autónomos Descentralizados Municipales, no existe participación de los usuarios en la gestión y/o manejo del agua, sus representantes son delegados por los gobiernos municipales de turno, y mantienen una representación de los usuarios como veedores.

Las empresas privadas, pese que en la Constitución prohíbe la privatización del agua, existe en el país una delegación del GAD Municipal a la empresa privada para que esta se encargue de la gestión y manejo del agua, este tipo de organización busca la rentabilidad financiera, lo que provoca que la dotación de agua se realice únicamente a sectores que les va a ser rentables.

A modo de reflexión podemos decir que las organizaciones comunitarias (comunidades y JAAP) son el motor del movimiento social en la lucha por el derecho al agua. Estas sostienen al Consejo de Coordinación de Juntas Administradoras de Agua Potable del Proyecto Regional Pesillo-Imbabura que se ha convertido en una organización con incidencia regional y nacional, articulándose además con otras organizaciones que persiguen los mismos objetivos. Es claro que, sin organizaciones comunitarias de base, la lucha por el agua sería débil y desarticulada, siendo a lo mucho como en décadas pasadas reclamos locales, coyunturales y de contenidos particulares. De ahí la importancia de las JAAP regionales, como organizaciones con una visión comunitaria e intercultural que logra la concreción del $\mathrm{PPI}^{29}$ (Figura 34).

29 Como se indicó en la presentación, los trabajos en estos momentos están estancados. Si se retoman los trabajos y se concluyen las obras, será un triunfo de las comunidades y JAAP organizadas. 
Figura 34

Asociatividad de organizaciones de base para conformar una organización de segundo nivel o grado

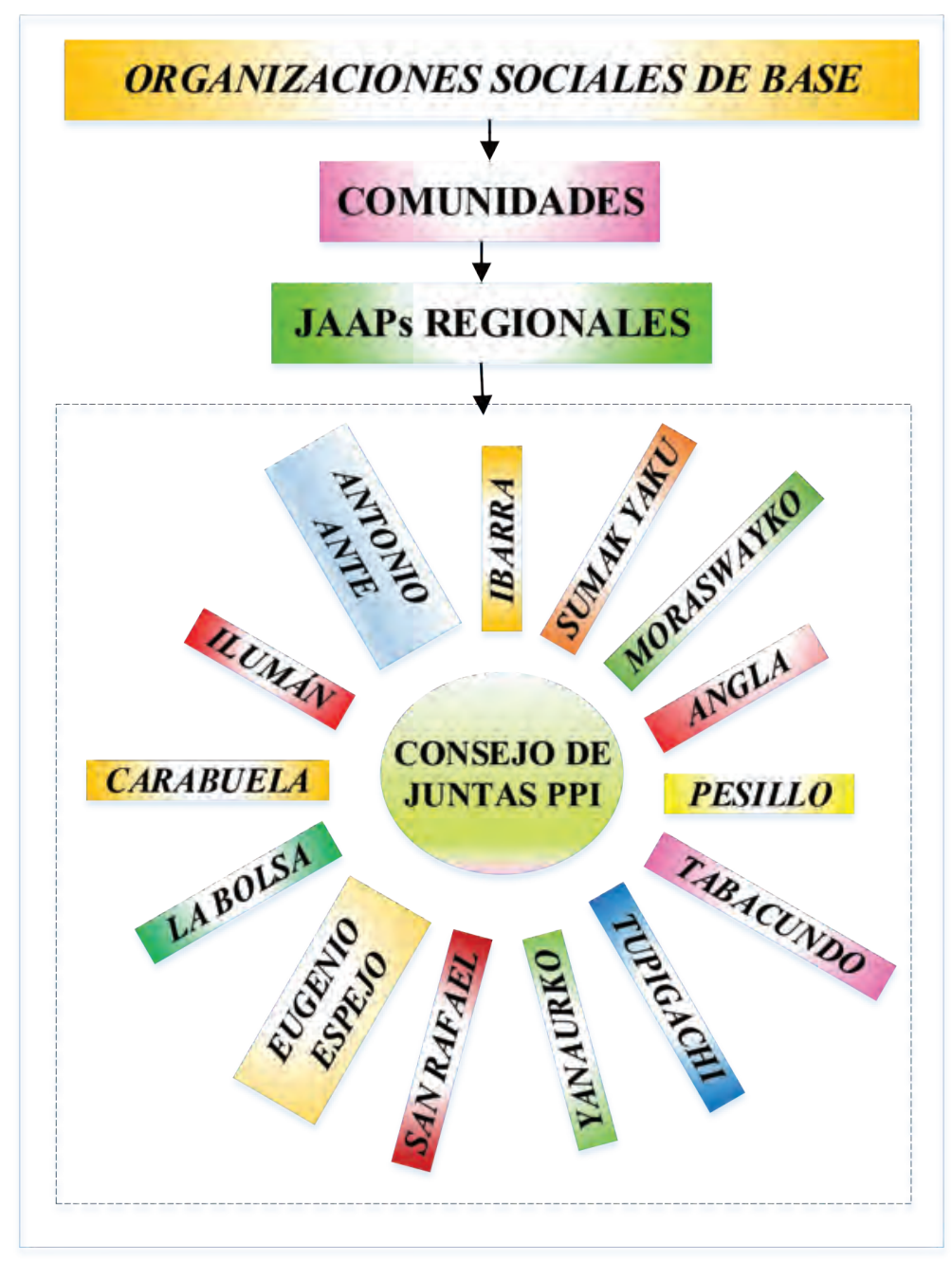




\section{La cultura organizacional comunitaria para la gestión y manejo del agua}

El acceso al agua es esencial para la concreción de los derechos humanos, es parte del derecho a la vida, debiendo los Estados invertir y proporcionar los recursos económicos necesarios para dotar del servicio del agua o la delegación a las organizaciones comunitarias. En la actualidad, a partir el decreto del 2017 se reconoce que las organizaciones comunitarias pueden gestionar y manejar el sistema de agua potable en los territorios. Cuando esto no sucede las comunidades se organizan para exigir su cumplimiento, siendo la capacidad organizativa el único recurso con el que cuentan las comunidades.

Las limitaciones económicas, la falta de voluntad de los gobiernos locales y las autoridades seccionales han hecho que, los sectores marginados deban organizarse, siendo la principal estrategia y herramienta del que disponen para hacerse escuchar. La organización en el marco de la solidaridad y la unidad, de intereses y demandas comunes han llevado a actuar de manera colectiva (Bastidas \& García, 2002). La organización tradicionalmente ejerce sus acciones en la Llakta $^{30}$ o comunidad, pero en proyectos de amplia cobertura son organizaciones donde es difícil el homogenizar las acciones de gestión y manejo por un sentimiento de apropiación, esto en ocasiones provocan conflictos.

Esta forma de organización comunitaria sirvió para defenderse de los abusos de los colonizadores ibéricos, de los hacendados y otras formas de explotación en los siglos XIX y XX. En la actualidad, es un nicho de poder local que articula sus acciones para dar alternativas ante un sistema político y económico capitalista predominante. Además de ser espacios de resistencia, se reproduce la matriz cultural y reivindicaciones para reclamar sus derechos.

30 Es un espacio territorial donde habitan hombres y mujeres emparentados entre sí, la comunidad propiamente. 
132

Las comunidades fueron el epicentro de las iniciativas para presionar a las autoridades e instituciones; en el caso del agua, en las décadas de 1970, 1980 y 1990 las luchas fueron locales y coyunturales, donde cada comunidad en base a sus problemas de acceso al elemento vital gestan proyectos que modifiquen estas realidades, volviéndoles comunidades resilientes, es decir, que tienen capacidades de adaptación, social, política, ambiental y económica y continuar con su vida basada en alcanzar el Sumak Kawsay. ${ }^{31}$

Con la creación de la Ley de agua de 1972, para que una organización colectiva y/o comunitaria pueda gestionar y manejar el agua, se conforman las JAAP de forma paralela al cabildo comunitario (comunidad), para que estas legalmente puedan prestar el servicio de dotación de agua de consumo humano. También se crean las JAAP regionales mediante la unión de varias comunidades, desencadenándose un lento pero sostenido proceso de organización que tiene como fin la gestión y manejo comunitario del agua. Sin embargo, dentro de ellas y en el ejercicio de la gestión del agua se desarrollaron valores y principios que rigen en las comunidades y guía y norman el accionar de la convivencia entre las personas en sus territorios (Sánchez-Parga, 2007). Eso sí, en muchas partes se generan conflictos, intereses y superposiciones de poder entre los directivos de la JAAP y el cabildo de la comunidad, que con el tiempo y considerando que son los mismos comuneros buscan alternativas de coordinación de acciones en la gestión del agua potable.

La apertura jurídica de la Ley de Recursos Hídricos emitida en el 2014, se evidencia un avance en la conceptualización de gestión y manejo comunitario que pretende que los conocimientos occidentales se articulen con las experiencias locales de las comunidades andinas, incorporando la cultura como elemento esencial. Así, las JAAP implementan formas propias de gobernanza y gobernabilidad

31 Buen vivir o la vida en armonía, principio y filosofía de vida de los pueblos indígenas. En la actualidad es un derecho ambiental y ecológico, y principio del régimen de desarrollo social y políticos del país. 
del agua, entrelazando las dinámicas sociopolíticas y ambientales del territorio y la normativa legal del Estado.

Cuando el abastecimiento del agua en las comunidades sufre una disminución en la disponibilidad de agua por el cambio climático, las inequidades políticas y conflictos de poder entre lo urbano y lo rural, las menos favorecidas para enfrentar estas realidades son las comunidades. Así, las comunidades y sus organizaciones como las JAAP son relegadas de la acción de la política en el destino de la inversión pública; ante esta situación optan por acercarse y realizar alianzas intercomunitarias o inter-JAAP para hacer fuerza social y ser atendidos; en palabras de Sánchez-Parga (2007) "cuando una organización se fortalece y se amplía más allá de las comunidades moderniza sus reivindicaciones", equilibrando el poder de diálogo y negociación.

El Consejo de Coordinación de Juntas Administradoras de Agua Potable del Proyecto Regional Pesillo-Imbabura, no es solo un sistema de modernización en forma de la ampliación geográfica y cobertura social para una reivindicación específica, es un modelo de organización que han adoptado las comunidades indígenas y JAAP para reclamar su derecho al agua ante el Estado, mejorando sus capacidades técnicas, económicas y de poder, "el hombre andino nunca es más frágil que cuando está solo, y más fuerte cuando está incorporado al grupo" (Sánchez-Parga, 2016).

\section{Capacidad de la organización comunitaria para la gestión y manejo del agua}

En los Andes ecuatorianos, las organizaciones comunitarias que realizan procesos de gestión y manejo del agua tienen amplia trayectoria. En el caso del territorio del PPI, la mayoría de las organizaciones - comunidades y las JAAP - tienen debilidades principalmente por falta de recursos económicos para remunerar a sus propios técnicos y no depender de instituciones externas para enfrentar problemas técnicos en la infraestructura del sistema. El Foro de los 
134

Recursos Hídricos (2013) señala algunas limitaciones, siendo estos: la escasez de recursos económicos, la conflictividad comunitaria, limitadas capacidades técnicas para el manejo de los sistemas, dificultad para la renovación de líderes o dirigentes, dificultades jurídicas legales, dificultad en el control y vigilancia de la calidad del agua e inequidades de género.

Los problemas más comunes que enfrentan la mayoría de las organizaciones son las condiciones deterioradas de la infraestructura y disminución de caudales o ausencia de fuentes de agua, la disputa de gestión entre las organizaciones públicas (EMAP) y la cambiante estructura gubernamental que es responsable en la operativización de la política pública (Foro de los Recursos Hídricos, 2015). Estos aspectos endógenos y exógenos a las organizaciones afectan la capacidad de gestión y de manejo del agua (Figura 35).

\section{Figura 35}

Factores endógenos y exógenos que debilitan a la organización comunitaria en la gestión y manejo del agua

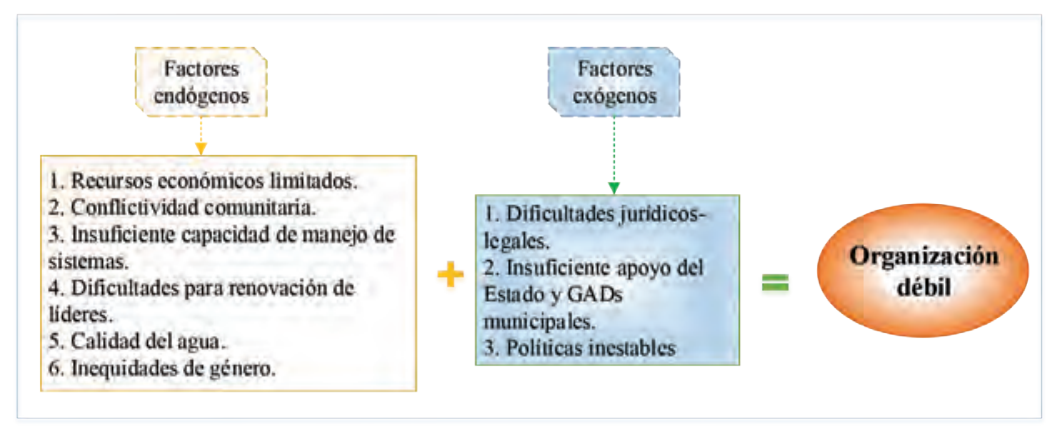

La capacidad de gestión y manejo del agua de las organizaciones con la participación de sus usuarios y los principios de solidaridad y equidad permite suplir la escasa presencia del Estado y enfrentar los factores endógenos que causan problemas al interior del territorio. Para suplir el déficit de recursos económicos la organización mantiene un sistema de aportes económicos de todos los usuarios cuando es 
necesario, por ejemplo: para complementar o reparar la infraestructura del sistema de manera que mejore la calidad del agua, se aporta económicamente y con los trabajos comunitarios "mingas".

La conflictividad comunitaria en algunos casos tiene sus orígenes en disputas por las fuentes de agua que se encuentran hidrográficamente en un mismo territorio. La Ley de Recursos Hídricos al exigir la creación de las Juntas Administradoras de Agua Potable para emitir la autorización de uso del agua abre disputas entre comunidades, prevaleciendo los ejercicios de poder basado en el dinero, es decir, cuando existe un litigio de este tipo, las comunidades que tienen mayor opción de ganar son las que pueden costearse abogados, y en ocasiones sobornar a técnicos y jueces. En otros casos se ponen en ejercicio practicas consuetudinarias en base a la capacidad de diálogo, que permiten a las organizaciones superar este tipo de conflictos, incluso les permite unir sus potencialidades para plantear proyectos conjuntos a problemas comunes como la escasez del agua.

Las comunidades andinas logran establecer sistemas organizacionales que reconoce y maneja procedimientos que les permite superar las diferencias según las realidades locales; es decir, pasar de los intereses personales y grupales a los intereses comunitarios, de los disensos a los consensos. Las asambleas y principalmente las mingas son los espacios idóneos de diálogo y de planificación para la gestión y manejo comunitario del agua.

Para incrementar las capacidades de gestión y manejo del agua, las organizaciones comunitarias tienen que considerar dos aspectos: el relevo generacional y la equidad de género, de manera que sea sostenible en el tiempo. La permanencia de los líderes en sus cargos a veces obedece a intereses personales que ven en las organizaciones comunitarias como medios para percibir recursos económicos o con fines de reconocimiento político. También hay poco interés de los jóvenes en involucrarse en los espacios de gestión y manejo del agua, aludiendo lo complejo que es desempeñar este tipo de delegaciones sin ningún reconocimiento económico, "estas funciones son honoríficas". La par- 
ticipación de la mujer en los cargos de las directivas de las organizaciones es baja, pues se ha construido socialmente la idea que la gestión y manejo del agua es una función de los hombres, debido a que las actividades son fuera del hogar y de la comunidad. Así, en la gestión comunitaria del agua los jóvenes son excluidos porque carecen de experiencia y las mujeres porque no es su espacio. Así, en el tiempo de vida del Consejo de Juntas ha sido baja la participación de la mujer.

Muchas JAAP que son parte del Consejo de Juntas han dado avances cualitativos importantes, superando los problemas endógenos, siendo en cierta medida autosuficientes en la gestión y manejo del agua, tanto de la infraestructura como del cuidado de fuentes y la administración de los recursos económicos. Esto es posible cuando hay capacidad económica de la organización o cuando la organización tiene capacidad técnica y administrativa con un alto grado de conciencia y participación de los usuarios, de jóvenes y mujeres insertadas en los diferentes niveles directivos de la organización.

Ciertas JAAP tienen limitaciones para afrontar con prioridad, técnica y legalmente las nuevas exigencias del Estado para la gestión y manejo del agua. Entonces, no todas las organizaciones comunitarias del PPI están con las mismas capacidades para la gestión y manejo del sistema. Por lo tanto, para que haya una participación de las organizaciones en el sistema del PPI deben mejorar sus capacidades a lo interno, implementando procesos de capacitación organizativa y técnica de sus dirigentes y usuarios.

Para la aplicación de la gestión comunitaria del agua requiere incluir como ejes transversales la interculturalidad y la integralidad; esto implica combinar una visión tecnicista a una propuesta que articule los ámbitos sociales, ambientales, económicos, culturales y técnicos. No limitarse a la concepción que el sistema de agua potable es solo la infraestructura, sino también abordar la administración, operación y mantenimiento, el control y vigilancia de la calidad del agua, el manejo de aguas residuales, el cuidado de fuentes, el fortalecimiento organizativo e incrementar los conocimientos de los/as usuarios/as del agua. Se debe también incluir el eje de género, ya que 
el agua está relacionada con los roles productivos, reproductivos y de la vida comunitaria misma, que asumen las mujeres en los sectores rurales (Foro de los Recursos Hídricos, 2015).

Las organizaciones consideradas medianas (entre 100 y 200 usuarios) y pequeñas (menos de 100 usuarios) son las que necesitan más ayuda de los GAD Municipales. Para dar sostenibilidad al PPI se firmó un documento en donde acuerdan la cooperación entre los GAD Municipales y JAAP para realizar la gestión y manejo del sistema de forma conjunta: acuerdo público-comunitario. Es importante que se generen debates en las JAAP sobre los ámbitos de atención y alcances de los acuerdos, puesto que "no existen diagnósticos de necesidades de capacitación ni planes institucionales con estrategias y presupuestos significativos para fortalecer capacidades en la gestión comunitaria del agua" (Foro de los Recursos Hídricos, 2015).

Mejorar las capacidades de la organización es necesario para implementar la gestión comunitaria del agua, así, obtener resultados que mejoren el acceso, control distribución y uso del agua y su articulación sea efectivas entre el sector público-municipalidad, ministerios sectoriales, y con el sector comunitario que conoce por experiencia el cómo trabajar en el ámbito rural (Foro de los Recursos Hídricos, 2015). Es importante crear consensos y fortalecer el rol de cada uno dentro del proceso de gestión y manejo del agua (Bastidas \& García, 2002), el Consejo de Juntas implementó un sistema de dialogo, al interno y externo de la organización.

Para mejorar las capacidades de las organizaciones e incrementar la eficiencia de gestión y manejo del agua, son importantes las alianzas público-comunitarias que en cada cantón pueden establecerse, siempre y cuando se respeten las diferentes dinámicas implementadas en las organizaciones comunitarias. La alianza estará encaminada a revertir las limitaciones y debilidades de las organizaciones, así, se tendrán un efecto por sí mismo positivo en las capacidades de las JAAP al momento de su participación en la Empresa Pública Pesillo-Imbabura que va a administrar el sistema regional de agua potable (Figura 36). 
José Manuel Perugachi Cachimuel - Charles Cachipuendo Ulcuango

138

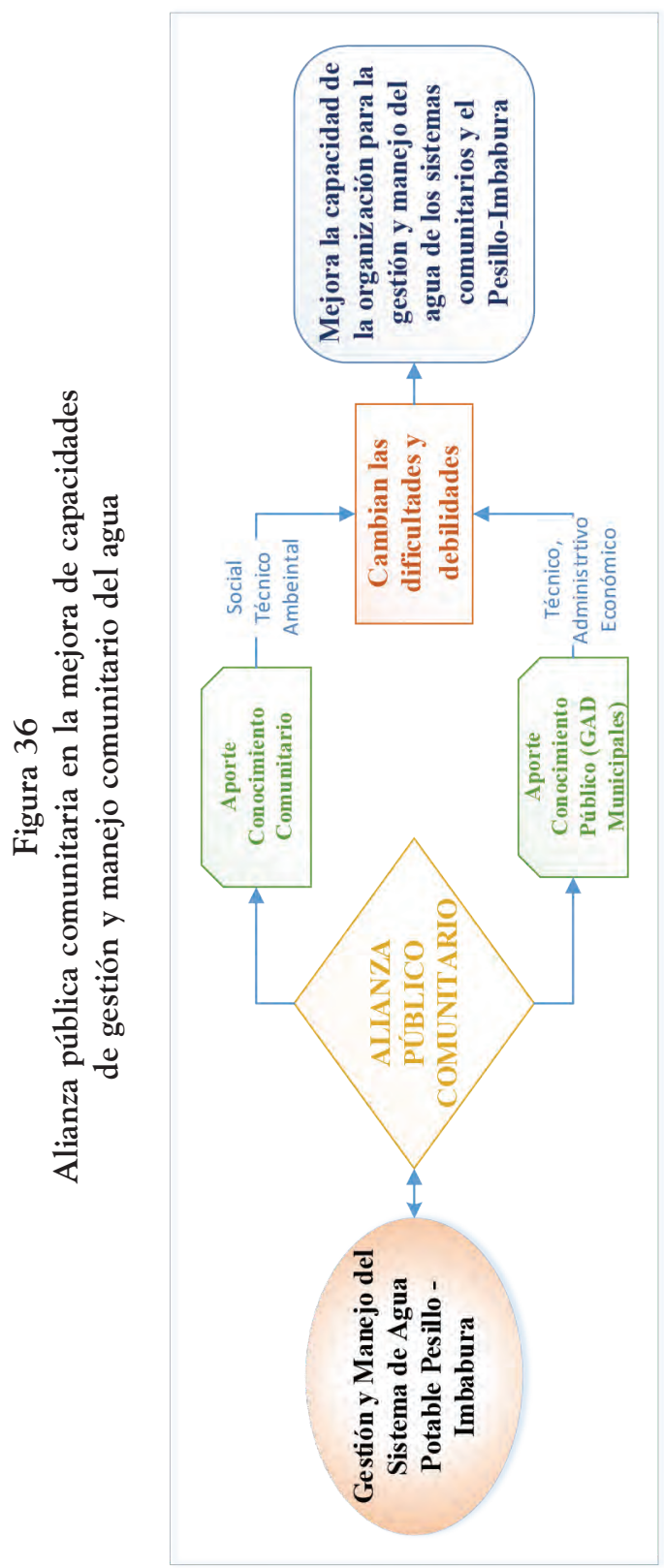


El articular y/o coordinar entre diferentes sectores se crea las condiciones para compartir conocimientos que se espera permita operar el sistema de agua potable de forma conjunta entre las organizaciones comunitarias y las instituciones públicas. La comunidad como la institución pública ha aportado a la consecución de los objetivos, la primera con sus conocimientos, su experiencia de la cotidianidad y la segunda con sus conocimientos y experiencia técnica y científico (Bastidas \& García, 2002).

La sostenibilidad de los servicios de agua potable dependerá de la organización y sus capacidades, técnicas, financieras y el diálogo entre los diversos (cohesión social), por lo que desde las instituciones públicas y de la sociedad civil deben generar acciones encaminadas a fortalecer esas capacidades, mediante procesos participativos e incluyentes en la toma de decisiones. Una de las acciones fundamentales es implementar procesos de capacitación en cada una de las organizaciones y de esa manera se rescaten los principios del Buen Vivir y de la sustentabilidad para maximizar la eficiencia de la gestión y manejo comunitaria del agua.

Si bien las JAAP gozan de muchas virtudes que hacen que la gestión y manejo del agua sea calificada como un modelo alternativo frente a las más comunes que hay en el Ecuador, también es cierto que se presentan dificultades que pueden atentar el continuar con esta práctica, debido a que la institucionalidad del Estado desconoce los principios y valores comunitarios. Por ello es necesario que las JAAP realicen un trabajo a su interior y detecten las debilidades y potencialicen sus capacidades, de manera que, al implementar las alianzas público-comunitarias con miras a mejorar las infraestructuras de los sistemas de agua, no elimine su identidad y cultura de gestión y manejo del agua.

Un proyecto que abarca varias comunidades con miles de usuarios y millonarias inversiones como el PPI tiene que contar con hombres y mujeres - en todas las organizaciones- capaces de gestionar y manejar el sistema, pues el proyecto trae consigo grandes retos que a 
140

futuro se pondrán a prueba, si las JAAP no están preparadas podrían enfrentar serias dificultades en los ámbitos sociales, ambientales, técnicos y económicos, generándose posibles conflictos entre los actores involucrados, por tal razón los GAD Municipales y JAAP deben trazar metas a corto, mediano y largo plazo enfocados en el mejoramientos de las capacidades locales para la gestión y manejo del sistema con un enfoque comunitario, que sea intercultural e integral.

La toma de decisiones en la gestión y manejo del sistema debe ser horizontal y no vertical. Si el usuario del agua participa en este proceso, sentirá que el sistema de agua potable del PPI es suyo y hará todo lo que le corresponda para que este sea sostenible en el tiempo y contar con agua segura tanto en calidad como en cantidad. La alianza pública-comunitaria debe innovar la forma de gestionar $y$ manejar el sistema y no ver al usuario como un cliente que hay que dotar de agua a cambio de una tarifa económica.

\section{Territorio y tejido social en la gestión y manejo del agua}

Un territorio se construye a lo largo de la historia sobre la base de asentamientos de una población en un espacio natural, se generan formas de producción y relaciones sociales con el medio natural. Una organización que gestiona y maneja el agua, afronta un complejo sistema de relaciones sociales, económicas, políticas, culturales y ambientales. En tal sentido los territorios étnicos son anteriores a la constitución del mismo Estado (Sánchez-Parga, 2007). Por lo tanto, las regulaciones de acceso, control, distribución, uso y disposición final del agua tienen que tomar en cuenta esos procesos históricos e incorporar en los lineamientos de gestión y manejo del agua al territorio como tal.

En la sociedad andina se distingue una matriz asociativa territorial (la llakta) cuyo espacio es compartido por asentamientos de familias pertenecientes a diferentes grupos de parentesco (el ayllu ${ }^{32}$ ), así, la

32 Familia nuclear y ampliada que vive en una comunidad indígena. 
dualidad territorio-familias (llakta-ayllu ${ }^{33}$ ) se reconoce como comunidad (Sánchez-Parga, 2007). El cuidado del territorio mediante manejos de páramos y fuentes de agua constituye parte de la memoria social del pasado y responsabilidad del presente. Por eso es que cuando se habla de comunidades, agua y territorio resultan ser inseparables (Isch \& Zambrano, 2015). Las comunidades del Consejo de Juntas del PPI mantienen una matriz natural agua y territorio y son las responsables de forjar relaciones sociales comunitarias, construyendo alrededor de estos elementos tejidos sociales entre - dirigentes, operadores, usuarios, representantes y técnicos de instituciones de la sociedad civil y públicas sean estas parroquiales, municipales, provinciales, nacionales e internacionales-.

Los pueblos originarios, que no sufren tanta fragmentación histórica en su cosmovisión, fueron construyendo sus propias formas de entender y actuar en su relación con la naturaleza y como son parte de esta. También el elemento vital el agua va generando relaciones espirituales en el que, el agua es tan aborigen ( $a b$-origine) como los pueblos, así, las fronteras entre la naturaleza, los seres humanos y los seres sobrenaturales se entrelazan en reciprocidades y respetos mutuos que aseguran la vida (Vargas, 2006) (Figura 37). No obstante, la mayoría de las instituciones cuando intervienen en las organizaciones lo realiza de forma separada, mas no consideran que para las comunidades indígenas un sistema se agua potable y/o de riego es complementario entre la comunidad, la naturaleza e infraestructura (Cachipuendo, 2017).

Las organizaciones de gestión y manejo del agua deben incorporar la noción territorial en la gestión e intervención de un proyecto de agua, considerando como componentes de un territorio: la naturaleza con el elemento agua y suelo, la infraestructura del sistema, al ser humano como ente social y espiritual. Numerosas experiencias demuestran que la gobernanza pública del agua fragmentada tie-

33 Familias asentadas en un territorio comunitario. 
ne efectos negativos, por lo que es necesario realizar esfuerzos para coordinar la gestión del agua de forma integral e intercultural en un territorio (Comité de Gestión Agua Chambo, 2015). Además, debe comprenderse que para las comunidades el manejo de su territorio está relacionada con su ejercicio de niveles de autonomía (Isch \& Zambrano, 2015), es decir, son capaces de gestar su Buen Vivir.

\section{Figura 37}

Relaciones sociales, económicas, políticas, culturales y ambientales en el territorio para la gestión y manejo del agua

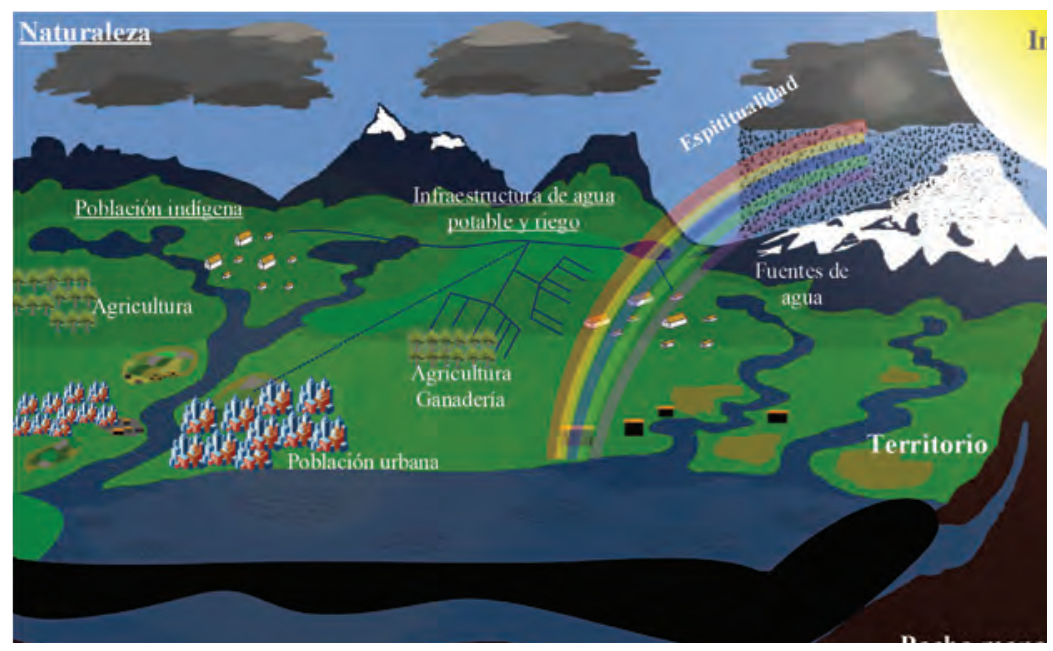

La gestión comunitaria del agua asumida por las organizaciones sociales refleja niveles de autonomía. En las comunidades, territorio y niveles de autonomía son construidos desde ejercicios de los derechos consuetudinarios que vienen forjándose desde tiempo atrás, y en tiempos más recientes el cuidado y manejo del agua, pues consideran al agua como un elemento perecedero que, si no se lo cuida, se acaba (Bastidas \& García, 2002), poniendo en riesgo la vida de los pobladores y resto de seres vivos. Razón por la cual el Consejo de Juntas propone que el PPI integre como eje principal el ambiental de forma que se generen políticas y proyectos de protección y conservación de las fuentes de agua. 
Pese a la autonomía de las comunidades para la gestión y manejo del agua, en un territorio que rebasa las fronteras geográficas de la comunidad, se generan dinámicas a partir de acciones entre varias organizaciones, de manera que sus miembros establecen una interrelación permanente con su entorno, factores que fortalecen el tejido social (Bastidas \& García, 2002), que para el caso del Consejo de Juntas se gesta un tejido social entre diferentes pueblos que se encuentran ubicados en diferentes territorios.

En el territorio, el agua se convierte en elemento indispensable en la construcción del tejido social entre los actores comunitarios, públicos, privados y de la sociedad civil. En el territorio ocurren conflictos por el acceso, control y uso del agua (consumo humano, riego, entre otros), porque no es abundante ni está presente en todos los territorios comunitarios. En comunidades que tienen fuerte influencia occidental (individualismo), han existido actitudes mezquinas, pero los principios ancestrales de sobrevivencia como la solidaridad prevalece, porque en la cosmovisión indígena los elementos de la naturaleza (pachamama ${ }^{34}$ ) deben ser compartidos tanto en su uso como en su cuidado.

En el caso de la JAAP regionales, la fuente de agua de una comunidad abastece a cientos de familias de otras comunidades. Este tipo de organizaciones comunitarias han visto fortalecer los tejidos sociales intercomunitarios y el cuidado del agua crea nuevas nociones de territorialidad, como un espacio que todos deben involucrarse para su gestión y manejo, aunque jurídicamente pertenezca a una comunidad "el agua no tienen fronteras construidas por el ser humano". El territorio para las comunidades es la casa grande en donde los seres humanos y no humanos acuden para cubrir necesidades elementales como el abastecerse de agua.

El tejido social en un proyecto multipropósito necesariamente inicia desde las fuentes de agua, así, para el caso del PPI es indispensa-

34 Madre naturaleza. 
144

ble que se introduzca el enfoque de territorio indígena, en el cual se involucran los territorios de los pueblos: Kayambis, Otavalos, Natabuelas y Karanquis. Entonces, todas las organizaciones involucradas en el proyecto deben aportar en el manejo y cuidado del territorio hídrico ubicados en la estribación del nevado Cayambe, la unidad de cuenca de la laguna de San Marcos y del río La Chimba, cuyo propósito es la eficiencia técnica, social, ambiental y económica del uso del agua.

Es importante tomar en cuenta el enfoque de territorio en el modelo de gestión y manejo del sistema con la participación de los/as usuarios, representados por: los Municipios agrupados en la Mancomunidad y a nivel de las comunidades por el Consejo de Juntas. Esta inclusión de las comunidades dará sostenibilidad social al proyecto ya que todas las JAAP comunitarias, siempre estuvieron involucradas, desde que el proyecto inició, miles de personas participaron en su ejecución, aportando con mingas en los trabajos para los estudios de captación del agua en ríos concesionados, siempre manteniendo la preocupación por la sostenibilidad de las fuentes hídricas, de esta manera al ser un proyecto regional trasvasa la cuenca hidrográfica convirtiéndose en cuenca social, es decir que por intervención del ser humano mediante la infraestructura se conduce el agua de una cuenca hidrográfica hacia otras (Cachipuendo, 2013). El agua del PPI se capta de ríos que hidrográficamente de forma natural van hacia la Amazonia.

La construcción del tejido social en proyectos que abarcan poblaciones que van más allá de los territorios comunitarios y de las JAAP, con una característica en que las fuentes de agua se encuentran fuera del territorio de la cuenca hidrográfica, son elementos que se puede pensar en territorios hidro-sociales, sitios en los cuales existe una interacción entre el ser humano y la naturaleza, siendo los usuarios del agua del PPI los que deben seguir mejorando las acciones de resguardo de las zonas de generación del agua. Entonces, la Empresa Pública Pesillo-Imbabura como la Organización Consejo de Juntas deben coordinar las políticas, estrategias y proyectos de intervención, manteniendo los principios comunitarios. 
Para que haya claridad de los roles y funciones que cumplen los diversos involucrados en un proyecto de características regionales (territorio hidro-social) es necesario implementar un plan de gestión territorial del agua, para que, las acciones de todos los actores que tienen alguna competencia, responsabilidad o interés en relación con el agua en el territorio, actúen sin duplicar actividades, peor aún sobreponer roles que conllevan a la generación de conflictos. Las organizaciones sociales, los municipios, los habitantes (usuarios/as) de las cabeceras parroquiales y cantonales se articulen potencializando el tejido social en todo el espacio territorial del proyecto, desde Cayambe-Pedro Moncayo por el sur, hasta Ibarra en el norte de la provincia de Pichincha.

\section{Gobernanza y gobernabilidad en la gestión comunitaria del agua}

La gobernanza y gobernabilidad son conceptos que se generan para relacionar las acciones implementadas en la gestión y manejo del agua por parte del Estado y sus instituciones con la sociedad civil. Sin embargo, según Murillo-Licea y Soares-Moraes (2013) consideran que la gobernanza es "cuando nos refiramos a la acción conjunta del gobierno y la sociedad para un objetivo positivo común (como el desarrollo), a fin de alcanzar un equilibrio", mientras que se refiere a la gobernabilidad "cuando se trate de la parte institucional conferida al gobierno y sus instituciones, es decir, su capacidad y rango de acción”.

Estos conceptos son generados desde la visión occidental que son impuestos a los territorios locales, que, para el caso del agua, provoca conflictos entre instituciones del Estado y las organizaciones comunitarias. Las organizaciones comunitarias por experiencias acumuladas generan formas propias de gestión y manejo del agua y se respalda en los procesos de cogobierno, autodeterminación, autogobierno y gobierno comunitario, formas que se encuentran respaldadas por la Constitución del Ecuador (Figura 38). 
146

Figura 38

Perspectivas para la construcción de esquemas de gobernanza y gobernabilidad comunitaria del agua

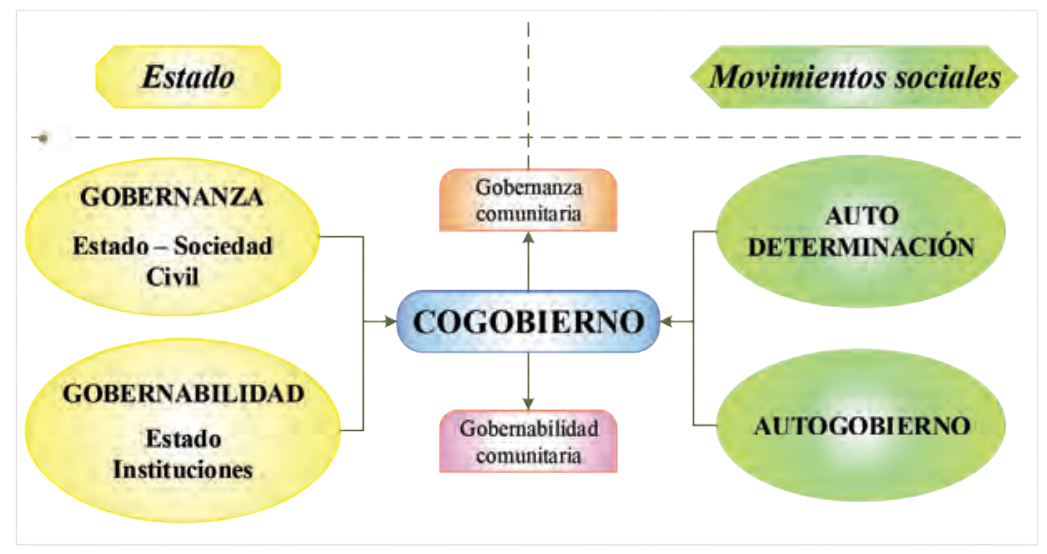

Gobernanza comunitaria del agua

El Consejo de Juntas con su dinámica social logra establecer relaciones con las instituciones del Estado mediante constantes diálogos y consigue la consecución del PPI, en ese contexto la gobernanza del agua se construye a través de procesos de diálogo e interacción entre organizaciones formales e informales; agentes estatales y no estatales, los cuales definen, a diferentes escalas, nuevas estructuras socio-hidrológicas, que configuran el acceso, control y uso del agua y sus territorios (Duarte, Hoogesteger \& Yacoub, 2016).

Entonces, en las organizaciones comunitarias la gobernanza se presenta como las interacciones entre estructuras, procesos y tradiciones que determinan como se ejerce el poder y las responsabilidades, como se toman las decisiones y como intervienen los comuneros (usuaria/os del agua) y otros actores en la gestión y manejo de sistemas de agua de consumo humano. Incluye los mecanismos, procesos e instituciones mediante los cuales los usuarios expresan sus intereses, ejercen sus derechos, satisfacen sus obligaciones y resuelven sus dife- 
rencias (Cobo, Yaguache, Piñeiros, Calisto \& Gay de Montella, 2018). También se puede entender como sistemas políticos, sociales, económicos, ambientales y administrativos que afectan, directa o indirectamente la gestión del agua y la prestación de servicios de agua a diferentes niveles de la sociedad (Comité de Gestión Agua Chambo, 2015).

La prestación del servicio del agua por organizaciones comunitarias atraviesa las estructuras, procesos, tradiciones e instituciones, como también los sistemas políticos, sociales, económicos, ambientales, tecnológicos y administrativos con participación directa de los usuarios del agua en todos los procesos y niveles de decisión; en estos contextos, las organizaciones comunitarias encuentran formas propias de gestionar y manejar los sistemas de agua potable respaldándose en el enfoque de la gestión comunitaria (Figura 39).

Figura 39

Elementos de la gobernanza comunitaria del agua

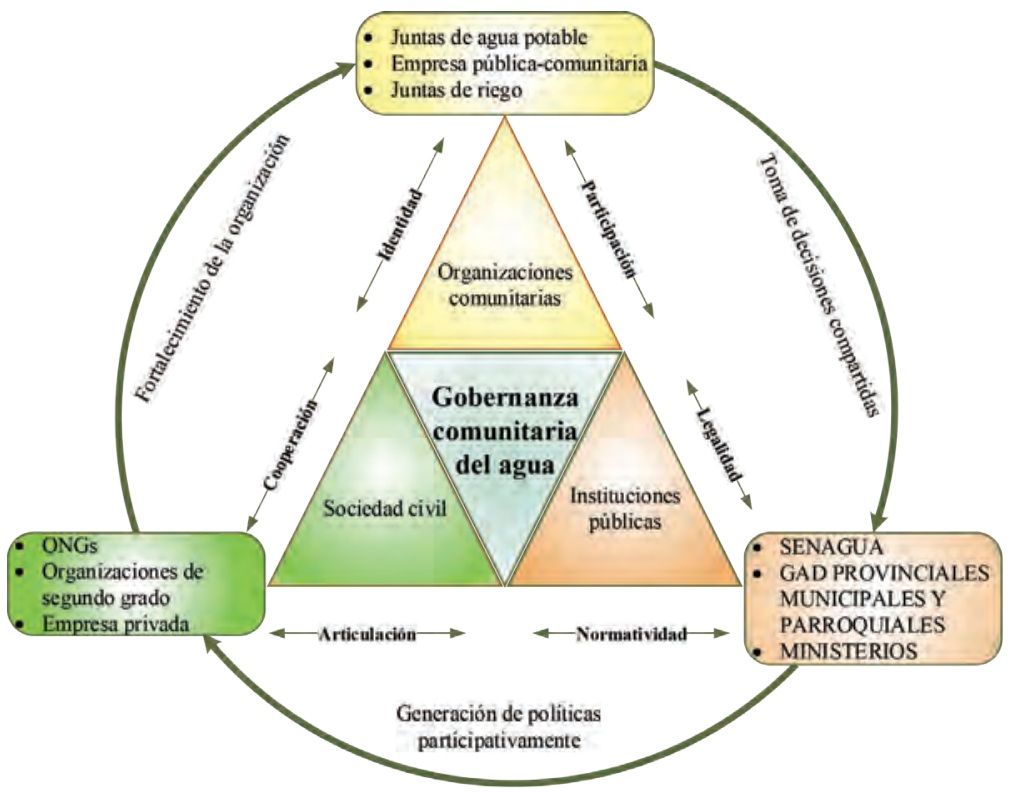


Las organizaciones comunitarias de base del Consejo de Juntas quienes impulsa el PPI seguirán ejerciendo la gobernanza del agua en sus territorios para garantizar su acceso. Sin embargo, es necesario reflexionar sobre la gobernanza del agua con la Empresa Pública de Agua Potable Pesillo-Imbabura (el ramal principal) en territorios que históricamente han ejercido la gobernanza comunitaria a excepción de las cabeceras parroquiales y cantonales que ejercen un modelo de gobernanza pública del agua.

En el mejor de los casos, si las alianzas públicas-comunitarias son alternativas para superar las debilidades y limitaciones de las organizaciones comunitarias; los principios de la gobernanza pública ejercidas a través de las Empresas Municipales de Agua Potable en cada cantón y la gobernanza comunitaria con sus principios y valores deberían unirse, ya que algunos aspectos son comunes, y ambos representan potencialidades que pueden aportar a la gestión y manejo eficiente del agua.

Aunque la mayoría de los usuarios y dirigentes de la JAAP están inconformes porque, para la administración, operación y mantenimiento del Sistema Regional de Agua Potable Pesillo-Imbabura, la mancomunidad de municipios creará la denominada Empresa Pública de Agua Potable Pesillo-Imbabura (EPAP Pesillo-Imbabura) con participación comunitaria, situación que desde las organizaciones comunitarias cuando gestaron el proyecto no lo tenían pensado. Las condiciones impuestas para el financiamiento del proyecto obligaron aceptar esta forma de gestión del agua. La empresa tendrá cinco representantes en el directorio, tres de los municipios y dos de la Organización Proyecto Pesillo-Imbabura (de las JAAP regionales). Esto supone que la conducción principal del sistema de agua, dentro del proceso de gobernanza, la gestión y manejo será pública, cuando el sueño y reto de las organizaciones fue implementar un sistema de gobernanza que fortalezca la gestión y manejo comunitaria del agua.

En un país que tiene el carácter de ser plurinacional e intercultural, la gobernanza del agua se implementa en un sistema de diálo- 
go con todos los actores, porque a criterio de José Juncosa, vicerrector de la UPS, implica el respeto con equidad en la convivencia entre pueblos y nacionalidades. Al mismo tiempo, la gobernanza propone que sus culturas políticas y económicas sean respetadas y tomadas en cuenta como una posibilidad de ser implementada en el resto de la nación, sobre todo por aquellos que no se reconocen como indígenas (Boletín Salesiano, 2019, p. 3).

La gobernanza comunitaria del agua implica que su gestión y manejo realizada por las comunidades indígenas desde hace mucho tiempo con sus propias dinámicas socioculturales, ambientales, políticas, tecnológica y económicas, no sea mirada como un proceso ineficiente desde el punto de vista tecnológico. En ese sentido desde las comunidades se impulsa que la Empresa Pública de Agua Potable Pesillo-Imbabura (EPAP Pesillo-Imbabura) adopte en sus políticas y planificación los principios y valores de la gestión comunitaria del agua y establecer un proceso de gobernanza del agua intercultural e integral.

Establecer un sistema de gobernanza del agua con una visión comunitaria es uno de los pilares para garantizar la sostenibilidad y conservación del agua en el territorio de los proyectos multipropósitos. Por eso, es importante la articulación plena al elaborar políticas, planes y programas entre las diferentes instituciones que fomenten la participación, que asegure la representación y en la negociación se involucren todos los actores y den a conocer sus intereses (Cobo et al., 2018), mismos que finalmente se conviertan en objetivos comunes.

El ejercicio de la gobernanza con visión comunitaria se produce cuando las normas y prácticas sociales empoderan y estimulan a las personas a tomar cada vez más control sobre su propio destino de una manera que no afecta negativamente a los derechos de los demás (Cobo et al., 2018). Las organizaciones comunitarias con la concreción del PPI pretenden contribuir al Sumak Kawsay de las comunidades indígenas y la población urbana del norte ecuatoriano. 
150

\section{Gobernabilidad del agua en comunidades rurales}

La gobernabilidad se refiere a la capacidad de las instituciones representantes del Estado en el diseño de políticas públicas que sean socialmente aceptadas, orientadas a la sostenibilidad del recurso hídrico, así como hacer efectiva su implementación junto a los diferentes actores involucrados. En síntesis, implica la capacidad de generar las políticas adecuadas, y de llevarlas a la práctica de manera que la gestión del agua sea eficiente (Peña \& Solanes, 2002).

La gobernanza del agua en las comunidades indígenas tiene éxito porque hay un escenario de gobernabilidad por voluntades de las instituciones públicas y presión de las organizaciones comunitarias, para que se practiquen procesos de: coordinación, colaboración y entendimiento entre los actores de las organizaciones que ponen en práctica el derecho propio o consuetudinario apoyadas en la costumbre, la tradición, y en las instituciones del Estado que regulan sus actuaciones.

Para ejercer gobernabilidad del agua en los diferentes territorios, los actores conocen cuáles son sus roles. El Estado tiene el rol de regulador según la Ley de Recursos Hídricos a través de la SENAGUA en un territorio la Demarcación Hidrográfica; las JAAP tienen el rol de gestionar y manejar el sistema para dotar de agua a las poblaciones que dependen de ella o que pertenecen a la organización comunitaria.

Las JAAP como organizaciones comunitarias implementan procesos de gobernabilidad que permiten desarrollar acciones de gestión comunitaria del agua en un marco de coordinación, colaboración y entendimiento entre los diferentes, es decir la práctica de la interculturalidad, de manera que se impulsa el manejo sostenible del agua en los territorios a favor de las comunidades y colectivos sociales.

La participación y el protagonismo en la toma de decisiones de los usuarios en la organización son claves, para evitar crisis de gobernabilidad o situaciones que puedan debilitar las condiciones para 
la buena gobernanza del agua. Estas características propias de la gestión comunitaria se espera que sean implementadas en la Empresa Pública de Agua Potable Pesillo-Imbabura (EPAP Pesillo-Imbabura).

Una condición básica para la gobernabilidad es que los diversos actores relacionados con la gestión del agua tengan voz directa o de forma representativa en la toma de decisiones, a través de instituciones legítimas y legales que representen a los intereses e intenciones de los usuarios/as del agua de las comunidades y colectivos sociales. Es indispensable asegurar la participación efectiva de diversos actores: mujeres y hombres; jóvenes y adultos; representatividad geográfica, entre otros, este involucramiento asegurará la gobernabilidad del agua en los territorios comunitarios (Cobo et al., 2018).

En las JAAP donde la participación u otras acciones tengan limitaciones, es indispensable mejorar los procesos de toma de decisiones para el fortalecimiento de la gobernanza. La descentralización y participación efectiva de los diversos actores son claves en la gestión del agua, así como cambiar las formas tradicionales de gobernanza del agua, de modelos "de arriba hacia abajo" a modelos "de abajo hacia arriba" (Cobo et al., 2018). Los modelos de gestión horizontales impulsan la igualdad y equidad entre los actores y en territorios comunitarios deben respetar las dinámicas de la vida comunitaria donde lo común esta sobre lo individual.

Las condiciones impuestas por los organismos del Estado y la cooperación internacional impulsan un proceso de gobernabilidad con una visión de arriba hacia abajo en la cual los usuarios no tienen poder de decisión. Así, para financiar la ejecución del proyecto, los representantes de las JAAP regionales, los dirigentes del Consejo de Juntas del PPI, alcaldes de los GAD Municipales, Banco del Estado, entre otros, proponen que, para la administración, operación y mantenimiento del Sistema Regional de Agua Potable Pesillo-Imbabura, se cree la denominada Empresa Pública de Agua Potable Pesillo-Imbabura (EPAP Pesillo-Imbabura) con participación comunitaria, esta propuesta no es generada desde la visión comunitaria. 
152

La gestión y manejo del agua se convierte un centro de poder y es ejercido generalmente por las organizaciones o instituciones que manejan los recursos económicos, generándose inconformidades por parte de las organizaciones comunitarias que no cuentan con los recursos económicos necesarios para manejar eficientemente el sistema. En el PPI las propuestas de las organizaciones comunitarias que clamaban la gestión comunitaria no fueron tomadas en cuenta, se convirtió en una participación sorda y las decisiones habían sido planificadas con anterioridad por parte de la mancomunidad de municipalidades y las instituciones que financiaron el proyecto; en palabras sencillas, las decisiones son verticales y jerárquicas siendo la participación de las comunidades solo parte de un trámite para avalar lo actuado por los otros actores. Esta forma de gobernanza del agua desvaloriza la participación efectiva de los usuarios/as, atentando con los principios democráticos, característica de la gestión comunitaria del agua. Este tipo de procedimientos conlleva a la generación de políticas desarticuladas al sistema de vida comunitaria (Peña \& Solanes, 2002), lo que puede provocar dificultades en los procesos de gobernabilidad del agua, que en muchas ocasiones las organizaciones se ven obligadas a desconocer a los organismos de control y de rectoría del agua del país.

La imposición de políticas, acciones, etc., generan problemas de gobernabilidad y conflictividad, porque las voces de la mayoría no son tomadas en cuenta. Sin embargo, como son procesos sociales siempre se dan en marco de tensiones y disensos, que pueden también entenderse como oportunidades, de forma que las condiciones de gobernabilidad parten desde situaciones negativas que en base al diálogo se convierten en positivas para dar sostenibilidad al acceso, control y uso del agua.

Entonces, las condiciones de gobernabilidad de los sistemas de agua potable Pesillo-Imbabura dependen de las formas de la toma de decisiones que sean un modelo de abajo hacia arriba y/o horizontales, de tal manera que las políticas y acciones que se implementen se 
construyan conjuntamente entre todos los actores del Estado, organizaciones comunitarias y de la sociedad civil.

La articulación de las acciones colectivas, públicas y comunitarias posibilitará una planificación efectiva en donde los principios y valores de la cosmovisión andina de los pueblos indígenas y acogiendo lo que determina la ley conllevan a plasmar una gestión y manejo del agua con solidaridad, equidad y armonía con la naturaleza.

\section{La gestión comunitaria del agua un proceso en construcción}

La gestión comunitaria del agua enunciada en la Constitución y Ley de Recursos Hídricos pretende reconocer las dinámicas de su gestión y manejo implementadas desde hace años por las comunidades indígenas andinas. Con la experiencia de las comunidades para acceder, controlar, distribuir, usar y la disposición final del agua con sus propias dinámicas, conlleva a un análisis propio de la cosmovisión indígena andina que repercute en algunos elementos conceptuales, valores y principios de los paradigmas de la sustentabilidad y el Buen Vivir. Así, se puede considerar que la gestión comunitaria del agua es, un enfoque propio de las comunidades que mantienen una identidad y se acogen elementos conceptuales de otros enfoques como la eco-hidrología, la hidro-sociología, el metabolismo socio ambiental, la gestión integral, etc., que en varios aspectos posiblemente confronta a enfoques conceptuales introducidos de países hegemónicos.

Una de las principales características del enfoque de la gestión comunitaria del agua, es la relación que existe entre los usuarios del agua que viven en comunidad, no solo compartiendo un espacio geográfico o una infraestructura de un sistema de agua potable o de riego, sino que existe una relación de vida, entre seres humanos y resto de seres, donde lo espiritual es parte de esta relación. Entonces, un sistema de agua para consumo humano está compuesto por tres elementos fundamentales que se relacionan y se complementan, la comunidad, la naturaleza y la infraestructura física (Figura 40), 
154

elementos que también se aplican para el caso de sistemas de riego comunitarios (Cachipuendo, 2017).

\section{Figura 40}

Características y principios de la gestión y manejo de sistemas de agua comunitarios

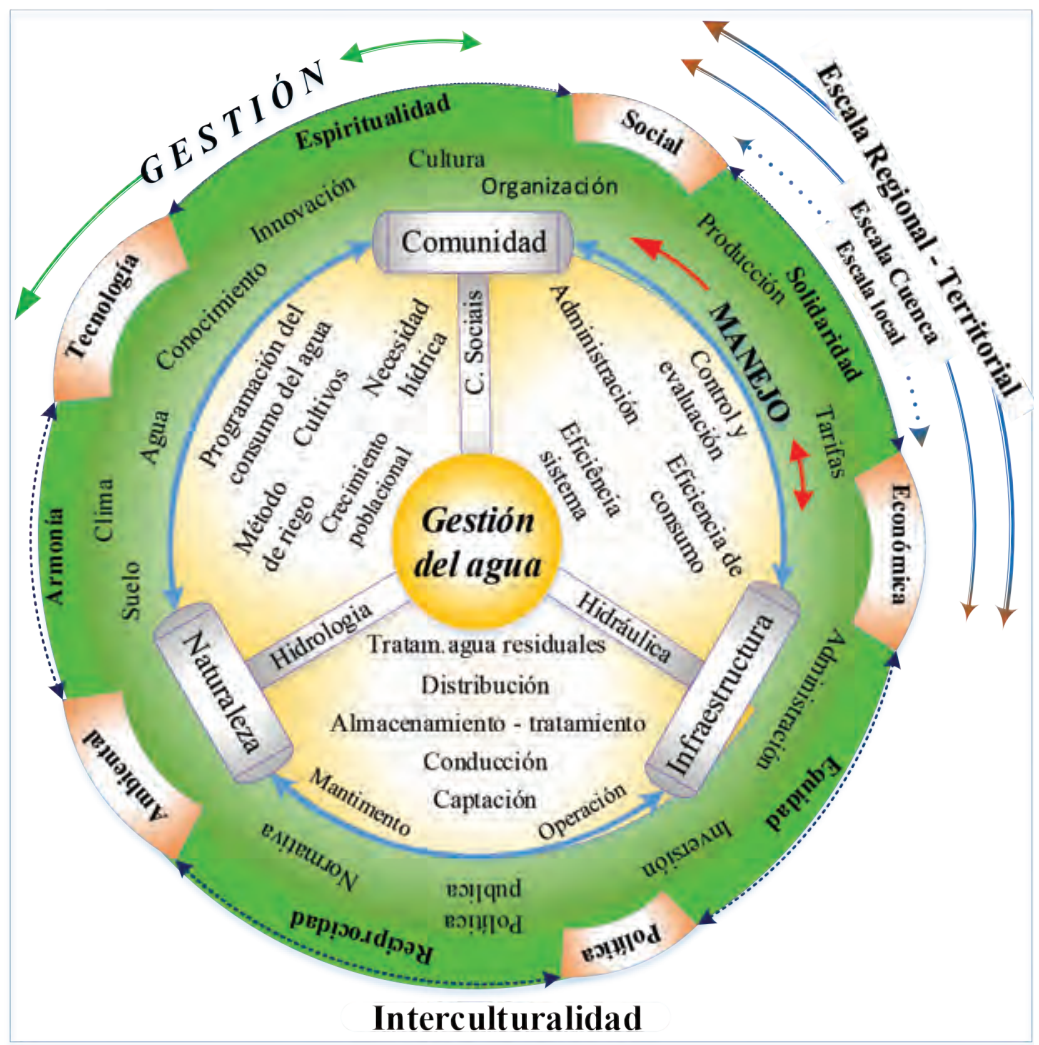

Fuente: Cachipuendo (2017)

En la comunidad, las decisiones y acciones implementadas para los procesos de acceso, control, distribución, usos y disposición final del agua, son tomadas y compartidas con todos los usuarios, estos no solo reciben un servicio de dotación de agua, por lo contrario están 
pendientes de su sistema, manteniendo una visión integral e intercultural sintiéndose parte de este, por ejemplo, para la conservación de las fuentes de agua, todos los usuarios salen a las mingas para realizar actividades de protección, cosa igual ocurre para el mantenimiento de la infraestructura del sistema.

La naturaleza, en dependencia de los ciclos climáticos y cobertura vegetal es proveedora de agua en un territorio comunitario, siendo los ecosistemas altoandinos (páramos) en donde mayormente se genera el agua. En estos territorios existen comunidades que por razones de la reforma agraria tienen títulos de propiedad individual, que con fines económicos se implementan actividades agropecuarias que amenazan las fuentes de agua. Ante los cambios naturales y sociales desde años atrás, las comunidades van siendo conscientes de estas realidades e implementan sistemas de conservación y protección de sus fuentes de agua, implementando sus propias regulaciones de uso de suelo con el principio fundamental que el beneficio comunitario está sobre el individual.

El agua para ser usada, la comunidad con apoyo de instituciones públicas y de la sociedad civil construyen infraestructura para captar, conducir, almacenar, tratarla, distribuirla en cada una de las viviendas, y en los últimos años también se encargan de la disposición final de las aguas residuales. Los saberes de las comunidades y la tecnología actual deben converger con el propósito que la infraestructura se encuentre en condiciones que asegure el agua en cantidad y calidad para el ser humano y devolverla a la naturaleza en condiciones que mantenga la vida de otros seres. Sin embargo, el sistema organizativo comunitario y público en ciertas ocasiones en dependencia del tamaño del sistema tienen dificultades en realizar procesos de control y vigilancia de la calidad del agua. Esta realidad se debe a diversos factores, entre otros a la debilidad institucional del Estado quien tiene las competencias en apoyar estos procesos en las comunidades.

Las organizaciones comunitarias andinas acceden, controlan, distribuyen, usan y realizan la disposición final del agua con el fin de 
satisfacer las necesidades de la población. Para mantener este elemento en el tiempo y dotar de agua a las futuras generaciones, implementan acciones sistémicas, integrales, con una visión de interculturalidad lo que fortalece el enfoque de la gestión comunitaria del agua. En este contexto, en un sistema de agua potable que tienen cobertura territorial intra e intercomunitaria se observan prácticas y acciones que permiten diferenciar lo que es gestión y manejo del agua.

\section{Gestión de sistemas comunitarios de agua de consumo humano}

En los sistemas comunitarios de agua de consumo humano, la gestión puede ser considerada como el correcto acceso, control, distribución y uso eficiente del agua (Cachipuendo, 2017), para el caso de las organizaciones de agua potable también se incluye su disposición final. La finalidad de la gestión es implementar acciones que permiten dotar de agua tanto en cantidad como de calidad a todos/as las personas que habitan en un territorio, de forma equitativa, solidaria, incluyente, con identidad, en armonía con la naturaleza y dialogando con los diferentes actores involucrados al externo como al interno del territorio de influencia del sistema y finalmente devolver el agua a la naturaleza en condiciones que siga generando vida.

Las organizaciones comunitarias del Consejo de Juntas que dotan de agua de consumo humano, por medio de sus representantes (dirigentes) realizan diferentes acciones que pueden ser consideradas como parte de la gestión del agua: 1) cumplir las normativas legales de acceso, control y vigilancia de la calidad del agua, 2) negociación de proyectos, 3) participación en la generación de la política pública, 4) participación en reuniones de planificación con los organismos de control y 5) velar por el buen manejo del sistema y de la disposición final del agua mediante un sistema del constante fortalecimiento organizativo (Figura 41). 


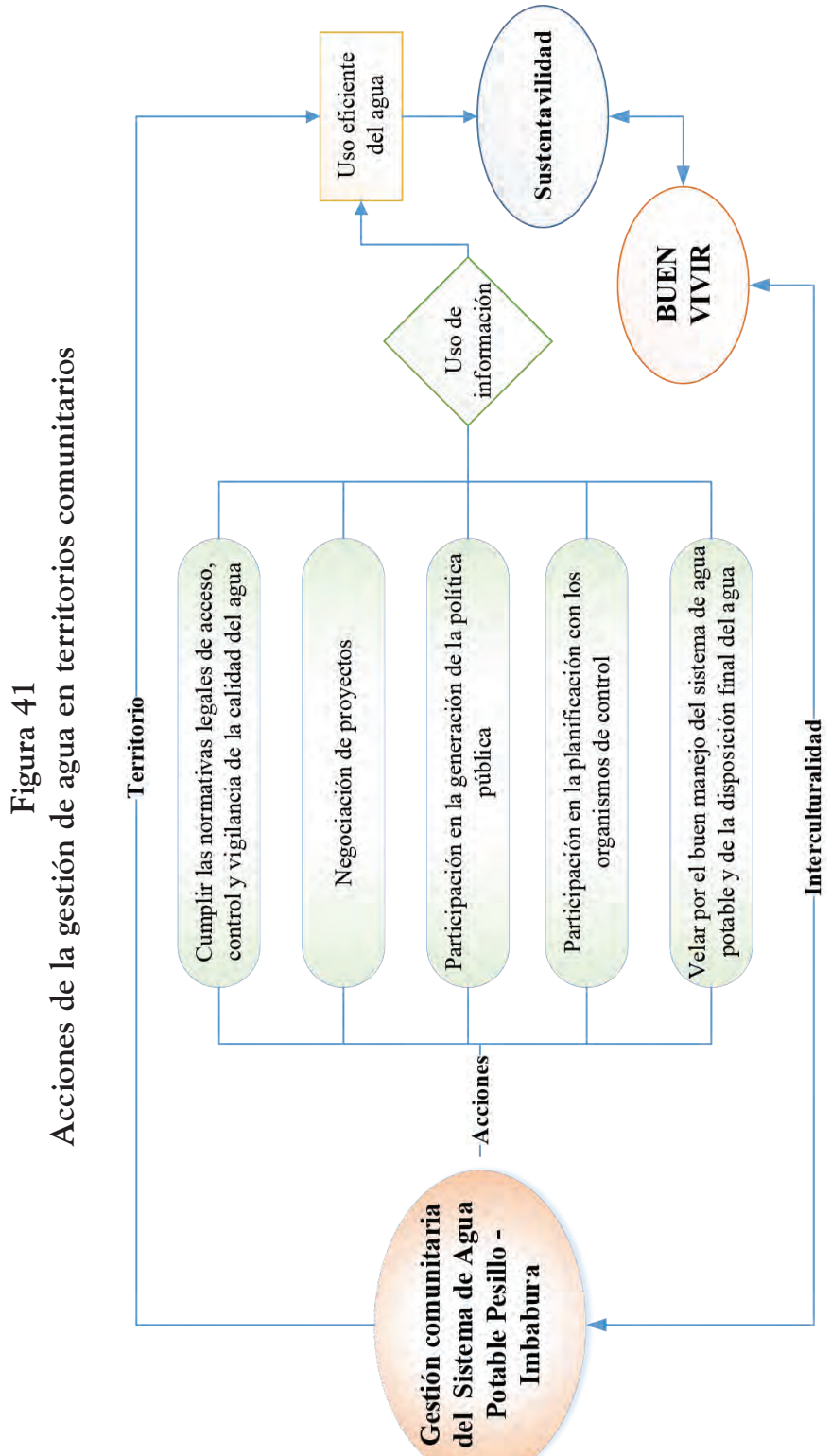


Para dar sostenibilidad a los procesos de gestión, la participación de todos/as los usuarios/as es fundamental, misma que se realiza mediante la toma de decisiones en las asambleas y se delega a los dirigentes para la puesta en marcha su cumplimiento, quienes son sujetos a procesos de veeduría y rendición de cuentas que también se conoce como la fiscalización del manejo de los recursos económicos de la organización.

\section{Manejo de sistemas comunitarios de agua de consumo humano}

De las prácticas de manejo de los sistemas comunitarios de agua de consumo humano implementadas por las JAAP del PPI se puede considerar "manejo" a las actividades encaminadas al uso eficiente de los diferentes componentes del sistema sea en la infraestructura, en la naturaleza y en las relaciones sociales entre usuarios. En los procesos de manejo del sistema se incentiva la participación de todos los usuarios/as, manteniendo una visión integral e intercultural; las actividades son impulsadas por los dirigentes y/o delegaciones emitidas por la asamblea de los usuarios/as del agua.

Las principales actividades que la organización comunitaria realiza para un correcto manejo del sistema están encaminadas a: 1) la conservación de fuentes de agua, 2) la operación y mantenimiento de la infraestructura del sistema considerando desde, la captación, conducción, almacenamiento, tratamiento, distribución domiciliaria del agua, 3) el control y vigilancia de la calidad del agua, 4) la administración económica del sistema y 5) la operación y mantenimiento del sistema de saneamiento (Figura 42).

\section{Características de la gestión y manejo comunitario del agua}

La gestión comunitaria del agua como una propuesta de valorización de antiguas prácticas que mantienen las comunidades indíge- 
159

nas para hacer uso de los elementos de la naturaleza. Es característico que las comunidades se organicen con base a la cooperación entre sus miembros, buscando la satisfacción de las necesidades humanas (Sandoval \& Gunter, 2013, p. 167). Es un claro ejemplo de como las comunidades del Consejo de Juntas que se unen para enfrentar la escasez de agua, y manteniendo sus dinámicas de vida comunitaria impulsaron una alternativa de solución a sus problemas con la ejecución del PPI.

Figura 42

Actividades de manejo del agua en territorios comunitarios

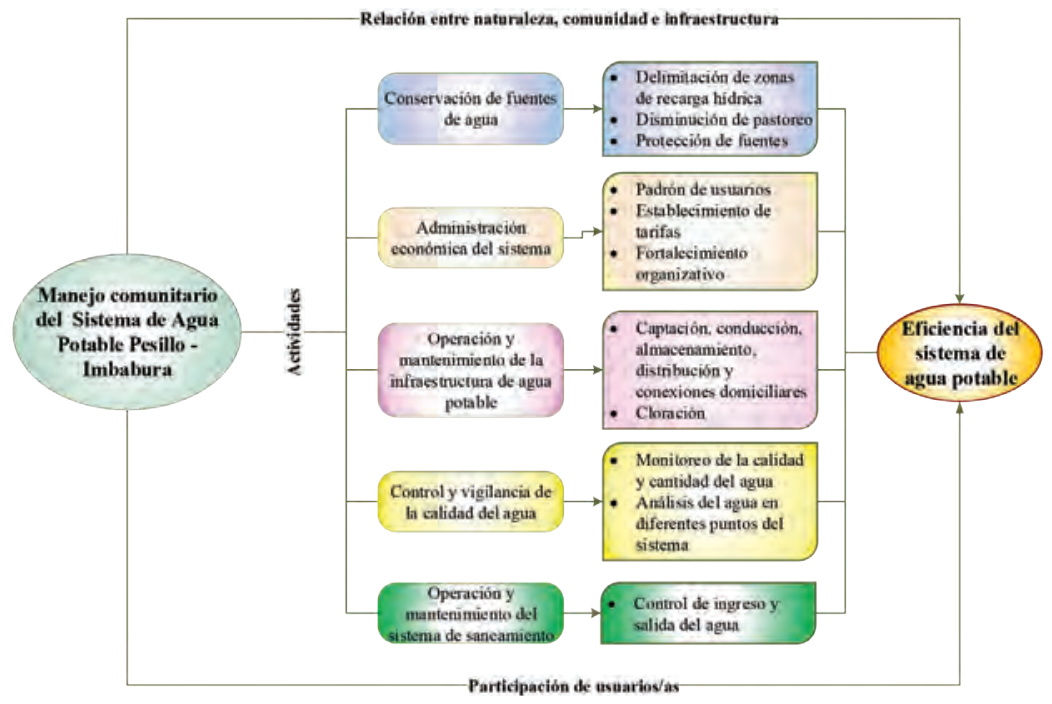

La gestión comunitaria también está relacionada con la autogestión, en el sentido de que es una propuesta holística basada en una racionalidad diferente a la dominante, que promueve otra concepción de la naturaleza y de las relaciones entre los seres humanos y la naturaleza no humana. Concibe el agua como un elemento constitutivo de la trama sociocultural y natural. 
Alude también a la organización que implementa acciones de gestión y manejo del agua desde lo local, en cuanto a su acceso, control, distribución, uso y disposición, sin perder el contexto nacional, regional o global, para lo cual se pueden establecer procesos de cogobierno. La gestión comunitaria del agua respalda a las organizaciones el ejercicio de autoridad ante los actores locales sobre el agua, respaldados en los derechos colectivos en el territorio, entendiendo por actores locales como el conjunto de individuos agrupados en comunidades, asociaciones, juntas de agua, comités, etc., pero que cumplan la principal característica: e interactúen que tengan un régimen de vida comunitaria e interactúan en un territorio común, en los cuales intercambien recursos-materiales, de información y de capacidades, según marcos socioculturales que les permite tener una lectura de su entorno y certidumbre para actuar en el territorio comunitario (Sandoval \& Gunter, 2013).

El enfoque de la gestión comunitaria del agua brinda a las organizaciones comunitarias elementos para implementar acciones de gestión y manejo del sistema de agua de consumo humano, que permita enfrentar la escasez del agua, las dificultades de recursos económicos para la operación, mantenimiento y control de la calidad, la dificultad de renovación de líderes, juicios legales, inequidades de género y generacional entre otros aspectos (Foro de los Recursos Hídricos, 2013).

El enfoque de la gestión comunitaria del agua también permite identificar una serie de prácticas que coexisten paralelas; la solidaridad para reconocer el problema, pero también para buscar soluciones; la desconfianza en sus líderes e instituciones, la cooperación entre grupos del mismo sexo, pero su poca cooperación con el sexo contrario, un liderazgo poco rotativo y excluyente, y una organización muy débil (Bastidas \& García, 2002), situaciones que en las condiciones actuales de reivindicación de los diferentes derechos se están superando por parte del Consejo de Juntas y respaldadas por la SENAGUA, se consideran puntos críticos que las organizaciones comunitarias tienen como prioridad superarlas y poder ser parte de la gestión y manejo del sistema del PPI. 


\section{La gestión comunitaria del agua en el PPI}

La gestión comunitaria pretende que la población en general cuide el agua y a través de las instituciones y organizaciones encargadas de gestionar y manejar los sistemas de agua potable garanticen la provisión de este líquido a futuro, para lo cual todos/as deben encaminar actividades a su cuidado y uso eficiente. En las comunidades rurales, el ejercicio del derecho humano al agua ha sido posible cristalizar a través de la gestión comunitaria, con un principio fundamental como la participación plena de los usuarios desde la concepción de la idea del proyecto, construcción, ejecución, gestión y administración de los sistemas de agua.

La gestión comunitaria permite a los individuos, en el caso del PPI a los futuros usuarios participar en las etapas del proyecto: idea, gestión, ejecución; sin embargo, las comunidades se encuentran dialogando para que también participen en la gestión y manejo (administración) de los sistemas comunitarios de agua construidos con la fuerza de trabajo de todos/as.

No obstante, los modelos de gestión comunitaria tienen resultados diferentes en la prestación del servicio de dotación de agua, debido a las diversas características de las organizaciones, que en base a su fortaleza organizativa y legitimidad ponen en práctica los principios comunitarios. La gestión y manejo comunitario del sistema de agua potable implementada por las organizaciones no es igual en los diferentes territorios, tampoco está exenta de intereses, conflictos y dificultades, porque son procesos sociales en construcción y de reconocimiento de derechos.

Un sistema de agua potable es una construcción socio-natural que políticamente no es neutral, más bien se generan relaciones de poder social (Perreault, 2015), por lo que, no está demás decir, que en la gestión comunitaria del agua se crean relaciones de poder horizontales reivindicativos de los sectores olvidados por el poder económico predominante y el Estado. Cuando en territorios comunitarios 
existe escasez de agua, basados en el derecho humano se construyen sistemas socio-naturales acoplados que doten agua a todos y todas.

La organización comunitaria en el proceso de construcción del proyecto de agua potable Pesillo-Imbabura en todas sus etapas invita a los diversos actores a que participen. Así, los usuarios estuvieron en la concepción de la idea y ejecución de la inversión, aportando con dinero y participando en mingas. La persistencia de los líderes permitió que, en casi dos décadas de gestiones ante el Estado y otros organismos, logren la consecución de los estudios técnicos, obtención de los recursos económicos que finalmente permitió iniciar la construcción de la infraestructura del sistema, mismo que hasta el 2019 las obras se encuentran paralizadas. Sin embargo, la organización en la etapa de ejecución del proyecto va disminuyendo su intensidad de participación y por último en la etapa de operación del sistema según el modelo de gestión, la participación de la organización en la toma de decisiones seguirá disminuyendo. Esta realidad en muchos usuarios del agua -miembros de la organización comunitaria- provoca que piensen y sientan que el proyecto es ajeno (de otros) a su realidad y prácticamente ya no es su proyecto.

La Constitución vigente reconoce dos formas de gestión del agua en el Ecuador: la pública y comunitaria; también deja abierta la posibilidad de realizar alianzas públicas-comunitarias. El modelo de gestión acordado para el PPI es la pública, para lo cual se crea una empresa que tendrá participación comunitaria; mientras que las JAAP y GAD Municipales pueden realizar alianzas público-comunitarios en cada cantón. ¿Qué significa esto? ¿Cuáles son los retos que esperan en adelante a los usuarios y comunidades en torno a sus JAAP y el PPI? 


\section{Reflexiones finales}

La disponibilidad o no de agua de consumo humano en la sierra norte del Ecuador tiene dos elementos de análisis: el ciclo natural y social. Lo natural: época de lluvias y épocas sin lluvias, de máximos y mínimos en términos de agua disponible; en lo social intervienen los factores políticos y del poder económico imperante.

Primero, como es conocido y vivido por todos, el clima en los Andes del norte ecuatoriano tiene dos periodos: una de lluvias intensas que provee agua de consumo humano, esto hace posible que la agricultura y la ganadería se desarrolle. La época seca desde mayo a septiembre; para la mayoría de las comunidades es la más difícil el acceso al agua, porque los volúmenes de agua disminuyen generándose conflictos por sus usos.

En la cosmovisión andina, cuando las lluvias se retrasan a su ciclo natural (septiembre-octubre), se hacen ceremonias-rituales como el Wakcha Karay, ${ }^{35}$ invocando a las deidades que envíen las lluvias. La reproducción social y cultural necesita agua, que tiene estatus sagrado, siendo en muchas partes invocada y venerada a través de fiestas sincretizadas andinas-religiosas como la de Agua Santa en San Pablo de Lago, Virgen de la Merced en la comunidad de Chilco

35 Es una ceremonia ritual que se realiza cuando las lluvias tardan en llegar; los pueblos andinos al ser sociedades fundamentalmente agrícolas esperan las lluvias de septiembre y octubre para iniciar el ciclo de la siembra. Cuando las lluvias no llegan, personas de todas las edades, sobre todo niños y niñas van a los centros ceremoniales con ofrendas y para pedir a la madre naturaleza que envíe las ansiadas lluvias. 
en la parroquia Angochawa. El razonamiento es simple, sin agua no hay reproducción social ni cultural, por lo tanto, no hay vida.

Segundo. Lastimosamente, el agua fue objeto de conquista, acaparada en la Colonia y la República por el poder predominante. Hasta hace poco el acceso a las fuentes de agua fue restringida, el Estado ha tratado de democratizarla con la emisión de Ley de Aguas, en donde se requiere la legalización de las Juntas Administradoras de Agua Potable, quienes dan el servicio de dotación del agua considerado como derecho humano fundamental.

Las comunidades se han beneficiado de concesiones -en la actualidad-autorizaciones del agua, misma que es conducida a las viviendas mediante la construcción de sistemas de agua potable comunitarios. El apoyo del Estado no ha sido de una envergadura que realmente supla las necesidades de las comunidades para alcanzar una justicia hídrica; lo realizado por el Estado ha sido insuficiente. Se puede deducir que, si en el pasado existió una injusticia hídrica por el predominio del poder económico y generaron problemas alrededor del derecho humano al acceso al agua, en la actualidad ocurren las mismas prácticas impuestas por el poder político, pese a la mayor conciencia que tiene la población de las comunidades indígenas en luchar por sus derechos.

Desde la década de 1990 a medida que pasan los años, por el crecimiento de la población, la demanda de agua ha ido en aumento y la oferta en descenso. Pero no solo tiene que ver que la oferta y la demanda dependen de los problemas ambientales que causan que los caudales disminuyan tanto en los páramos como en las zonas bajas, sino que son agravados por los conflictos en los territorios comunitarios por el acceso a fuentes y caudales de agua, sin embargo, esta realidad es poco visible en los sectores urbanos que han tenido prioridad en el acceso al agua.

Las poblaciones que viven en los territorios comunitarios han pasado y enfrentado realidades ambientales, económicas y políticas 
adversas, pero en base a la unión aportan en la generación de alternativas que permita conllevar y/o solucionar los problemas de escasez de agua en el territorio. Por ello nace la propuesta de acceder al agua por parte de las comunidades mediante la construcción de un sistema regional de agua potable. El PPI nace en las comunidades para las comunidades — suena mezquino, pero así fue-. Siendo una de las iniciativas que con mucho esfuerzo comunitario se convierte en una las propuestas más importantes en la reciente historia de las comunidades indígenas de los cinco cantones de las dos provincias beneficiarias del PPI.

Pese a las capacidades de gestión y organización de las comunidades la puesta en marcha del proyecto no lo podían hacer solos. Para buscar fuentes de agua, gestionar los estudios técnicos, y el presupuesto para la ejecución acudieron al Estado (MIDUVI, SENAGUA, Gobierno Provincial de Pichincha e Imbabura, Banco de Estado, GAD Municipales entre otros), quienes basados en las presiones sociales intervienen de diferentes formas en la consecución del PPI. Sin embargo, las organizaciones comunitarias no esperaron que el Estado les conceda todo, las comunidades han aportado significativamente en la formulación del proyecto con: ideas, mingas y aportes económicos. En las primeras etapas del proyecto para su concreción existe un esfuerzo articulado entre las organizaciones y las instituciones del Estado, lamentablemente en la etapa final del proyecto (administración del proyecto) el involucramiento de las organizaciones va disminuyendo en especial en la toma de decisiones del manejo de la red principal de conducción del agua.

El camino no ha sido sencillo, a lo largo de los años se han presentado muchos problemas por conseguir las autorizaciones de las fuentes de agua. Los estudios técnicos y la ejecución de la infraestructura a cargo del Estado tuvieron numerosas demoras, demostrando su debilidad institucional para la construcción de este tipo de proyectos en forma más rápida. Varios dirigentes de las organizaciones comunitarias y del Consejo de Juntas manifiestan que hubo funcionarios en contra 
del proyecto que obstaculizaban todo, pero la unidad de los dirigentes de las organizaciones comunitarias de base y la tenacidad de los dirigentes de Consejo de Juntas han sido claves en la consecución del PPI, manteniendo una estrategia de llegar a las máximas autoridades del Estado para dar a conocer las dificultades en la consecución del proyecto.

No cabe dudas que el PPI ha sido un proceso social y técnicamente complejo. Para las comunidades y los dirigentes la consecución del proyecto ha sido una prueba de resistencia, inteligencia y capacidad de diálogo para lograr acuerdos entre comunidades, las JAAP, y conllevar procesos de negociación con el Estado, es decir lucharon por el agua y la vida. Ahora que el proyecto está ejecutándose, la mayoría de las comunidades con sus dirigentes y futuros usuarios del agua piensan que, valió la pena luchar y esperar. Fruto de esa resistencia, las aproximadamente 165 comunidades y las localidades urbanas tendrán agua permanente y segura. Esta forma de gestionar los derechos por el acceso al agua por parte de las comunidades es una muestra de madurez comunitaria y del Estado en atender los reclamos de las comunidades. El agua no se puede negar, pese a la ausencia de sectores urbanos organizados estos también serán beneficiarios.

Una de las grandes lecciones de este proceso es que la organización comunitaria es fundamental para reclamar por el derecho humano al acceso al agua consagrado en la Constitución. Una organización no es impuesta ni estática, se dinamiza en función a las circunstancias y objetivos comunes, así, las JAAP se juntan para dar vida al Consejo de Juntas. Esta lucha de las comunidades por el acceso al agua indirectamente beneficia a los sectores urbanos, es decir, las comunidades no lucharon solo para ellos, "nada solo para los indios" frase que merece ser recordada y puesta nuevamente en práctica como en la década de 1990 en el levantamiento indígena, que se luchó por la reivindicación de los derechos sociales y no solo de los indios.

El PPI es un proyecto que resuena del pasado, que hace soñar en el presente y avizorar el futuro. Es un legado o contribución de las personas mayores para los jóvenes, legado que se considera como 
una complementariedad generacional, los dirigentes siempre han pensado en el tiempo — en el presente y en el futuro-, por lo tanto, vale recordar y valorar el proceso que han construido y vivido en estos veinte años de consecución del proyecto. Este proceso servirá para pensar en soluciones a problemas que afectan a las comunidades indígenas en sus territorios con propuestas alternativas, identidad e innovación social y técnica.

Debido a la envergadura de la inversión los organismos que financiaron el proyecto imponen un modelo de gestión del PPI, lo que incomoda a los principales protagonistas y gestores de la idea del proyecto, las organizaciones comunitarias. La propuesta de creación para la gestión y administración del PPI de una empresa pública con participación comunitaria despoja la oportunidad de manejo del sistema a las organizaciones comunidades. La propuesta de gestionar y manejar el sistema del PPI por parte de las comunidades y JAAP representados por el Consejo de Juntas fue relegada y hasta la actualidad queda la incertidumbre.

Los usuarios al ser y sentirse parte del proyecto Pesillo-Imbabura acorde con sus entendimientos en la relación con el agua y la naturaleza, las formas de manejo de los sistemas de agua potable y el territorio hidro-social, propuso la gestión comunitaria que poco a poco se transforma en una alianza pública-comunitaria para llevar acciones de gestión y actividades de manejo del sistema de agua potable Pesillo-Imbabura, pero el Estado se esforzó para implementar lo público, incluso condicionando ese hecho para financiar el proyecto.

La lección incómoda e injusta de este proceso es que el Estado es una instancia de poder, capaz de subordinar los procesos comunitarios. En este caso, la gestión comunitaria fue catalogada como de limitada capacidad para hacerse responsable de la gestión y manejo de un sistema de agua potable de la magnitud del Pesillo-Imbabura.

Como ha pasado muchas veces en otras áreas, las organizaciones luchan para que se cumplan los derechos básicos como el acceso 
al agua, pero cuando se reclama el derecho de gestionar y manejar (administrar) el sistema de agua potable, el mismo Estado pone trabas e impide que se lo haga, parece ser, que muchas personas de las instituciones que tienen el control del agua lo ven únicamente como espacios de ejercicio del poder político.

Lo importante y valorable de todo el proceso es que se dieron pasos importantes hacia adelante como sociedad comunitaria el ser gestores de su propio desarrollo. Las organizaciones comunitarias de buscar dádivas y limosnas en las haciendas pasan a idear y construir sistemas comunitarios de agua potable, cuando las circunstancias lo exigieron se construyeron sistemas regionales e intercomunitarios, y ahora, también se sortearon circunstancias adversas por lo que se logró la construcción de un sistema de agua potable inter-cantonal y bi-provincial.

Finalmente, es evidente que las organizaciones comunitarias ponen en práctica los principios de la sustentabilidad y el Buen Vivir en sus territorios comunitarios, cuando implementan acciones de gestión y actividades de manejo del agua, mismas que fortalece el enfoque de la gestión comunitaria del agua. Sin embargo, al ser un enfoque de gestión del agua en construcción queda la interrogante, para el caso del PPI ¿la puesta en práctica de los principios y valores del enfoque de la gestión comunitaria del agua garantiza a los usuarios, el acceso, control, distribución y uso del agua en el territorio comunitario? 


\section{Bibliografía}

Archivo del Consejo de Juntas del proyecto Pesillo-Imbabura.

Archivo del Consejo Provincial de Imbabura. Proceso del Proyecto Pesillo-Imbabura.

Bastidas, P., \& García, M. (2002). La gestión comunitaria en proyectos de abastecimiento y saneamiento como base de sostenibilidad y de construcción de tejido social. Cinara. Universidad del Valle Colombia. Disponible en: http://bit.ly/2CZ5DZb

Boletín Salesiano (2019). Cultura y lenguas de pueblos originarios. Marzo-abril/ISSN 1390- 4094. Quito: UPS.

Borja, G. (2002). El agua potable en el sector rural: un análisis de las formas de intervencibn social y de la política a partir de un estudio de caso. (Tesis). Quito: FLACSO.

Castañeda, E. (2009). Gobierno Comunitario: el caso de las comunidades de la parroquia de Gonzáles Suárez. Quito: Abya-Yala.

Castro, E. G., Chasiluisa, C. B., Giné, D. S., \& Sánchez, R. G. (2018). Análisis de la variación temporal y espacial de la cobertura glaciar del nevado Cayambe, Ecuador, mediante fotografías aéreas e imágenes landsat. GeoFocus. Revista Internacional de Ciencia y Tecnología de la Información Geográfica, (22), 97-113.

Cachipuendo, Ch. (2013). La gestión social del agua en las organizaciones de usuarios/as del territorio de la subcuenca del río Pisque (Tesis maestría). Universidad Politécnica Salesiana.

(2017). Modelo dinâmico para a gestão e manejo sustentável de sistemas de irrigação comunitários, no marco do Bom Viver: estudo do caso na bacia do Rio Pisque (Doctoral dissertation). Universidade de São Paulo.

Cobo, E., Yaguache, R., Piñeiros, M.L., Calisto, M., \& Gay de Montella, R. (2018). Aguas compartidas. Enfoques y herramientas para una mejor gestión del agua. Quito: BRIDGE.

Comité de Gestión Agua Chambo (2015). Aportes a la planificación para la gestión integral de los recursos hídricos. Imprefepp. 
170

Diario El Comercio (18-04-2010). La protesta por el canal de riego Tabacundo se activa. Disponible en: http://bit.ly/37mu8xB (14 de julio de 2018).

Diario El Telégrafo (4-10-2015). Caranqui fue un asentamiento inca. Disponible en: http://bit.ly/37lCHbP (5 de diciembre del 2017).

(3-06-2015). Banco del Estado otorga crédito por \$ 47,6 millones para proyecto Pesillo-Imbabura. Disponible en: http://bit.ly/2QAJmsI (23 de julio de 2018).

Diario Hoy en Imbabura (3-06-2015). Proyecto regional de agua potable Pesillo-Imbabura recibió financiamiento. Disponible en: http:// bit.ly/2qmxf86 (30 de julio de 2018).

(23-01-2018). El primer mandatario verificó el avance de la obra civil del proyecto de agua potable Pesillo-Imbabura. Disponible en: http://bit.ly/2O3XYiz (23 de julio de 2018).

Derecho Ecuador. Registro Oficial No. 638-lunes 18 de julio de 2016, Edición Especial. Disponible en: http://bit.ly/334R9Sn (23 de julio de 2018).

Duarte-Abadía, B., Hoogesteger van Dijk, J. \& Yacoub López, C. (2016). Introducción: La gobernanza del agua: Visiones desde la ecológica y la justicia hídrica. Gobernanza del agua, 24, 13-24. Justicia Hídrica.

Foro de Recursos Hídricos (2013). Agua, Estado y Sociedad. Aportes para políticas públicas. Quito: Graphus.

(2015). Agua, matriz productiva y gestión público-comunitario. Documentos de discusión. Quito: Graphus.

GAD Otavalo (15-04-2015). Firma de acuerdo para gestión del proyecto "Pesillo-Imbabura". Disponible en: http://bit.ly/2O2Zodk (23 de julio de 2018).

INEC (1974). Censo de Vivienda. Quito.

(1982). Censo de Vivienda. Quito.

(1990). Censo de Población y Vivienda. Quito.

(2001). Censo de Población y Vivienda. Quito.

(2010). Censo de Población y Vivienda. Quito.

Hortelano Villanueva, L., \& Hidalgo García, M. del M. (2016). El agua como derecho humano: retos y limitaciones. bie3: Boletín IEEE (4), 329-352.

Isch, E., \& Zambrano, Á. (2015). La consulta prelegislativa y la Ley Orgánica de Recursos Hídricos, usos y aprovechamientos del agua en el Ecuador. En Gobernanza del agua. Una mirada desde la ecología política y la justicia hídrica (pp. 255-273). Quito: Abya-Yala.

Knapp, G. (1992). Riego colonial y tradicional en la sierra norte de Ecuador. Hombre y Ambiente, 22. Cayambe: Abya-Yala.

Mann, M.E., Bradley, R.S., \& Hughes, M.K. (1998). Global-Scale Temperature Patterns and Climate Forcing over the past six centuries. Nature, 392, 779-787. 
Miller, G. (2007). Ciencia ambiental: Desarrollo sostenible, un enfoque integral, 8va edición. México: Editores Internacional Thomson.

MIDUVI. Proyecto de Agua Potable Regional Pesillo-Imbabura. Disponible en: http://bit.ly/2CZSRtF (27 de julio de 2018).

Murillo-Licea, D., \& Soares-Moraes, D. (2013). El péndulo de la gobernabilidad y la gobernanza del agua en México. Tecnología y ciencias del agua, 4(3), 149-163.

Peña, H., \& Solanes M. (2012). Gobernabilidad del agua en las Américas, una tarea inconclusa. Foro Temático del Foro "Agua para las Américas en el Siglo XXI”. México: Ciudad de México, 8 al 11 de octubre de 2002. Disponible en: http://bit.ly/2pFMita

Perreault, T. (2015). ¿Un tipo de gobernanza para un tipo de equidad? Hacia una teorización de la justicia en la gobernanza. En Gobernanza del agua. Una mirada desde la ecología política y la justicia hídrica (pp. 27-47). Quito: Abya-Yala.

Ramón, G. (2008). Formas ancestrales de almacenamiento de agua en los andes de páramo: una mirada histórica. COMUNIDEC.

Sandoval-Moreno, A., \& Günther, M. (2013). La gestión comunitaria del agua en México y Ecuador: otros acercamientos a la sustentabilidad. Ra Ximhai, 9(2), 165-179.

Sánchez-Parga, J. (2007). Estudios y análisis: El movimiento indígena ecuatoriano. Quito: Centro Andino de Acción Popular CAAP. Albazul Offset.

(2016). Estudios y análisis: Crónicas de los Andes. Memorias del "Otro". Quito: Centro Andino de Acción Popular CAAP. Albazul Offset.

Saransig, C. (2017) Evaluación de la capacidad de resiliencia del bosque protector "Loma de Guayabillas" a la perturbación producida por incendios forestales dentro del marco de un convenio de vinculación interinstitucional de la PUCESI. (Tesis). Ibarra.

Secretaría Nacional de Planificación y Desarrollo, SENPLADES (2013). Plan Nacional del Buen Vivir 2013-2017.

Secretaría Nacional del Agua. Base de datos de autorizaciones de agua, demarcación hidrográfica del río Esmeraldas. Quito.

Base de datos de autorizaciones de agua, demarcación hidrográfica del río Mira. Ibarra.

UPS (2013-2014). Proyecto de Calidad y Disponibilidad del agua de consumo humano bajo la gestión social del consejo de jutas del Proyecto Pesillo-Imbabura. Cayambe.

Vargas, R. (2006). La cultura del agua. Lecciones desde América indígena. Programa Hidrológico Internacional de la UNESCO para América Latina, serie Agua y Cultura PHI-LAC, No. 1. Montevideo-Uruguay. 

El enfoque de la gestión comunitaria del agua en el Ecuador es un tema de vital importancia. El ejemplo del Proyecto de Agua Potable Pesillo-Imbabura, en donde la organización comunitaria fue impulso fundamental para la ejecución de ese proyecto, dio lugar a esta investigación. Este libro es, entonces, fruto de la investigación participativa impulsada por la línea de investigación de gestión sustentable del agua y del suelo, desarrollada con el aval de la Carrera de Gestión para el Desarrollo Local Sostenible de la Universidad Politécnica Salesiana. A partir de la experiencia de Pesillo, los investigadores hacen su reflexión conceptual y de puesta en práctica de la importancia de la participación de la comunidad en proyectos de desarrollo.
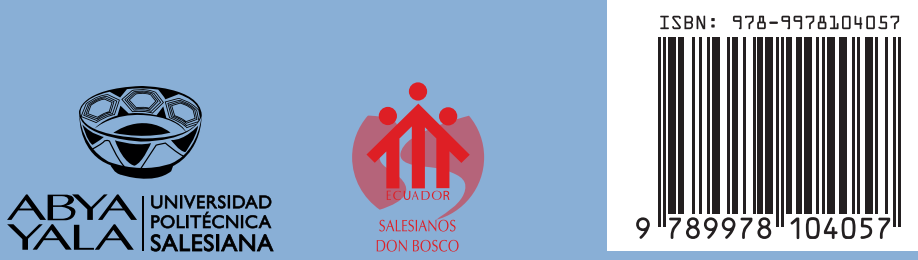